\title{
Eye, Head and Torso Coordination During Gaze Shifts in Virtual Reality
}

\author{
LUDWIG SIDENMARK, Lancaster University, United Kingdom \\ HANS GELLERSEN, Lancaster University, United Kingdom
}

Humans perform gaze shifts naturally through a combination of eye, head and body movements. Although gaze has been long studied as input modality for interaction, this has previously ignored the coordination of the eyes, head and body. This article reports a study of gaze shifts in virtual reality (VR) aimed to address the gap and inform design. We identify general eye, head and torso coordination patterns and provide an analysis of the relative movements' contribution and temporal alignment. We quantify effects of target distance, direction and user posture, describe preferred eye-in-head motion ranges, and identify a high variability in head movement tendency. Study insights lead us to propose gaze zones that reflect different levels of contribution from eye, head and body. We discuss design implications for HCI and VR, and in conclusion argue to treat gaze as multimodal input, and eye, head and body movement as synergetic in interaction design.

\section{CCS Concepts: • Human-centered computing $\rightarrow$ Empirical studies in HCI; Virtual reality;}

Additional Key Words and Phrases: Eye gaze, Gaze shifts, Eye-head coordination, Eye, head and body movement, Eye tracking, Gaze interaction, Multimodal interaction

\section{ACM Reference Format:}

Ludwig Sidenmark and Hans Gellersen. 2019. Eye, Head and Torso Coordination During Gaze Shifts in Virtual Reality. ACM Trans. Comput.-Hum. Interact. 1, 1, Article 1 (January 2019), 41 pages. https://doi.org/10.1145/ 3361218

\section{INTRODUCTION}

Gaze shifts are of fundamental interest to human-computer interaction (HCI) - where we direct our gaze is a powerful cue for attention, interest and intent, and can be leveraged as context and input. Gaze shifts occur as we can only see detail of objects of interest when they become aligned for a sufficient time with the fovea, the small region of highest visual acuity at the centre of our eyes. We therefore move our gaze rapidly from object to object, to sample information of interest and guide our interactions.

In our interaction with the world, gaze shifts are achieved through a combination of eye, head, and body movements. We move the eyes in the head, the head relative to the torso, and the torso relative to the world [34]. For example, when we look from a display in front to a second screen in hand, we will lower our eyes in coordination with tilting of our heads; neither head nor eyes will cover the full distance [72]. When we look up and to a person next to us, we will not only move our eyes and head again but also shift our torso toward the new target. This illustrates the seamless coordination of the three movement systems for efficient acquisition of gaze targets. However, although gaze has been studied as computer input since the eighties, this has thus far

Authors' addresses: Ludwig Sidenmark, Lancaster University, Lancaster, United Kingdom, l.sidenmark@lancaster.ac.uk; Hans Gellersen, Lancaster University, Lancaster, United Kingdom, h.gellersen@lancaster.ac.uk.

Permission to make digital or hard copies of all or part of this work for personal or classroom use is granted without fee provided that copies are not made or distributed for profit or commercial advantage and that copies bear this notice and the full citation on the first page. Copyrights for components of this work owned by others than the author(s) must be honored Abstracting with credit is permitted. To copy otherwise, or republish, to post on servers or to redistribute to lists, requires prior specific permission and/or a fee. Request permissions from permissions@acm.org.

(C) 2019 Copyright held by the owner/author(s). Publication rights licensed to the Association for Computing Machinery. 1073-0516/2019/1-ART1 \$15.00

https://doi.org/10.1145/3361218 
not reflected the coordination of eye, head and torso movements through which gaze shifts are naturally achieved.

In this article, we present a study of eye, head and torso coordination during gaze shifts using virtual reality (VR). Our motivation is to close a fundamental gap in understanding gaze as input modality. Eye, head and body movements have each been studied extensively as separate input modalities, but we envisage that insight into their coordination will uncover new design opportunities. In analogy, insight into hand-eye coordination [64] has been foundational for instance for gaze prediction from manual action [24, 62], gaze-enhanced manual input [79] and multimodal techniques that fully integrate hand and eye input $[50,51]$. We surmise that there is equivalent potential for leveraging knowledge of eye coordination with head and body, and propose novel gaze depth estimation, pointing and selection techniques in follow-on work [37, 61].

The literature on gaze interaction is not consistent in its use of terminology. Where eye-trackers are used as input device, gaze is commonly treated as synonomous with eye movement $[27,28]$ while head movement is suppressed or filtered $[20,80]$. In contrast, other work has conceived gaze as the direction a user faces, in abstraction from the finer-grained movement of the eyes within the head $[42,78]$. In this work, we use terminology consistent with research on eye movements in natural behaviour [33]. We refer to gaze as the direction in which the eye points relative to the world. As such, gaze presents the sum of the eye-in-head rotation and the head orientation (or head pose) toward the gaze target. The head orientation itself is the sum of torso orientation toward the gaze target, and head-on-torso rotation. Gaze shifts can occur within the user's current field of view (e.g., triggered by a stimulus in the peripheral vision), but can also extend beyond view (e.g., when a user turns to look behind their back).

We use VR in a head-mounted display (HMD) with an integrated eye-tracker as our tool for data collection in this study. However, we are also specifically interested in VR and HMDs as target platform and context for gaze interaction. Most of the existing work on gaze has focussed on interaction with computer displays that cover a comparatively narrow visual angle in the user's field of view (FOV) and are therefore comfortably viewable without any significant head and body movement. Immersive VR, in contrast, supports viewing of virtual scenes that are not limited to the FOV of the HMD but that can extend over a wider field of regard (FOR). For instance, if the virtual world completely surrounds the user, the FOR is $360^{\circ}$ while the FOV would be limited to around $100^{\circ}$ with current HMDs. The display position and orientation in space determines the part of the FOR that is within the current FOV, based on the premise that users naturally move their head and body to control what they see. Gaze is therefore central to interaction in VR but commonly only represented by head orientation in space, in abstraction of eye-in-head movement and contribution of the torso. Our work questions how well head orientation captures gaze, and aims to inform how eye input can be integrated with head and body movement for interaction through VR headsets.

We collected eye, head, and torso motion data for a total of over 7,600 gaze shifts, from 20 participants in both seated and standing conditions. Participants were presented with two basic gaze pointing tasks, to reach within-view targets displayed in the user's FOV, and beyond-view targets positioned in the wider FOR beyond the initially visible display. All targets were presented at a fixed depth around the user while varying the amplitude and direction of the gaze shift from a starting position at the centre of the HMD. Based on the data, we provide an exhaustive analysis of the contribution and temporal coupling of eye, head and torso toward target-reaching, and of eye and head motion ranges. The outcome is a detailed description of movement coordination patterns, the effects of amplitude, direction and user posture on the relative movements, preferred ranges for eye-in-head motion, and user variability.

We discuss key insights from the study, including: identification of gaze zones that represent different ranges of visual interaction at which gaze tends to be performed eyes only, with head 
support, and additionally with torso movement; a tendency of users to follow the eyes with head orientation toward targets but only to within comfortable range; individual differences in tendency to support gaze with head motion; and a stepped behaviour of the eye we observed in large shifts that may be linked to FOV limitations of HMDs. We also consider transferability of observations on gaze behaviour between VR and real world, and discuss implication of our findings for VR and interaction design.

In sum, we presents the following contributions to advance HCI:

- An introduction of the HCI field to fundamental knowledge of eye, head and body coordination, of relevance to any form of visual interaction that involves attention shifts over wider fields of view.

- A detailed description of eye, head and body coordination patterns during gaze shifts, the understanding of which will enable designers to consider and reflect natural movement in visual interaction.

- "Hard data" on contribution and temporal alignment of movements, effects of gaze amplitude, gaze direction, user posture, and preferred motion ranges; which establishes a point of reference for design of novel interactions that integrate input from eyes, head and body.

- Identification of gaze patterns, gaze zones and distinct user behaviours, and their design implications for VR and interaction; thereby providing designers with practical guidance on eye, head, and torso movement and their coordination for gaze and visual attention.

\section{BACKGROUND AND RELATED WORK}

This work studies the coordination of eye movement with head and body from an HCI perspective. To contextualise our work, we first review fundamentals of eye-head gaze shifts established in neuroscience, and existing understanding of factors in the head contribution to gaze. Based on this, we review research in HCI and VR, first examining the different ways in which work on gaze has reflected eye versus head movement, and then providing generally related work on eye, head and body movement related to gaze and VR.

\subsection{Eye-head gaze fundamentals and study paradigms}

The motion range of the eyes is approximately $50^{\circ}$ in any direction for a healthy adult $[33,67]$. The total FOV of human vision is $210^{\circ}$ in the horizontal plane and $120^{\circ}$ in the vertical plane $\left(50^{\circ}\right.$ up, $70^{\circ}$ down). However, gaze shifts are not limited by the FOV and can also be performed to targets beyond. The neck has a motion range of about $80-90^{\circ}$ for head movement in the horizontal axis and $60-70^{\circ}$ in the vertical axis [12]. Eyes and head together thus provide a movement range of around $130-140^{\circ}$ in the horizontal axis and $110-120^{\circ}$ in the vertical axis. Gaze shifts with a larger amplitude are only possible with additional use of the torso. With a combination of eyes, head and torso movement, humans can reach gaze targets on the full range surrounding them (unless torso motion is constrained, as for instance in seated positions).

The relationship of eye and head movement is complex. During a gaze shift, head movement augments the saccadic movement of the eye, such that the movements are additive toward reaching the target. The faster the head moves in synchrony with the eyes, the smaller the required saccade [17]. When a gaze target has been reached, the head will typically continue to move while the eyes fixate the target by performing compensatory eye movement in the opposite direction. This allows the eyes to rotate back into a more central and comfortable position relative to the head [73], mediated by the vestibulo-ocular reflex (VOR) which stabilises the visual axis on the target while the head is still in motion [5]. There is a similar interaction between head and torso rotations, with a corresponding vestibulo-collic reflex [34]. 
Eye-head gaze shifts and their relative timing were first described in the 1930s [44], and have been studied under controlled conditions since the 1960s [5]. A conventional study paradigm is to have light stimuli arranged in a semicircle or hemisphere around the subject, and task participants to initially fixate in the centre from where to shift to a flashing target. Subjects are seated and their body movement is suppressed by a belt, while bite bars and brakes have been used to manipulate available head movement [17]. Since the 1990s, gaze has also been studied in naturalistic contexts, enabled by wearable eye-trackers that capture eye-in-head orientation relative to the visual scene which is recorded from a head-centred perspective [33]. These studies lack in control but draw attention to the role the body plays in active gaze, in addition to eye and head [36].

Our study design is a lab-based experiment that reproduces a conventional hemispherical arrangement of stimuli in VR for comparability with prior studies. However, we are not constraining head and body as our goal is to inform design by capturing natural behaviour, in both seated and standing postures. By using VR we are able to record eye, head and body motion and their relative timing at higher accuracy than in previous studies. Head-mounted VR, however, limits the FOV in comparison with real-world studies. How this limitation affects gaze is of explicit interest in this work, as one of our goals is to inform adoption of gaze for interaction in VR.

\subsection{Factors affecting a head contribution to gaze}

The amplitude of a gaze shift has been shown to have a significant effect on whether and how much the head contributes. Gaze shifts extending less than $20^{\circ}$ are almost entirely made by the eye movement $[13,16,33]$. While the eyes have a physical range of $50^{\circ}$, it has been found that they rarely rotate beyond $30^{\circ}$ relative to the head [33]. In natural tasks, the head contributes about $1 / 3$ to gaze shifts of up to $30^{\circ}$, and more to gaze shifts that are larger [58]. Large gaze shifts can be achieved in a single-step head-supported saccade but may also exhibit stepping movements [34]. These observations provide us with a baseline for assessing whether the head contribution is comparable when people interact in a virtual rather than natural environment.

Gaze shifts made within the limits of the eye-in-head range may or may not be associated with a head movement, as observed in the lab [15, 47, 67] as well as naturalistic settings [11, 71]. The decision whether to move the head involves an internal weighing of costs and benefits, specifically energy required to accelerate and decelerate the mass of the head in a short time versus fixation accuracy and stability which decrease at far-eccentric eye-in-head positions [68]. Amplitude, as noted, is a significant factor but others have been identified, including the initial eye-in-head position $[14,15,67]$, the expected duration of maintaining gaze in the general vicinity of the current target, and the position of the next target [47]. It has also been shown that there are individual differences in how much head movement is used [15, 47, 67, 70, 71]. Fuller proposed a notion of "head-movers" versus "non-head movers" [15] and other work suggests that observation of different types of head movement tendency carries over from controlled to real world contexts [70]. This prompts us to look closely at eye-head gaze patterns in our study, as differences in tendency to move the head are of obvious importance for head-mounted display paradigms.

\subsection{Gaze tracking for interaction}

Much of the HCI literature treats orientation of the eyes as synonymous with gaze. Work has mostly focused on tracking gaze relative to a personal computer display where, at typical viewing distances, the display width is usually within $40^{\circ}$ visual angle [60]. In such a setting, the display is viewable with eye-in-head rotations of up to $20^{\circ}$ from a central position, and therefore does not require any significant head contribution. Desktop gaze tracking has consequently focussed on eye movement and viewed any associated head and body movement as undesirable and problematic for tracking, as it interferes with the calibration of the eye orientation to the display [43]. Past 
work went as far as suppressing movement with chin rests, while modern eye trackers are able to compensate for smaller changes in head and body orientation during viewing [20,80]. However, eye tracked interfaces continue to be based on a conceptual model of gaze as solely represented by eye movement.

Gaze tracking has been studied beyond personal computer displays, for interaction with multiple screens and devices in the user's environment $[35,74]$. This has been facilitated by portable eye trackers that are worn as a head-mounted device. These devices track eye-in-head rotation as the gaze direction, relative to the view in front of the user which is captured by a scene camera. Head and body movement are implicitly reflected by changes in the scene view, but they are treated as incidental to gaze. The conceptual model, not explicit but generally implied, is that head and body movement change the context within which gaze is viewed as solely based on eye movement. A problem in this model is that it assumes the viewing area of interest to be centred around the head. However, the relationship between viewing area and head orientation depends on context, for instance whether we look at a device in our hand or at one that is in front of us [72].

Conversely, gaze attention over wider visual fields is often approximated by head pointing and ignores eye-in-head movement. Various works have used face pose tracking for gaze pointing on large displays $[45,46]$. Early work on interaction in VR proposed gaze directed input but treated gaze as synonymous with head orientation $[42,78]$. State of the art interactive devices similarly associate head pose and gaze. For example, the Smart Eye Pro 3D eye tracker supports a tracking mode based on a head model instead of eye movement, and Microsoft's HoloLens 1 assumes head pose as the user's gaze vector. This reflects the major role head movement plays in contexts where gaze is not focussed on small viewing areas, but engaged with wider environments. However, the general assumption that we look where our head points is problematic. We address this in this work with an in-depth analysis of how head and gaze relate.

\subsection{Eye, head, and body orientation as input}

The HCI field has extensively studied eye, head and body movement for interaction. Both head pointing and eye pointing were developed in the eighties, to provide users with limited motor control with an alternative to mouse input $[18,25,54,77]$. In comparison, eye movement is faster and requires less energy, while head movement has been found less jittery and more controlled [6]. In VR and AR (augmented reality) HMDs, users prefer head over eye input due to accuracy limitations of eye tracking $[7,19,32,53]$, and it has been proposed to combine eye movement for coarse positioning with subsequent head movement for refinement [29, 31, 32, 65] and target alignment, disambiguation and confirmation [38-40,66]. These works show that head and eye movement have been considered as separate rather than integral modalities for gaze interaction.

Other work in HCI has considered eye, head, and body orientation as implicit cues for interaction. Bolt, in early seminal work, described eye tracking as "mode par excellence" for directing attention and selecting focus in multimedia environments [8]. Eye contact has been employed as cue for interaction with surrounding devices under an attentive user interface paradigm [59, 75], and to mediate human-robot interaction [1]. In proxemic interaction, cues for interaction are instead derived from the relative position and orientation of users toward devices [4, 41]. Vogel, for instance, demonstrated an adaptive display that reflects both a user's body orientation toward a display, and additionally how far their head is turned toward it [76]. These works recognise, implicitly, that not only eye movement but also head and body movement relate to attention. However, the field has not previously considered how eye, head and body movement are coordinated for overt orienting of attention, as represented by gaze shifts. 


\subsection{Eye and head movement in VR, Head-mounted Displays and Virtual Characters}

A variety of studies provide insight related to gaze behaviour and eye and head movement in VR and HMD contexts. In contrast to natural viewing, HMDs limit the user's view, blocking out the wider visual periphery as if wearing blinkers. This was observed to lead to less eye rotation and consequently more head rotation to achieve the same lateral shift of gaze direction [30] However, the magnitude of eye rotations was still considerable in the HMD condition, showing that head orientation alone is limited for predicting attention. A recent study comparing eye-head coordination in virtual versus physical reality likewise observed that display limitations induce more head movement in VR [49].

Related work has used head-mounted VR to study visual attention to content that surrounds the viewer and requires head movement for exploration. Analogies have been drawn between eye movement in desktop viewing and head movement in VR viewing, as the latter exposes similar relationships between amplitude, duration and peak velocity [22]. In visual exploration, "head fixations" were observed during which subjects only made eye movements over a mean range of $18^{\circ}$ horizontally, while larger shifts usually involve head movement [23]. Other work on visual saliency observed coupled head and eye movement, suggesting the head following the eye with an average delay of $58 \mathrm{~ms}$ on the basis of cross-correlation of movements, with a mean gaze direction of around $14 \pm 12^{\circ}$ [63] relative to the head orientation. Another study found that the distribution of gaze fixations did not peak at the centre of the view-port where they align with head orientation, but at a distance of about 14 degrees from the display centre, proposed to be attributable to the exploratory nature of image viewing [55]. These studies provide insight into general correlation patterns of eye and head movement in visual exploration, whereas we focus on the systematic analysis of explicit gaze shifts and the relative movements by which they are accomplished.

Last not least, there is also a substantial body of work on eye-head coordination in gaze animation for virtual characters and embodied conversational agents. Gaze models in the graphics literature reflect insights from neuroscience, for example rendering gaze shifts as eyes-only when their amplitude falls below a threshold of $10-15^{\circ}$ [57], and accounting for factors such as target predictability [2]. These works are aimed at generating realistic gaze [26] or aiding animators in creating specific communicative effects (e.g., glances out of the corner of eye) [48]. In contrast, our focus is on gaze as input, and understanding of eye, head, and body coordination for the design of interaction techniques.

\section{STUDY DESIGN AND METHODOLOGY}

The aim of our study was to understand how eye, head and body movement is coordinated during gaze shifts in virtual reality, and how this depends on a variety of factors. Our main questions were: How are eye, head and body movement aligned in time? What is the relative contribution of each of the movement systems to reaching gaze targets? How much do head and torso move in total toward a target? What are preferred motion ranges for eye and head? We identified four principal factors of interest, for investigation in our study:

Amplitude. The significant effect of gaze amplitude is well established and our objective was to systematically quantify it for gaze shifts in VR. In our study, we cover a range from $5^{\circ}$ to $100^{\circ}$ from a central position.

Direction. The mechanics of eye and head imply differences in effort and range for horizontal, upward and downward movement, raising the question how this affects the composition of gaze shifts. We study this on the basis of gaze shifts in the four cardinal directions, as well as diagonals combining horizontal and vertical components. 


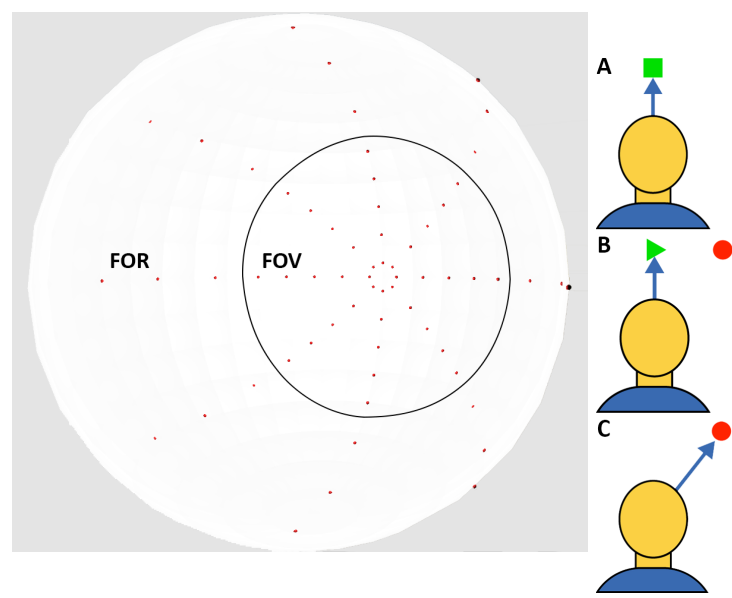

Fig. 1. Left: Virtual environment used in the study, showing the spherical layout of gaze targets around the user. The black circle represents the participants' FOV at the start of a trial. Right: Participants started each trial by aligning with a square shown in the display centre (A); the square disappears and a gaze target is presented; for targets outside the FOV, an arrow replaces the square pointing in the direction of the target (B); the participant shifts their gaze towards the target and dwells on it until it disappears (C), upon which the next trial is initiated.

Visibility. In VR, gaze targets can be visible within the initial FOV (within-view), or invisible in the wider FOR (beyond-view). In comparison with natural vision, HMDs provide a limited FOV (around $100^{\circ}$ in contemporary devices) in which objects become more easily hidden from view in the course of interaction. We are therefore interested in how gaze shifts compare for within-view versus beyond-view targets.

Posture. Head-mounted VR can be used standing with more freedom of body movement, or seated for safety or comfort. Existing platforms and experiences differ in how they are geared for standing versus seated usage. Playstation VR for example advocates seated use, whereas HTC Vive fosters room-scale interaction for which users typically need to be standing. We study gaze shifts in both postures as we expect a significant effect on the performance of gaze shifts.

The experimental design for our study was inspired by prior work on eye-head coordination in other fields, where gaze targets were arranged on a hemisphere, equidistant from the user, with gaze shifts initiated from a central position $[16,47,67,68,70]$. As shown in Figure 1, we placed gaze targets in VR around the user, along the cardinal axes as well as diagonally in between. The targets were small $\left(1.5^{\circ}\right)$ and placed in spherical coordinates at $5^{\circ}, 15^{\circ}, 25^{\circ}, 35^{\circ}, 45^{\circ}, 60^{\circ}, 80^{\circ}$ and $100^{\circ}$ visual angle from the centre of the display, at a fixed depth of 2 meters from the viewer. The spread of amplitudes was chosen to have a clear separation of within-view $\left(5^{\circ}-45^{\circ}\right)$ and beyond-view targets $\left(60^{\circ}-100^{\circ}\right)$.

\subsection{Tasks}

We constructed two tasks for our user study, one for gaze shifts within-view, and one for gaze-shifts to targets placed beyond-view. In both cases, a trial started with participants aligning their eyes, head and torso straight towards a central target used as a starting point for all gaze shifts. Colour feedback on the central target indicated when the participant had aligned correctly. Trial initiation was complete when participants had been in the correct position for 1.2 seconds. In the first task, 


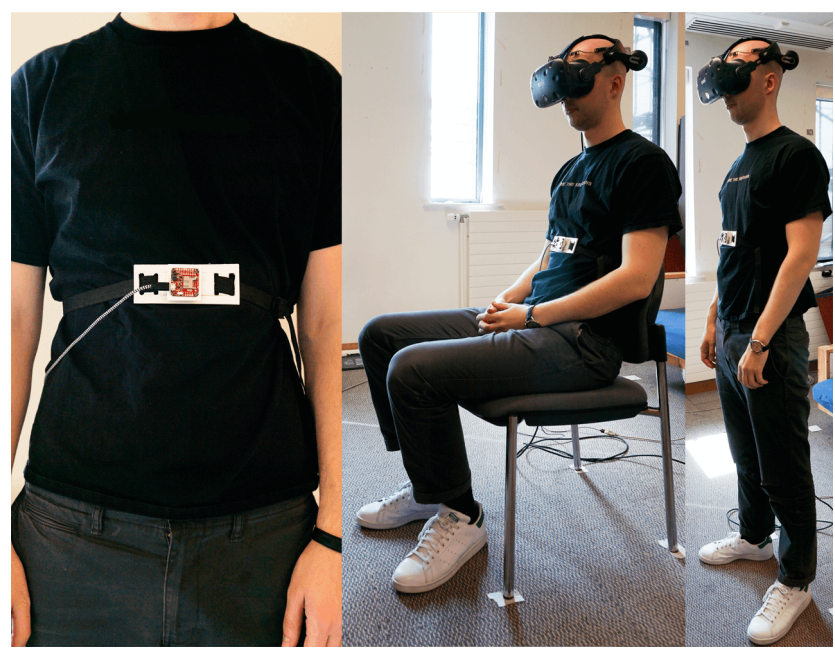

Fig. 2. Set-up of the experiment and each posture. Left: The IMU attached to the participant's torso. Middle: The participant is seated on a non-swivel chair in seated posture. Right: The participant stands in a natural position when in the standing posture.

the central target then disappeared, and a new within-view target appeared. The participants were instructed to shift their gaze towards the new target as accurately and quickly as possible and dwell on it. The participants were allowed to use their eyes, head and body at their discretion. The target disappeared when the participant had dwelled within $\pm 2.5^{\circ}$ of it for 1.4 seconds, upon which the central target reappeared. The same procedure then repeated for the next target (Fig. 1). Each within-view target on our spherical grid was presented three times, where every target was presented once in random order before a target could reappear, for a total of 120 trials ( 5 amplitudes $\mathrm{x} 8$ directions $\mathrm{x} 3$ trials).

The first task is a conventional pointing task, whereas the second task (beyond-view) can be described as peephole pointing, as the target is not initially visible and only revealed by moving the display [9]. In our study, this is initiated by the user aligning centrally, as in the first task. After initiation, the central target was replaced by an arrow showing the direction towards a target beyond-view (Fig. 1). The task was otherwise organised in the same way as first one, for a total of 72 trials (3 amplitudes $\mathrm{x} 8$ directions $\mathrm{x} 3$ trials).

\subsection{Apparatus}

Both tasks used in the study were developed in Unity Version 2017.1.0f3. The position of the head was placed in the zero vector position with the central target placed along the z-axis. An HTC Vive with an integrated Tobii Pro Eye Tracker and data output frequency of $120 \mathrm{~Hz}$ was used to record eye and head movement. We were able to record data at full frame rate and mean gaze accuracy of $1.533^{\circ}$. Eye and head data were synchronised by the Tobii SDK. The HTC Vive has a FOV of $100^{\circ}$ in the horizontal plane, $110^{\circ}$ in the vertical plane and a frame rate of $90 \mathrm{~Hz}$. A "SparkFun 9DoF Razor IMU M0" attached to the centre of the torso recorded torso movement at $50 \mathrm{~Hz}$. Torso data was recorded with eye and head data during run-time in the Unity application. Sensor latency was later adjusted during data analysis. The full set-up is seen in Fig. 2. 


\subsection{Procedure}

The experiment took place at Lancaster University, approved by the Lancaster University FST Research Ethics Committee. Twenty participants (14 male, 6 female, ages $26.7 \pm 3.6$ ) participated in the study. After giving informed consent and answering a basic demographic pre-study questionnaire, the participant put on the HMD and body tracking device. The participants would always perform both tasks in one posture (sitting or standing). Participants always started with the first task containing within-view targets. Posture order was counterbalanced with a Latin square. The participants sat in a non-swivel chair when in sitting posture, and was asked to stand in a neutral position when in standing posture (Fig. 2). Participants started each task by conducting an initial eye tracking calibration. The participant would then perform the task while eye, head and torso movement was tracked for each trial. Each task took 5-12 minutes to complete, and the participant was asked to take off the HMD and rest in-between tasks until ready to continue. The whole study took 30-45 minutes to complete for each participant, during which 384 gaze shifts were recorded.

\subsection{Measures and Data Analysis}

For each gaze shift we measured the total gaze movement, and the movement of head, torso, and eye as the contributing movement systems:

- Gaze movement during a shift was found by retrieving both eyes' combined directional gaze vector in the VE from the eye tracker.

- Torso movement associated with a gaze shift was found by retrieving the directional vector of the torso by calculating the quaternion retrieved from the IMU. Since the tracking of the torso was in a different coordinate space than the VE, the initial direction of the torso was always set to forward in the z-axis at the time of a new target appearing.

- Head movement associated with a gaze shift was found by retrieving the directional vector of the HMD in the VE. The head-in-torso movement was found by subtracting the head vector with the torso vector.

- Eye movement (eye-in-head rotation) associated with a gaze shift was found by subtracting the gaze vector with the head vector.

For the data analysis, we split all gaze shifts into their respective target amplitude, direction and posture. We divided the data analysis into four main parts:

Temporal Coupling. We analysed how the three movement systems aligned in time by comparing the start times of the eyes, head and torso movements. Only trials with an eventual head movement were used when comparing the coupling between the eyes and the head movement. The eyes were considered used if their velocity exceeded $100 \% \mathrm{sec}$. A head movement was considered used if head velocity exceeded $20 \% \mathrm{sec}$. Similarly, only trials where both head and torso movements were found was used when comparing the coupling between the head and torso. A torso movement was considered used when torso velocity exceeded $10 \% \mathrm{sec}$. All thresholds were found through data testing.

System Contribution. We determined the contribution of each system towards a gaze shift by comparing the eye-in-head, head-in-torso and torso directional vectors with the directional gaze vector at the point in time where a gaze shift first reached the target. Statistical analysis was done via repeated measures ANOVA, Greenhouse-Geisser-corrected in cases where Mauchly's test indicated a violation of sphericity to evaluate the effect of amplitude, posture and direction on each system contribution. Bonferroni correction was used for pair-wise comparisons. An alpha value of 0.05 was used for all tests. The analysis was done on all targets together as well as within-view and beyond-view targets separately. 


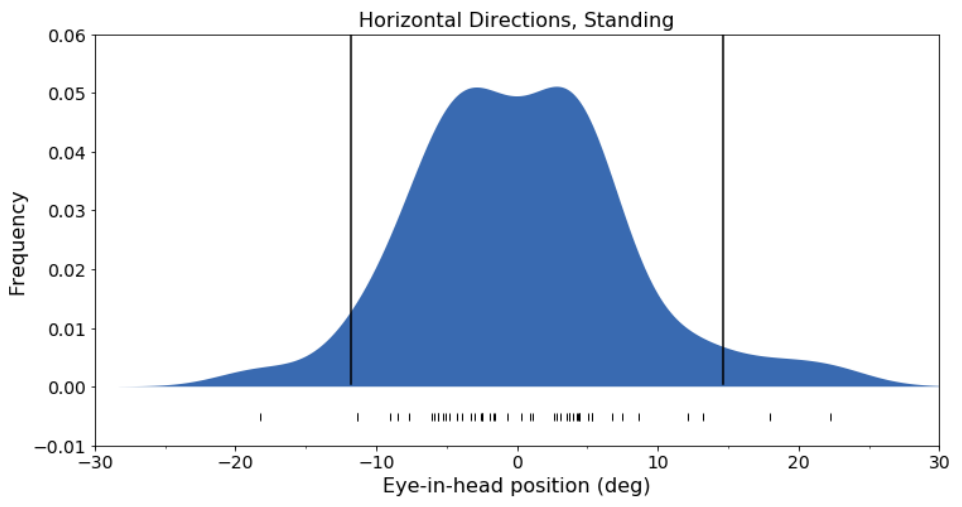

Fig. 3. The distribution of eye-in-head positions for one participant at the end of the head movement. The central $90 \%$ consists of the area between the vertical lines.

Relative Total Movement. Head and torso can continue to move toward a target after it has been reached by gaze. We captured the total head movement by retrieving the directional vector of the head at the end of the head movement, and similarly the total torso movement by retrieving the directional vector of the torso. For head movements, the reported values are from the head direction and not from the head-in-torso direction. This allows us to see the total amplitude of the head movement from its initial position independently of whether the torso was used. All analyses are then based on the total movement relative to gaze amplitude, as we are interested in how far head and body are turned toward a gaze target. Statistical analysis was done via repeated measures ANOVA, Greenhouse-Geisser-corrected in cases where Mauchly's test indicated a violation of sphericity to evaluate the effect of amplitude, posture and direction on each system's total movement. Bonferroni correction was used for pair-wise comparisons. An alpha value of 0.05 was used for all tests. The analysis was done on all targets together as well as for within-view and beyond-view targets separately.

Preferred Movement Range. Any movement of the systems after first reaching a gaze target serves to reach a preferred eye-in-head and head-on-torso position. We captured preferred ranges using the Costumary Ocular Motor Range (COMR) and Costumary Head Orientation Range (CHOR) as used in previous studies of eye-head coordination [47, 67, 68, 70, 71]. We used a Gaussian kernel method with a standard deviation of $3^{\circ}$ to plot the frequency of the relative eye-in-head position at the end of the head movement of a gaze shift to calculate the eye-in-head range (COMR) as in previous work $[47,67,70]$. If no head movement was registered, then the end of the eye movement was used instead. The preferred eye-in-head range was then defined as the central $90 \%$ of the area under a curve plotting the distribution of eye angle relative to the head (Fig. 3). The preferred head-in-torso range (CHOR) was calculated by applying the same principle to the frequency of the head position relative to the torso at the end of the torso movement. If no torso movement was registered, then the end of the head movement was used, and if there was no head movement either, then the end of the eye movement was used. Note, that the values calculated represent the whole range in a particular axis, for example, left and right for the horizontal axis.

A disadvantage of the COMR is that it only captures the eye-in-head range after completion of all movements associated with a gaze shift. However, we observed that long shifts to targets beyond the FOV did not conform to the straight ballistic movement to within-view targets, and therefore also analysed eye-in-head range during gaze shifts for beyond-view targets. We defined 
the preferred eye-in-head position as the mean eye-in-head position between the start of the eye movement until the target was reached. Movement ranges were analysed with repeated measures ANOVA to study the effect of posture and direction (and amplitude in the case of the eye-in-head range during gaze shifts), using Greenhouse-Geisser correction in cases where Mauchly's test indicated a violation of sphericity. Bonferroni correction was used for pair-wise comparisons. An alpha value of 0.05 was used for all tests.

\section{STUDY RESULTS}

The 20 participants performed gaze shifts towards each stimulus three times in sitting and standing posture which resulted in a total of 7680 gaze shifts among all participants. 4800 gaze shifts were performed towards within-view targets, and 2880 gaze shifts towards beyond-view targets. 87 gaze shifts $(1.1 \%)$ were removed from the data analysis due to failed tracking or the participant not finding the target. The analysis showed that gaze behaviour was symmetrical in both horizontal directions, both upwards diagonal directions and both downwards diagonal directions. However, differences were found between the two vertical directions. Therefore, the results presented in this section have been categorised into upwards, downwards, horizontal, upwards diagonal and downward diagonal gaze shifts for readability.

\subsection{Temporal coupling and patterns of movement}

For each gaze shift, we analysed the start- and end-time for associated eye, head and torso movement, to identify general patterns of coordination and temporal relationships. The reaction time before any movement was registered was on average $200 \mathrm{~ms}$ for within-view targets, and $375 \mathrm{~ms}$ for beyondview targets. The additional reaction time for beyond-view targets is explained by participants needing to process the directional arrow.

4.1.1 Patterns of movement. Fig. 4 illustrates the different gaze shifts that participants performed during the study. The choice of movements during the gaze shift was dependent on multiple factors; amplitude, direction, posture as well as individual differences. The eyes were generally first to move toward a target, followed by optional head and torso movement. Head movement generally preceded any torso movement.

Smaller gaze shifts at amplitudes of $15^{\circ}$ or less were generally performed by the eyes only, without any significant head or torso movement. This corresponds with observations reported for gaze in the real world $[13,16,33]$. Head movement that supported larger gaze shifts generally started before the gaze target was reached, whereas any torso movement was further delayed, and frequently only occurred after a gaze target was first reached.

Both the head and torso would often continue to move or start moving after the target had been reached by the eyes, to which the eyes responded with stabilising VOR movement in the opposite direction. These movements were made by the participants to reach an eye-in-head and head-in-torso position that is more comfortable over an extended period. We observed these movement patterns across all amplitudes and postures in our VR study, and they correspond with gaze behaviour observed in real-world studies [58, 73].

4.1.2 Lag between eye, head and torso. For any gaze shifts supported by head movement, we observed that the lag between eye and head differed depending on visibility of the target. For within-view targets, participants started a head movement on average at $150 \mathrm{~ms}$ after the start of the eye movement, whereas the difference was only $30 \mathrm{~ms}$ on average for beyond-view targets (Fig. 5). These results seem to confirm previous research suggesting that there is an earlier head movement when the gaze shift is the result of top-down goal-driven behaviour, as is the case for 

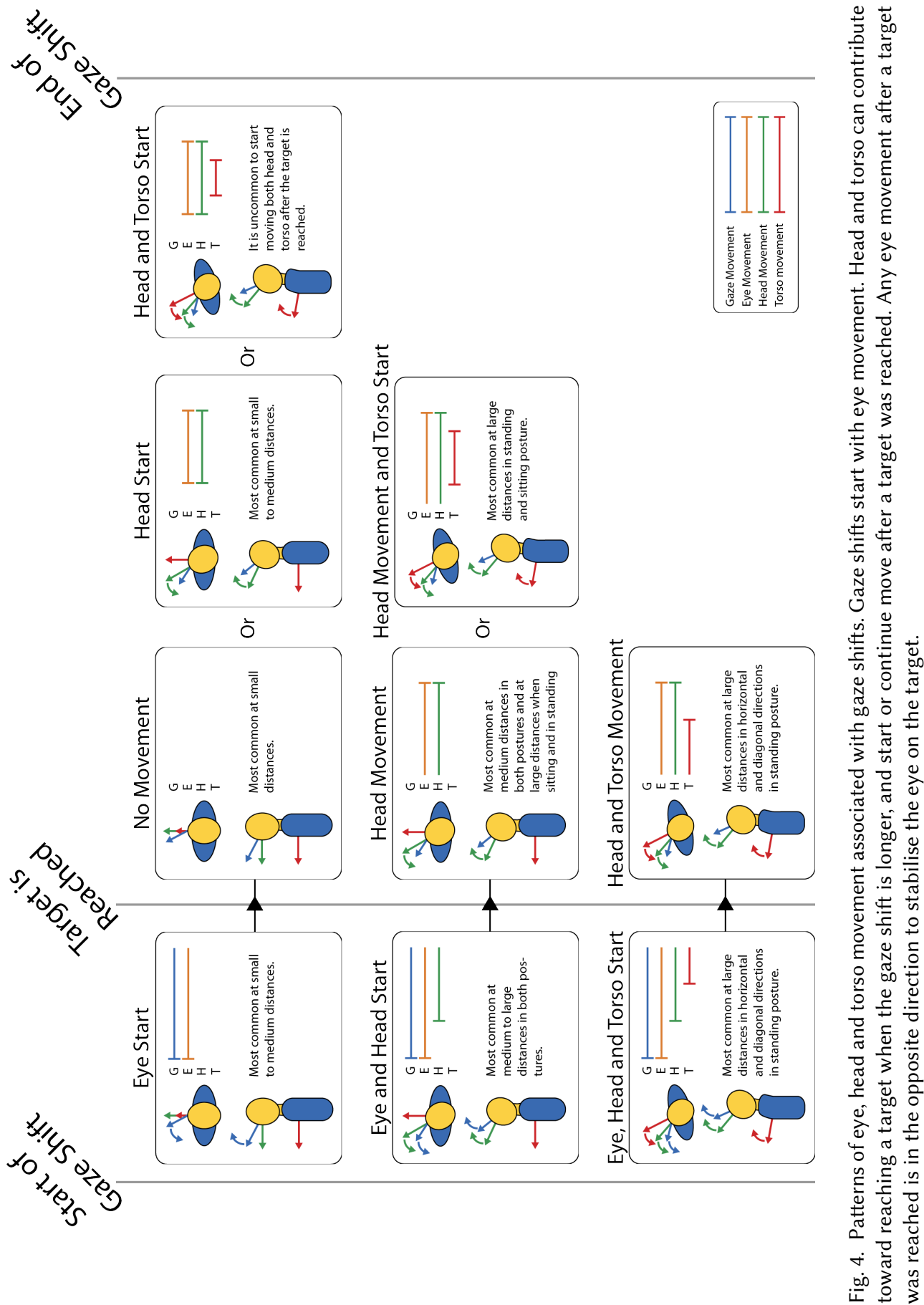

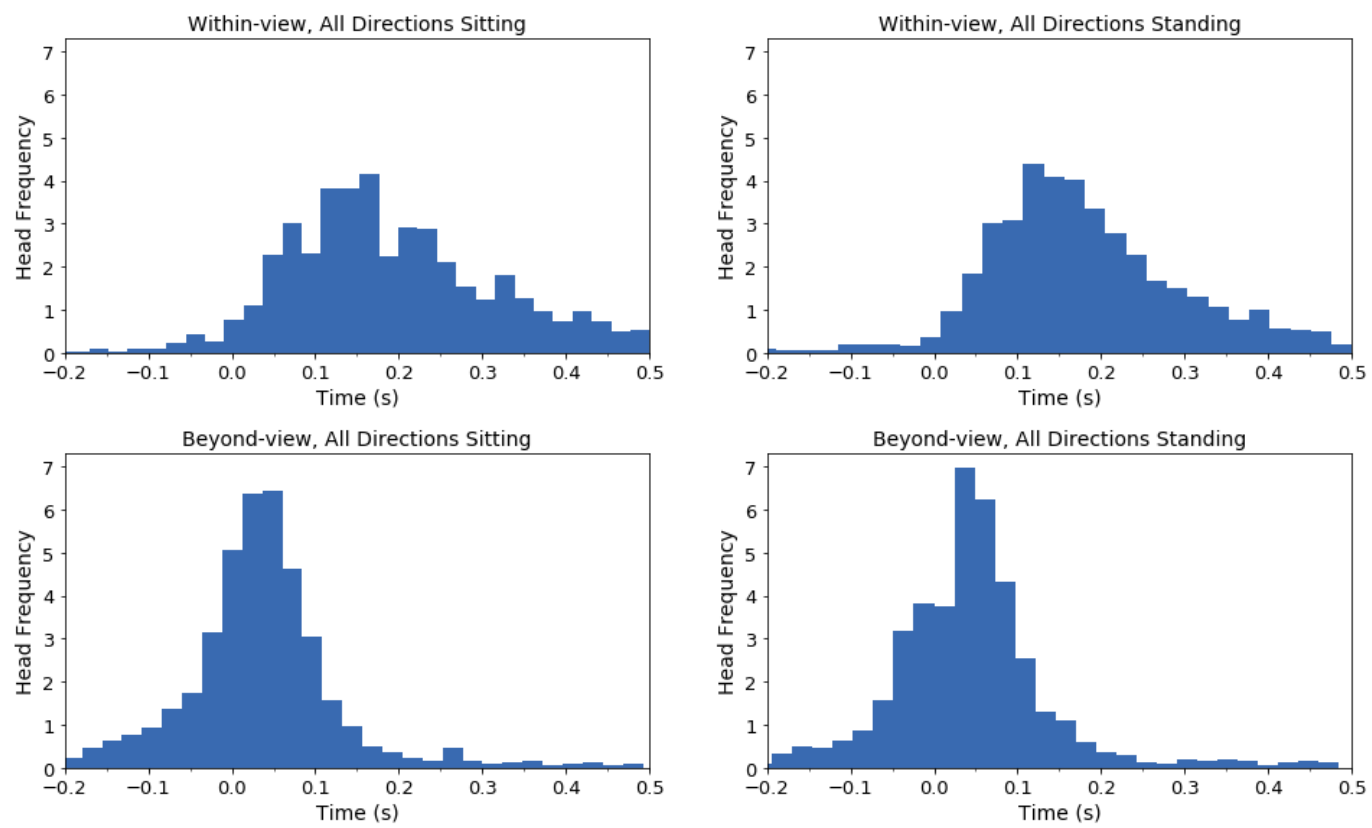

Fig. 5. Distribution of head movement start-times relative to the start of the eye movement, shown for the different combinations of posture (left: sitting; right: standing) and target visibility (top: within-view; bottom: beyond-view).
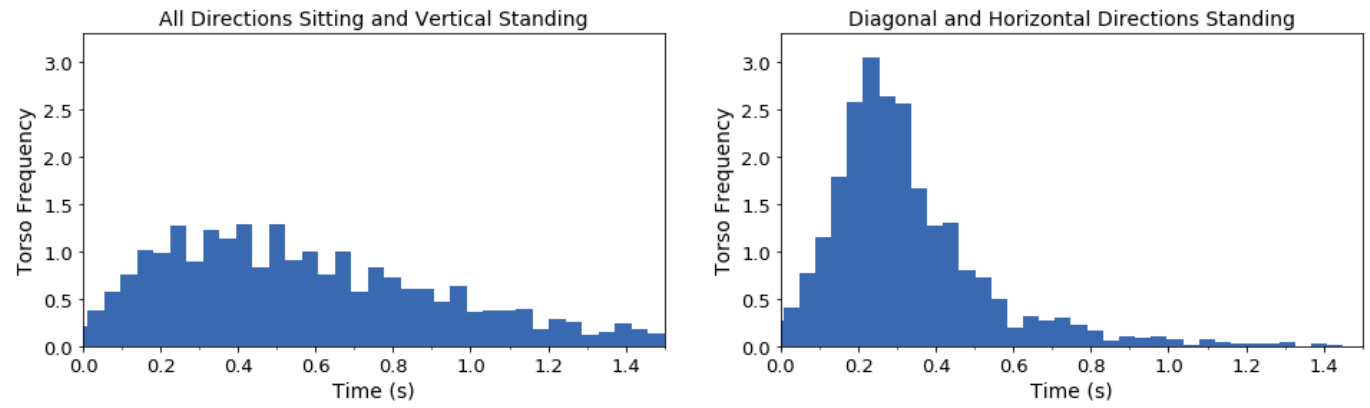

Fig. 6. Distribution of eventual torso movement start-times relative to start of the head movement. The torso is used more and follows the head with less delay when users stand and the gaze shift involves a horizontal component.

beyond-view targets, as opposed to a bottom-up reaction to a target appearing, which may be a factor for within-view targets [10].

The torso would rarely move independently and would mainly start after the head movement. Torso movement was generally not used in conjunction with the gaze shift for amplitudes under $45^{\circ}$. Additionally, torso movement was rarely used in vertical directions or in sitting posture. If a torso movement was used, then it was often used in a later period during the gaze shift, on average $550 \mathrm{~ms}$ after the head movement. However, torso movement was found for $85 \%$ of all horizontal and 

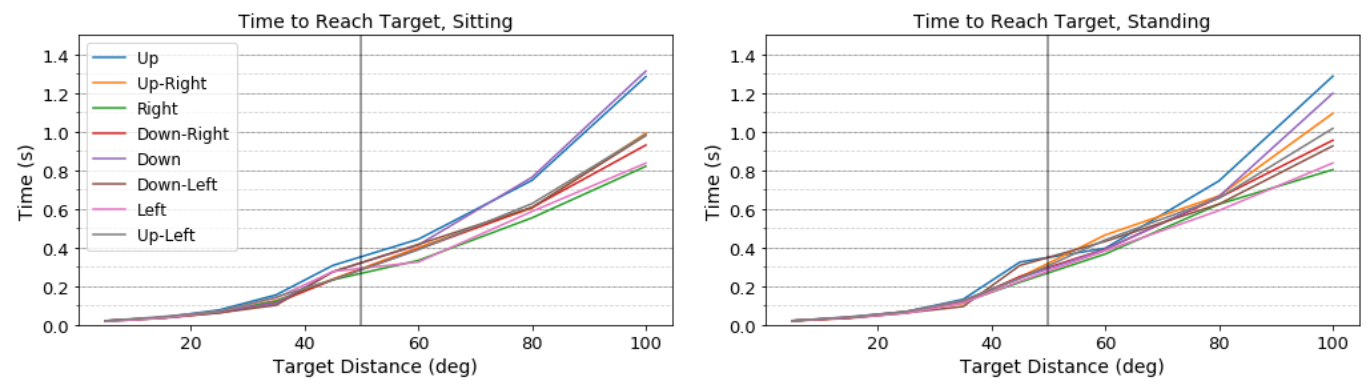

Fig. 7. Median time to reach the target as a function of amplitude for each direction and posture, excluding reaction time. The vertical line denotes the boundary between within-view and beyond-view gaze shifts. Gaze shifts in the horizontal direction are fastest, and vertical gaze shifts are slowest.

diagonal shifts in the standing posture at amplitudes of $45^{\circ}$ or larger, and in these cases followed the head more quickly, with a lag of only $300 \mathrm{~ms}$ on average (Fig. 6).

4.1.3 Time to Reach Target. Figure 7 shows the median time to reach the target. For small amplitudes, the reach time is quick since only the fast eyes are needed to reach the target. However, the reach time increases for amplitudes larger than $35^{\circ}$ due to that the slower head needs to be used to be able to reach the target. We observed no HMD specific effect; once a gaze shift had been initiated, there was no marked slowing down in reaching targets just beyond view, compared to just within view.

We also see a pattern in both postures where the vertical gaze shifts require a longer time to reach the target compared to diagonal and horizontal gaze shifts. Horizontal gaze shifts were shown to be the fastest. No large differences were found when comparing between postures. Also, note that differences between directions mainly appear at the largest amplitudes $\left(80^{\circ}\right.$ and $\left.100^{\circ}\right)$.

4.1.4 Single Trial Examples. Figure 8 shows single-trial examples of typical gaze shifts performed by participants during the study. The top row shows gaze to a target within-view at a amplitude of $35^{\circ}$. The target is reached in one ballistic movement, largely based on eye movement with some support by the head. Upon reaching the target, head and eye movement become opposing and the gaze is stabilised. The pattern is equivalent for sitting versus standing posture.

The bottom row in Figure 8 shows a typical example of a larger gaze shift, to a target presented beyond-view at a amplitude of $100^{\circ}$, exposing a strikingly different movement pattern. Large gaze shifts would commonly start with the eyes and head moving towards the target. However, as the eyes are much faster than the head, the eyes would move and then wait for the head to catch up before making another movement. The eyes would in general stay closer to the head compared to what we initially expected. We thought that the eyes would continuously stay ahead of the head at larger eccentricity, gazing toward the edge of the HMD screen where the target is expected to appear, whereas what we found is a distinct stepped behaviour of less eccentric eye shifts and VOR eye movements until the gaze target is reached. This pattern starts to appear at amplitudes of $45^{\circ}$ and becomes more prevalent when the amplitude increases. We observed this behaviour in both sitting and standing posture, for all gaze directions.

The single-trial examples also illustrate the absence of torso movement for smaller gaze shifts versus their contribution to larger shifts. Note that the head position shown in these plots represents the combination of torso orientation and head-on-torso relative rotation. 

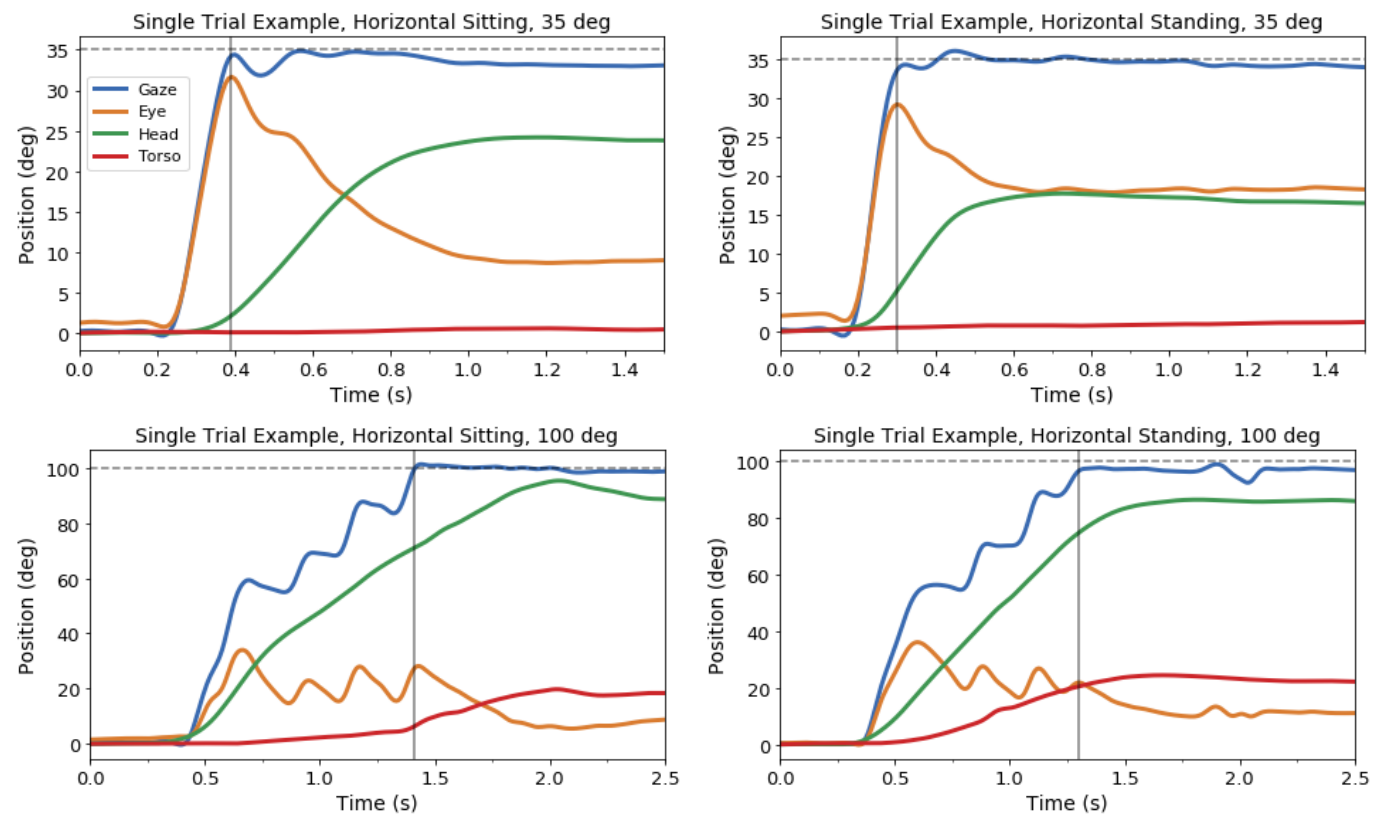

Fig. 8. Single-trial examples of gaze shifts showing the movement of each system as a function of time. Eye movement is shown relative to the head; all other movements are shown relative to the environment. Note the ballistic movement to targets in closer range versus stepped movement to targets over a larger amplitude, in both seated and standing posture.

\subsection{System contributions towards reaching the gaze target}

Our next analysis examined the relative contribution of eye, head and torso movement toward first reaching the gaze target, i.e. which proportion of the amplitude each of the systems covered. Fig. 9 provides a complete overview of the system contributions, depending on amplitude, and shown for the different directions and postures.

4.2.1 Eye Contribution. Amplitude had a main effect on eye contribution, but direction and posture also had an influence. The eyes perform the significant majority (>90\%) of the gaze shift towards the target for amplitudes of $25^{\circ}$ or less, with the head and torso contributing a minimal amount. These amplitudes are easily reached by the eyes alone, and these results were seen in both postures and all directions. However, the eyes contribute less towards the gaze shift as the amplitudes increase beyond the preferred eye range, down to $30-35 \%$ for targets at a $100^{\circ}$ amplitude.

In general, there was no interaction between amplitude and posture. However, the results showed a significant interaction between amplitude and direction. The direction had a significant effect on eye contribution for gaze shifts of $25^{\circ}$ and larger, in both postures. Participants would, in general, have a larger eye contribution for downwards shifts compared to the other directions. The results showed that eye contribution was symmetrical within the horizontal, upwards diagonal and downwards diagonal directions respectively but this was not the case for vertical directions, where eye contribution were larger in downwards direction than upwards. This can be explained by many tasks naturally require us to gaze downwards at our hands and the limited visual FOV upwards.

Posture did not have any significant effect on eye contribution and no significant interaction with either amplitude or direction. For full statistical analysis, see Appendix A. 

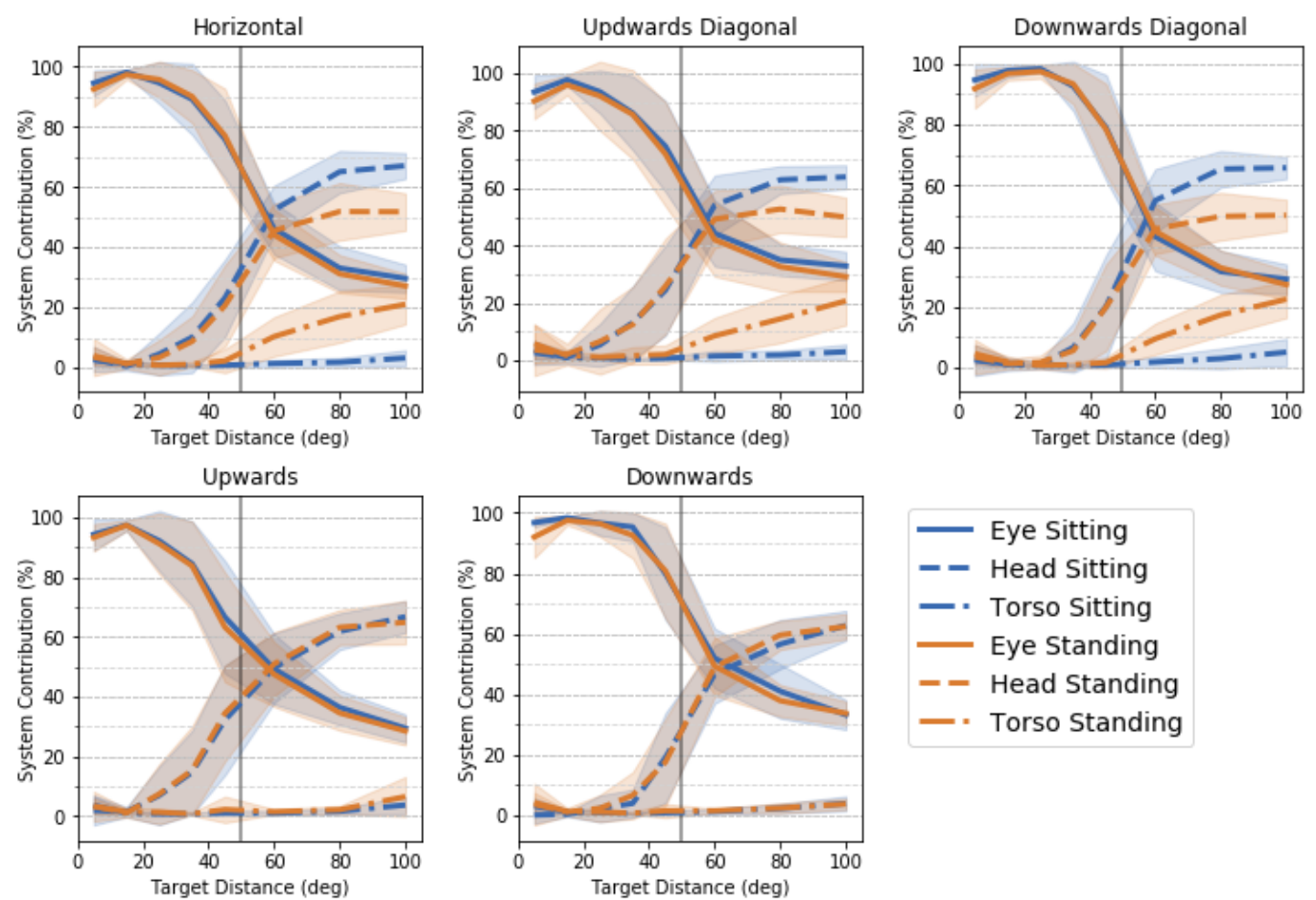

Fig. 9. The average contribution from eye, head and torso toward first reaching the target, depending on target amplitude, and shown different directions and postures. The vertical line indicates the edge of the participants' initial FOV.

4.2.2 Head Contribution. Unsurprisingly, amplitude had a significant effect on head contribution. The head provided a minimal contribution for small amplitudes in both postures and all directions $(<10 \%)$. However, the head contribution became more substantial as the target amplitude increased, reaching up to $60 \%$ contribution at $100^{\circ}$. The results also showed a significant interaction between amplitude and direction for both postures and both within-view and beyond-view amplitudes. In sitting posture, participants tended to use their head less downwards for within-view amplitudes compared to the other directions. In standing posture, the head contributed more in vertical directions due to less torso movement. Head contribution was symmetrical within each posture when comparing the two horizontal, upwards diagonal and downwards diagonal directions respectively. However, the head would contribute slightly less in downwards direction compared to the downwards direction. Posture and amplitude had a significant interaction for beyond-view amplitudes in horizontal and both diagonal directions due to the added torso movement in standing posture, where the difference in head contribution between the postures could be up to $20 \%$ of the gaze shift. Posture showed no significant effect in vertical directions. Posture and direction showed to have a significant interaction for amplitudes at $80^{\circ}$ and $100^{\circ}$ due to the added torso movement. For full results, see Appendix B.

4.2.3 Torso Contribution. Torso contribution was in general only prevalent in standing posture in horizontal and diagonal directions for beyond-view amplitudes where it would reach up to $20 \%$. Amplitude and posture only had a significant interaction for horizontal, and both diagonal 
directions as the torso was rarely used for vertical directions. No significant interaction was found for within-view amplitudes as participants rarely used their torso at such small amplitudes. Amplitude and direction only had significant interactions in standing posture. However, amplitude showed to have a main effect on torso contribution in all directions and postures. Posture and direction had a significant interaction at beyond-view amplitudes. Additionally, the direction had a significant effect on torso contribution in standing posture for beyond-view amplitudes. Posture had a significant effect on horizontal and both diagonal directions for amplitudes at $45^{\circ}$ and above. Just as with the eyes and head, torso contribution was symmetrical horizontally and diagonally. For full results, see Appendix C.

\subsection{Total movement of systems}

As illustrated by the single-trial examples shown above (Fig. 8), much of the head and torso movement associated with gaze shifts occurs after a target is first reached by the eyes. Our next analysis thus considered the total movement of head and torso toward the gaze target. The results are summarised in Figure 10, showing how far head and torso turned toward a target as a percentage of the gaze amplitude.

4.3.1 Total Head Movement. The results show that the relative total head movement was larger than the head and torso contribution together, as participants generally continued to move their head after the target was reached in order to obtain a more comfortable eye-in-head position. We observed a high variance in the amount of head movement from participant to participant, with differences of up $30^{\circ}$ in how much they oriented their head toward a target at the end of gaze shift. This indicates that different tendencies in using head movement, previously observed in real-world studies, also show in VR.

We further observed that the total head movement was generally short of the full gaze amplitude. While participants often continued to rotate their head toward a target after first reaching it with their eyes, their head did not follow their eyes all the way. This behaviour was found in both postures and all directions. It can be explained by the relative effort required for head versus eye movement, and relative saving of energy by only moving the head as far as reaching a comfortable as opposed to central eye-in-head position.

The total head movement was symmetrical in horizontal, upwards diagonal and downwards diagonal directions but participants tended to move their head further upwards compared to downwards. Statistical analysis showed that not only amplitude but also direction and posture affected total head movement.

Over shorter amplitudes within-view, head movement is not necessarily needed to achieve a gaze shift, but given the short range it can be performed in any direction without strain. As such the amount of head movement can be highly varied, and we observed relative head movement from none to almost $90 \%$ of the gaze amplitude. However for beyond-view, head movement was essential to bring the target into the FOV and we therefore saw less variation in the amount of relative head movement. Direction had a main effect in both postures for beyond-view amplitudes where more head movement was generally made in horizontal and diagonal directions. Posture only had a significant main effect in horizontal and both diagonal directions where the extra torso movement would help the head move further. Amplitude only showed a main effect for movements with horizontal component in seated posture, where the relative total head movement peaks at $60^{\circ}$ and then decreases as the torso is not able to help the head to travel further. For full statistical analysis, see Appendix D.

4.3.2 Total Torso Movement. Just as with the head, we saw torso movement continued or started after a target was reached, but to a much smaller extent. Participants would generally only use 

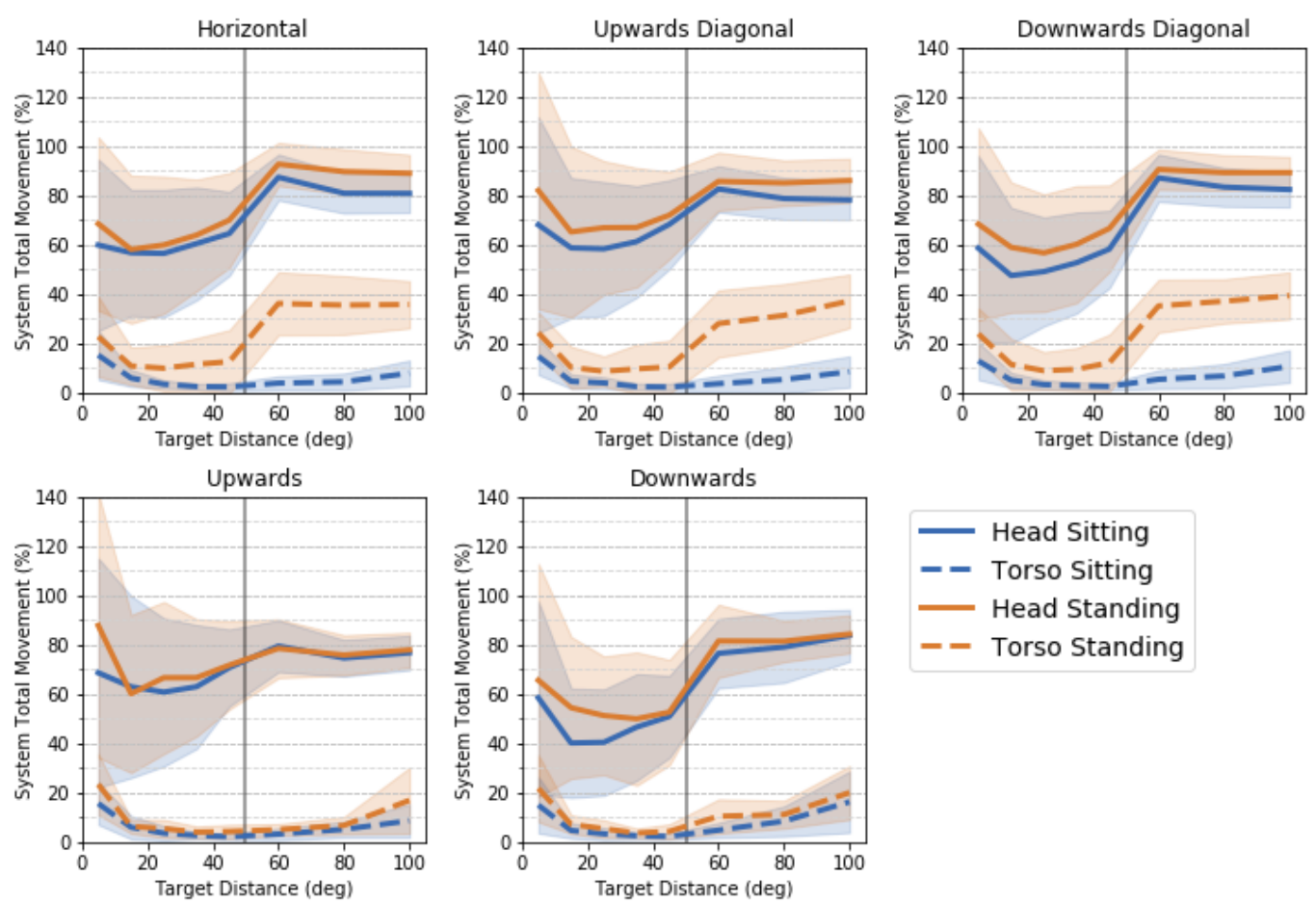

Fig. 10. The average total movement of the head and torso toward a gaze target as a percentage of the target amplitude, depending on target amplitude, and shown for different directions and postures. The vertical line indicates the edge of the participants' initial FOV.

the torso for beyond-view amplitudes, in horizontal and diagonal directions in standing posture during which the torso would turn horizontally. The torso was rarely used in vertical directions or sitting posture. For these conditions, torso movement was generally only seen at the largest amplitudes. The results indicate that torso movement may not be necessary to reach a position of comfort toward targets in the range we studied. However, participants would still support any non-vertical head movement with their torso when they were not constrained by sitting.

Statistical analysis again showed that amplitude, posture and direction had a significant effect on total torso movement. Large differences in total torso movement were found for beyond-view amplitudes. In this range, a significant interaction was found between amplitude, posture and direction. Also, significant interactions were found between amplitude and direction in both postures as well as amplitude and posture in horizontal directions. Additionally, amplitude had a main effect on total torso movement regarding percentages in both postures and all directions except for horizontal directions in standing posture. Posture and direction showed to have significant interaction and main effects for all beyond-view amplitudes. For full statistical analysis see Appendix $\mathrm{E}$ (Note the full analysis shows significant effects also for within-view gaze shifts, however the total torso movement in that range was minimal and observed effects pertain to small differences only).

\subsection{Preferred Motion Ranges}

The next set of analyses was on the range of eye and head motion used, to gain insight into preferred ranges. 


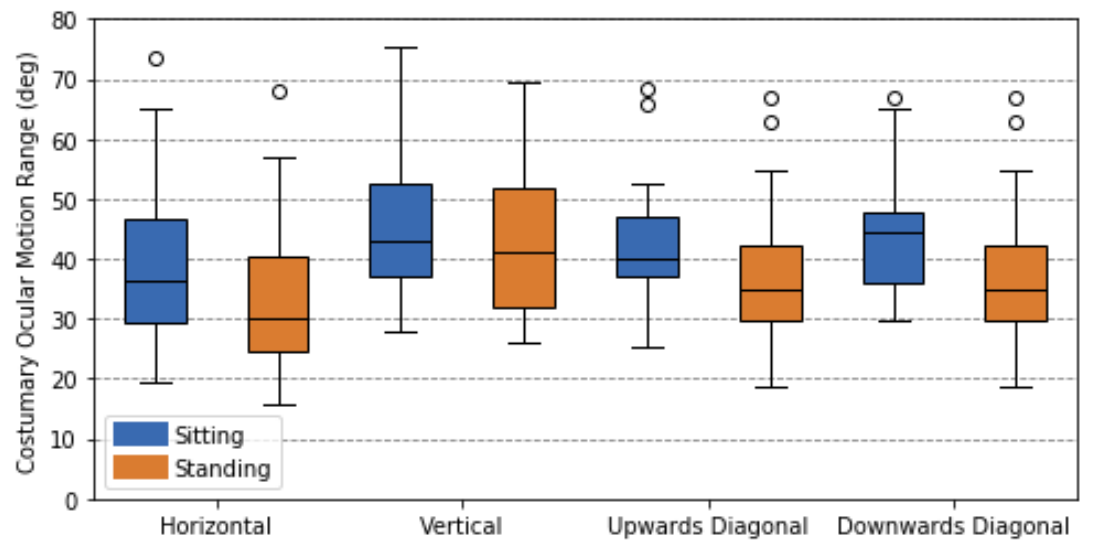

Fig. 11. The Customary Ocular Motion Range among all participants, with the median value marked.

4.4.1 Costumary Ocular Motion Range. As shown above, the head continues to move toward a gaze target after it has been reached by the eyes, so to reach a preferred eye-in-head position. Figure 11 illustrates the range of final eye-in-head positions observed in the study. The eyes' motion range varied from $20^{\circ}-70^{\circ}$ among the participants for all postures and directions showing large individual differences. In range and variance, the results are comparable with findings in real-world studies of eye-head coordination $[15,47,67,70,71]$. The results show that the preferred range is significantly smaller than the physiologically possible range of eye movement $\left(100^{\circ}\right)$, and as such also significantly smaller than the FOV of contemporary HMDs.

Statistical analysis showed that the COMR was significantly higher in sitting posture for horizontal $(\mathrm{F}(1,19)=9.23, p=.007)$, downwards diagonal $(\mathrm{F}(1,19)=9.78, p=.006)$, and upwards diagonal $(\mathrm{F}(1,19)=7.56, p=.013)$ directions compared to standing posture. These results align with our observation that participants would move their heads further in standing posture than when seated, for directions with a horizontal component. Direction had a significant effect on COMR in both sitting $(\mathrm{F}(3,57)=7.00, p<.001)$ and standing posture $(\mathrm{F}(1.80,34.28)=18.93, p<.001)$ where vertical directions had a significantly larger COMR compared to horizontal directions. The larger COMR can be explained by the more limited range of the head vertically versus horizontally [12], and lack of support by the torso for vertical head orientation shifts.

4.4.2 Costumary Head Orientation Range. As shown in Figure 12, the preferred head-in-torso range was between $130^{\circ}-180^{\circ}$ in sitting posture and $80-160^{\circ}$ in standing posture, showing large individual differences. We observed a significant interaction between posture and direction on $\mathrm{CHOR}(\mathrm{F}(1.81,34.36)=27.32, p<.001)$. CHOR was significantly higher in sitting posture for horizontal $(\mathrm{F}(1,19)=170.03, p<.001)$, downwards diagonal $(\mathrm{F}(1,19)=85.48, p<.001)$ and upwards diagonal directions $(\mathrm{F}(1,19)=96.37, p<.001)$ compared to sitting posture. No significant difference was found between postures in vertical directions as participants tended to not use their torso. Direction showed a significant effect in standing posture $(\mathrm{F}(2.15,40.93), p<.001)$ where vertical directions had a significantly higher $\mathrm{CHOR}$ compared to the other directions, and the diagonal directions had a significantly higher CHOR compared to horizontal directions. No significant differences were found in the sitting posture as there was minimal torso movement in all directions.

4.4.3 Preferred Eye Range During Gaze Shifts. The COMR analysis above is based on eye-in-head position upon completion of a gaze shift. We additionally analysed the range within which the 


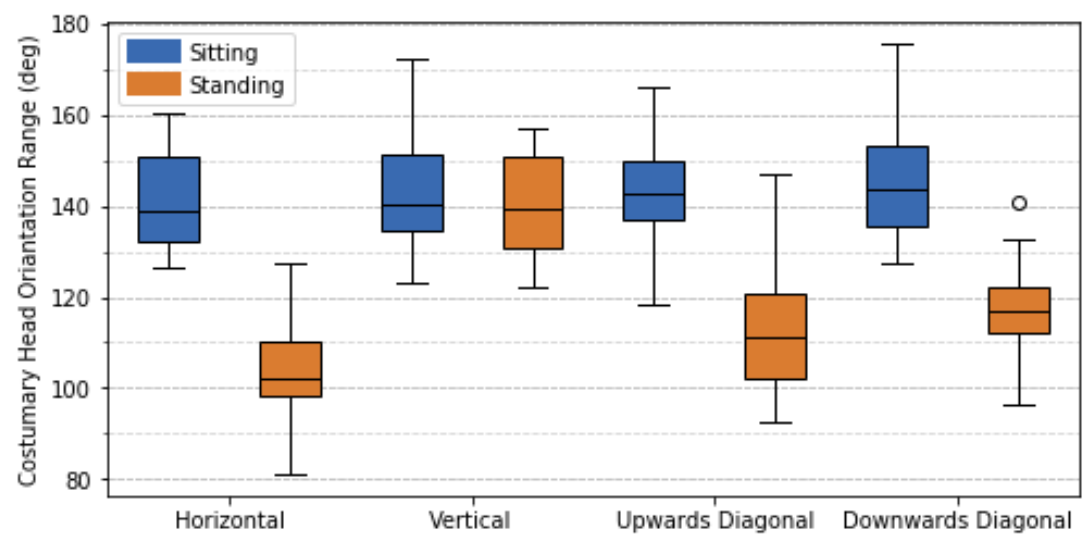

Fig. 12. The Customary Head Orientation Range among all participants, with the median value marked.

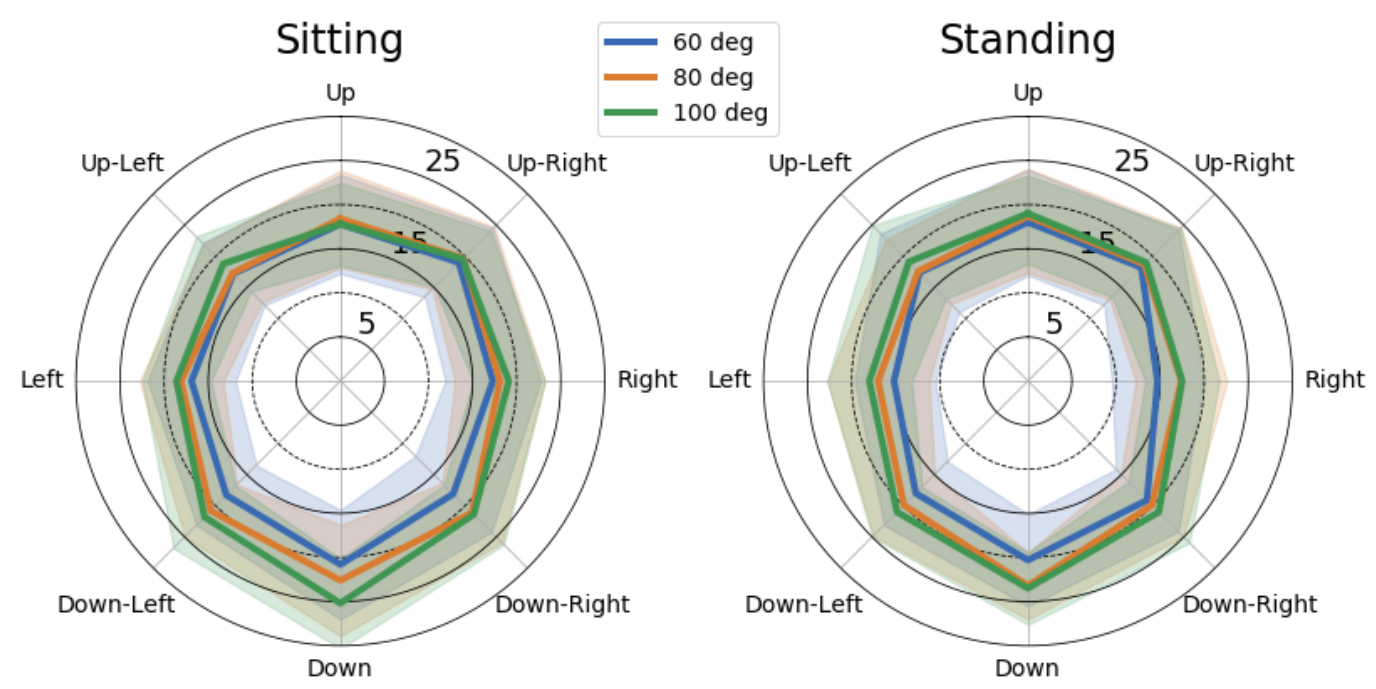

Fig. 13. Average eye-in-head position from start of a gaze shift to reaching the target, as a function of target direction and amplitude, shown for larger amplitudes and sitting versus standing posture.

eyes moved relative to the head during the movement to a gaze target. Figure 13 shows the average preferred eye-in-head positions from the start of the gaze shift to the first hit on the target, for shifts towards beyond-view targets $\left(60^{\circ}, 80^{\circ}\right.$ and $\left.100^{\circ}\right)$. As shown, the range is not symmetric but larger in downward direction. We observed large individual differences where the standard deviation was around was around $5^{\circ}$.

Statistical analysis showed a significant interaction between amplitude, posture and direction on eye-in-head range during gaze shifts $(\mathrm{F}(10.44,553.12)=1.93, p=.037)$. Amplitude and direction had significant interaction in sitting posture $(\mathrm{F}(10.17,549.23)=3.26, p<.001)$, and in standing posture $(\mathrm{F}(10.31,587.88)=2.81, p=.002)$. The results showed that an increase in amplitude would lead to a significantly larger eye-in-head range for participants, except for upwards and upwards diagonal directions in both postures. The direction also had a significant effect, with a larger eye-in-head 


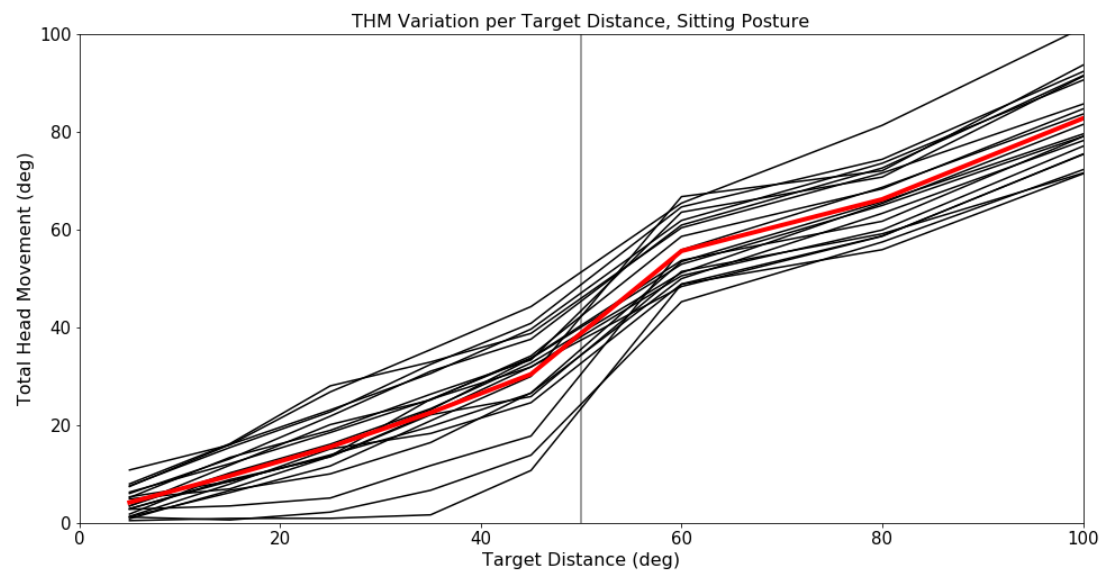

Fig. 14. Total Head Movement (THM) for horizontal gaze shifts in sitting posture. The red line indicates the mean THM across all participants, while each black line represents the mean THM for a single participant. The vertical line indicates the edge of the participants' initial FOV. Note that some participants displayed distinctly less head movement for targets within-view.

range downwards compared to other directions, coinciding with our observation of a larger eye contribution downwards compared to other directions. Participants also tended to have a larger eye-in-head range for sitting posture compared to the standing posture. A possible explanation is that the standing posture affords more freedom of head and torso movement to the effect that participants have less need to "stretch" their eyes.

\subsection{Participant Variability}

A common theme for all results was the high variability. Gaze shifts made by the same participant showed consistent behaviour, but gaze shifts between participants showed high variability. The results showed that this was primarily due to differences in the amount of head movement used.

Figure 14 shows the difference between participants in total head movement in the seated condition. The majority of participants used their head to support gaze at all target amplitudes, but a number of participants tended to do so only for larger target amplitudes where head movement became unavoidable. For sitting horizontal gaze shifts of $35^{\circ}$, the total head movement had a mean of $21.19^{\circ}$ (s.d. $8.02^{\circ}$ ) but there were clear outliers. Participant P20 reached all targets at this amplitude without any head movement, and P1 exhibited only little head movement (5.60 (s.d. $\left.1.89^{\circ}\right)$. We found corresponding results for the COMR measure of eye movement range. The mean COMR was $39.56^{\circ}$ (s.d. $14.33^{\circ}$ ) but P20 and P1 had much larger COMR values (P20: 73.47 and P1: 65.21), highlighting their more extensive use of eyes.

The observation that some participants would use their head frequently, while others would not move their head unless it was needed for reaching a gaze target, aligns with findings in fundamental neuroscience research $[15,47,67,70,71]$. However, it is not clear whether there are distinct groups of "head-movers" versus "non-head-movers" as proposed in past work [15], or whether there is a continuum in individual tendency to support gaze with head movement.

\section{DISCUSSION}

The study results provide in-depth insight into eye, head and torso coordination of gaze shifts. Here, we discuss the results with regards the factors of interest we had identified, starting with a 
general comparison of our findings in VR with findings of studies in real environments. Note that we cover design implications and limitations separately, following the discussion.

\subsection{Virtual Reality vs. Real World}

Our study indicates that gaze shifts are generally performed in the same way in VR as in the real world. Just as in the real world, smaller gaze shifts up to $25^{\circ}$ were mostly performed with the eyes while the head and torso contributed more when gaze shifts were larger [13, 16, 33]. Our results on eye-in-head motion are also similar to customary ocular motion ranges observed in the real world (COMR means in the range $45-55^{\circ}$, with standard deviations $7-24^{\circ}[47,67,68,70,71]$ ), and we found comparable variability in head movement tendency as previously observed in real world gaze [15]. The correspondence of our results with prior observations is of importance as it implies that general knowledge of visual attention and gaze can be transferred to head-mounted VR. This was not necessarily expected, given the limited FOV of HMDs and additional weight they impose on head movement. However, our study did not directly compare virtual and physical reality, and a recent direct comparison observed that a higher proportion of gaze shifts were supported by head motion when users were in VR [49].

Our study had more extensive coverage than prior studies of eye-head coordination, which primarily focussed on horizontal gaze shifts, in seated position, and frequently over shorter ranges. Given the similarities observed for horizontal gaze shifts, we expect that observations on gaze shifts in other directions and in standing versus seated posture are generalisable from our study in VR to gaze in the real world. Note, the head orientation ranges (CHOR) we observed were considerably higher than reported by prior studies but this is explained by the wider range of gaze shifts we covered $\left( \pm 100^{\circ}\right.$ compared to, e.g., $\pm 45^{\circ}$ in [68]).

We observed a distinct pattern of stepped gaze shifts where the eyes performed a series of saccadic shifts toward the target interleaved with VOR movement to let the head catch up (Fig. 8). We have not found any detailed description of this behaviour in prior literature, although Land noted that large gaze shifts can occur in steps [34]. It is reasonable to assume that people perform gaze shifts similarly in the real world, to keep their eyes within a preferred range during transition to a gaze target. However, the question arises whether the limited FOV of the HMD affects how frequently the eyes wait for the head. The further the eyes rotate from the head, the more of the viewer's peripheral vision lies beyond the displays boundary without stimulation by the virtual scene, and this might trigger the eyes to wait. It might also be that gaze is stepped so to stay within a visual range of the display that is reachable by both eyes.

\subsection{Amplitudes and Gaze Zones}

Amplitude has a critical effect on eye, head and torso coordination. This effect is natural as both the eyes and head have a limited range of motion and therefore need to coordinate, also with the torso, to achieve gaze shifts over larger amplitudes. However, we saw that head and torso supported gaze not only to extend the reach of the eyes, but also to stabilise gaze in a comfortable position. This effect becomes more apparent for larger gaze shifts. Based on our results, we propose three gaze zones: gaze shifts up to $25^{\circ}$ that can be comfortably achieved eyes-only; gaze shifts in the range $25-50^{\circ}$ where eyes and head together reach targets comfortably; and gaze shifts over amplitudes larger $50^{\circ}$ where eyes, head and also torso need to work together for comfortable viewing. The larger the amplitude, the more apparent are also differences between directions and postures.

\subsection{Within-view vs. Beyond-view}

Visibility effects overlap with amplitude effects, as the targets were within-view in our study when they were within the first two gaze zones proposed above, and beyond-view when they were in 
the third gaze zone. However, there was a distinct effect on the relative starting times of head and eye movement, with the head movement more quickly initiated when targets were beyond-view. The effect is explained by significant differences in the two tasks we used. Within-view targets required the user to perform a reactive gaze shift, in response to a stimulus appearing in their peripheral vision. Beyond-view targets, in contrast, required the user to process a directional cue and perform a predictive gaze shift toward the direction in which the target is expected. Prior work in neuroscience suggests that reactive gaze is led by the eyes followed by the head, whereas predictive gaze involves earlier head movement [10]. The results in our study appear to support these prior observations.

However, in our study, participants only had knowledge of the target direction but not of how far beyond the view it was positioned, adding to relative complexity of the task. Search for the target may have played a role in the stepped gaze behaviour we observed for beyond-view targets. We saw more frequent interleaving of the saccadic shift with VOR eye movement than we had expected and this could be explained by the eyes intermittently stabilising on the virtual scene to be able to assess whether the target has come into view.

\subsection{Sitting vs. Standing}

The results showed that the head and torso were used significantly more in standing posture compared to sitting posture for large gaze shifts. Standing posture offers more freedom of movement for the torso, and in extension the head, compared to sitting posture and therefore induces a different user behaviour. The head moves further from its initial position in standing posture compared to sitting posture (see total head movement, Fig. 10), but the head-in-torso range is significantly larger in sitting position where the torso is not able to provide as much support (see CHOR, Fig. 12). This shows that users prefer to support head movement with torso rotation for head shifts even when these are well within head motion range.

\subsection{Comparing Directions}

The coordination of eye, head and torso is also influenced by direction of gaze shifts. We found no differences between the horizontal directions, but significant differences between the vertical directions. As a consequence, differences were also found between upwards versus downwards diagonal directions. In general, participants would use their eyes more and their head less for downwards shifts compared to upwards shifts, explained by the asymmetric structure of the head where the visual range upwards is more constrained in range.

In the standing posture, participants tended to have different coordination for vertical shifts compared to horizontal and diagonal shifts. These differences are mainly due to the torso not being involved in vertical shifts but in other directions. In the sitting posture, the different directions showed less of an effect, with exception of downwards shifts for which the eyes were used more in comparison with other directions.

\section{DESIGN IMPLICATIONS}

The insights we gained into eye, head and torso coordination lead to a range of implications for VR and interaction design. We reflect implications pertaining to eye, head and torso movement, in each case identifying factors to take into account in design, and suggesting how to reflect them. We also reflect on limitations of our study, and validity of findings.

\subsection{Eye Movement}

The eyes can be used for interaction in many VR design areas. However, certain factors should be taken into account when designing these interactions, namely: 
- The eyes contribute more than $90 \%$ of the gaze shift for targets at $25^{\circ}$ or less amplitude.

- The contribution of the eyes is not affected by the posture.

- The eyes move further downwards relative to the head compared to other directions.

- The eyes prefer to remain within a certain range relative to the head and will wait for the head to catch up in order to remain within that range.

- The eyes' range of motion relative to the head is dependent on the user.

The preferred eye-in-head range during gaze shifts and at the end of gaze shifts (COMR) can be used for the placement of non-diegetic UI elements. The preferred eye-in-head range indicates where to place UI elements in the FOV so that they are not in the area where the user spends most of their time looking. However, while it is possible to place UI elements further out than the average user will naturally look, it may cause long-term strain on the user as they then have to reach eye-in-head positions that they would normally not do. Additionally, placing elements too far out in the FOV may expose limitations of current VR technology at the edges of the screen such as chromatic aberration or reduced eye tracking accuracy.

A common theme in the results was that participants tended to use their eyes more downwards compared to other directions. Therefore, placing objects below the current object-of-interest should be more suitable if the aim is to reduce head movement. For example, when placing subtitles that are attached to the speaker, it may be more suitable to place them below the speaker to decrease the likelihood of unnecessary head movement when users are shifting between the subtitles and speaker. The placement naturally depends on the user's relative position to the speaker, but placing subtitles under the current object-of-interest should leave a larger eye comfort range.

The factors can also be used for the design of future eye tracking applications in VR. Eye tracking in VR offers multiple advantages over common screen-based eye tracking such as the blocking of external light, the eye tracker being closer to user's eyes, the eye tracker being less affected by user's head movement [21]. However, VR applications induce different user behaviour that often requires more body movement compared to interaction with regular desktops, and it is vital to understand the gaze behaviour in VR to transfer relevant design knowledge from desktop applications to VR applications. First implementations of gaze interaction techniques in VR have already been investigated $[52,53,56,69]$ but we expect that better understanding of eye, head and body coordination can inspire new techniques.

\subsection{Head Movement}

In $\mathrm{VR}$, the head position determines the view that is exposed to the user. In existing work, it tends to be assumed that this coincides with where the user looks. However, our results show that head orientation is problematic as an approximation of gaze. There are multiple factors regarding head movement that should be taken into consideration when designing VR experiences:

- Users rarely shift their head fully towards an object to which they have shifted their gaze.

- The amount of head movement towards the target is dependent on the user.

- A significant part of the head movement is performed after the gaze has reached the target, especially for targets reachable by the eyes only.

- The amount of head movement is dependent on the direction. Head movement is symmetrical horizontally, upwards diagonally and downwards diagonally, but not vertically. People use less head movement downwards compared to upwards for within-view amplitudes.

- Standing posture offers more freedom of movement compared to sitting posture and therefore more movement towards the target in horizontal and diagonal directions.

- Users perform head movement earlier, relative to the yes, if the gaze target is outside their current FOV. 
The knowledge of these factors can be used for many fundamental design considerations. For example, the factors can be used to better place upcoming objects of interest. If the approximate position of the FOV at the end of a gaze shift is known, then the next object of interest can be placed within that theoretical FOV to maximise the likelihood of the object being visible upon completion of the gaze shift. This information can also be used ergonomically, where objects can be placed in a manner that decreases unnecessary head movement and reduces strain on the user. For example, if the user is expected to shift back and forth multiple times between objects of interest then it would be advantageous to place the items within $20^{\circ}$ of each other where the eyes can do most of the work. On the other hand, if the user is expected to shift once between two objects of interest, then it may be advantageous to have the objects of interest further apart in order to increase the likelihood of head movement so that more of the upcoming objects of interest appear in the FOV.

The large variability among users in head movement tendency is important to reflect in VR design. Head pointing is widely used for interaction in contemporary VR applications [3] but may be unnatural and more straining for users who tend to avoid head movement when gaze targets are attainable by the eyes only. Comparative studies of head versus gaze pointing generally find head pointing preferred [53], but this fails to account for individual differences and growing evidence that a significant proportion of people can be regarded as "non-head movers". Another aspect to consider is that since the HMD is attached to the head, the amount of head rotation a user performs will, in turn, impact what they will see in the VE. As a consequence, different users may have completely different visual experiences.

It also important to consider the posture of the user when designing experiences in VR. Whether the user is standing or sitting affects the head movement of the user, which in turn will influence the user's FOV and overall visual experience. Additionally, VR experiences that require much turning may prove strenuous in seated posture, as they induce head movement over larger ranges than users would choose if their torso movement was not constrained.

\subsection{Torso Movement}

Torso movement is used to reach further than is possible by the eyes and head alone as well as to reach more comfortable eye-in-head and head-in-torso positions for the user. Forcing users to overextend their head in order to reach targets may be unsustainable ergonomically and may negatively affect the user experience. Therefore it is important to understand factors that affect torso movement:

- Torso movement is rarely used for amplitudes up to $50^{\circ}$

- Torso movement is highly dependent on posture and direction where torso movement is generally only performed for horizontal and diagonal shifts in standing posture.

- Participants perform torso movement even if it is not necessary to reach the target.

- A significant part of the torso movement is performed after the target has been reached by the gaze.

Knowledge of the torso movement behaviour can be used to roughly approximate the torso's current position based on the position of the head and gaze. In this user study we attached an IMU to the torso to record the current torso movements, however such devices are generally not available in commercial VR devices and it is common to assume that the rest of the body is aligned with the HMD. The findings from our user study could be applied to better estimate torso orientation relative to the virtual environment, as a possible context or input for interaction. 


\subsection{Limitations}

Any study design represents choices that may pose limitations on the validity of results. First to consider is the abstract nature of the tasks we chose, in which participants were instructed to shift their gaze to a unique target, in the absence of any distractors. Prior eye-head coordination research, in particular the extensive work of Land and colleagues [33,34], has shown that fundamental insights gained under such a paradigm generalise well to naturalistic use of gaze. This gives us confidence that the results we discussed hold in principle, but other types of tasks, for example visual search or free-viewing, might expose specific differences.

One of our key observations, of the head typically following the eyes only to within $80-90 \%$, is corroborated by recent works on visual exploration of $360^{\circ}$ images and provides an explanation for the head-to-eye fixation offset those work reported [55, 63]. In our study, there was always only one target to reach, after which to return to the display centre. Users might use their head and body more if they have further targets to reach in the same direction. We suspect that this might affect gaze shifts that are otherwise not supported by the head. It is also possible that the total head movement would increase but we consider this less likely given that other work also observed a general offset between head and eye fixations.

Although we used a 3D virtual environment, we chose to present all stimuli at a fixed depth to ensure that our results would not be confounded by accommodation effects. However, it will of course also be interesting to study depth as a factor in gaze shifts. We speculate that there is not much interaction between depth accommodation and eye-head-torso contribution, although it is possible that depth conflicts could induce more central alignment of the head with gaze targets.

With $\mathrm{N}=20$ participants, our study was significantly larger than most prior studies on eyehead coordination, however not of sufficient scale to attain conclusive results on head movement variability. We observed participants who displayed distinctly less head movement than the majority and this may indicate that there are users for whom head-based control may be less natural than generally assumed for interaction in VR and HMDs. The neuroscience literature lends credibility to a possible differentiation of users with more head movement versus users with wider eye movement ranges $[15,70,71]$. However, it may also be that some participants chose to use their head less than they otherwise would as the task required them to return their gaze to the display centre after they dwelled briefly on a target.

Our study was conducted in a head-mounted VR environment. However, the subset of our results for which we found comparable data in real world studies of eye-head coordination shows a strong correspondence. We therefore suggest that most results, such as on proposed gaze zones and preferred motion ranges, will be valid and relevant also beyond VR and HMD-based interaction, especially for settings that involve gaze over wider fields of view (e.g., display walls, multi-device environments, and wearable augmented reality). However, for some of the behaviours we observed, for instance stepped eye movement in large gaze shifts, it is not clear how much they may have depended on the nature of the VR environment with limited FOV.

The specific choice of apparatus also presents potential limitations. Eye, head and body tracking all can involve measurement error but we regard this as negligible in our study, given the use of high-end sensors and careful calibration. The display technology can also influence gaze behaviour. We suspect that the FOV might be a factor in how large gaze shifts are performed, but other potential factors include the weight added to the head, and optical features such as pincushion distortion with lower resolution toward the edges (e.g., Playstation VR HMD). The HMD we used had a FOV that is representative for contemporary devices, but at $100^{\circ}$ it implied that we can not know whether effects observed for gaze shifts larger $50^{\circ}$ from the centre were more due to increased amplitude, or to targets not being visible at the onset. 


\section{CONCLUSION}

The study we reported provides detailed insight into eye, head and torso coordination during gaze shifts. We learned that posture and direction in addition to amplitude has an effect on gaze shifts, identified gaze zones reflecting different levels of eye, head and torso contribution, and observed preferred motion ranges and how these vary for different user groups. There are a number of fundamental conclusions we draw from the work:

First of all, gaze is multimodal. That gaze involves not only eye but also head and body movement is not new knowledge as such. However, the HCI field has generally treated gaze as unimodal, most commonly associated with eye movement only. We argue that understanding gaze as multimodal is critical as we move to forms of interaction that expose wider fields of view, including display walls, room-scale interactions, head-mounted displays, virtual environments and mixed realities. We propose gaze zones to guide design of gaze interaction beyond single screens, with each zone relating to a range over which we interact, and movements on which we draw for visual attention

Secondly, eye, head and body movement are connected. All three movement systems, the eyes, head and body, have been considered separately (and extensively) as input, control or cue for human-computer interaction. Our work shows that they are in fact closely coupled as we shift our gaze and attention. This is fundamental for any visual forms of interaction. We argue that knowledge of the underlying interactions between eyes, head and body holds rich potential for design of novel interactions techniques.

Thirdly, eye and head do not compete but cooperate. Eye and head orientation have been compared and contrasted as computer input in a range of studies over the last 20 years [6, 7, 19, 32, 53]. We argue that this dichotomy is unhelpful as eye and head are naturally coupled. Existing ideas of combing eye and head for interaction reinforce their treatment as separate (e.g. with mapping to different steps in an interaction), whereas we suggest to leverage them as integral to take advantage of natural eye-head coordination behaviour.

Finally, there are significant individual differences in head movement associated with gaze. While the majority of users display head movement that complements eye movement during a gaze shift to different extents, the data also suggest there are users who prefer to use their heads only when gaze targets were not reachable by the eyes alone, and in contrast use a wider eye motion range. Evidence of individual head movement differences is highly significant for interaction in VR and HMDs, where head movement is central to navigation and visual experience of the environment.

\section{REFERENCES}

[1] Henny Admoni and Brian Scassellati. 2017. Social Eye Gaze in Human-robot Interaction: A Review. fournal of Human-Robot Interaction 6, 1 (May 2017), 25-63. https://doi.org/10.5898/JHRI.6.1.Admoni

[2] Sean Andrist, Tomislav Pejsa, Bilge Mutlu, and Michael Gleicher. 2012. A Head-eye Coordination Model for Animating Gaze Shifts of Virtual Characters. In Proceedings of the 4th Workshop on Eye Gaze in Intelligent Human Machine Interaction (Gaze-In '12). ACM, New York, NY, USA, Article 4, 6 pages. https://doi.org/10.1145/2401836.2401840

[3] Ferran Argelaguet and Carlos Andujar. 2013. A survey of 3D object selection techniques for virtual environments. Computers \& Graphics 37, 3 (may 2013), 121-136. https://doi.org/10.1016/j.cag.2012.12.003

[4] Till Ballendat, Nicolai Marquardt, and Saul Greenberg. 2010. Proxemic Interaction: Designing for a Proximity and Orientation-aware Environment. In ACM International Conference on Interactive Tabletops and Surfaces (ITS '10). ACM, New York, NY, USA, 121-130. https://doi.org/10.1145/1936652.1936676

[5] Albert E. Bartz. 1966. Eye and Head Movements in Peripheral Vision: Nature of Compensatory Eye Movements. Science 152, 3729 (1966), 1644-1645. https://doi.org/10.1126/science.152.3729.1644

[6] Richard Bates and Howell Istance. 2003. Why are Eye Mice Unpopular? A Detailed Comparison of Head and Eye Controlled Assistive Technology Pointing Devices. Universal Access in the Information Society 2, 3 (Oct. 2003), 280-290. https://doi.org/10.1007/s10209-003-0053-y

[7] Jonas Blattgerste, Patrick Renner, and Thies Pfeiffer. 2018. Advantages of Eye-gaze over Head-gaze-based Selection in Virtual and Augmented Reality Under Varying Field of Views. In Proceedings of the Workshop on Communication by 
Gaze Interaction (COGAIN '18). ACM, New York, NY, USA, Article 1, 9 pages. https://doi.org/10.1145/3206343.3206349

[8] Richard A. Bolt. 1981. Gaze-orchestrated Dynamic Windows. In Proceedings of the 8th Annual Conference on Computer Graphics and Interactive Techniques (SIGGRAPH '81). ACM, New York, NY, USA, 109-119. https://doi.org/10.1145/ 800224.806796

[9] Xiang Cao, Jacky Jie Li, and Ravin Balakrishnan. 2008. Peephole Pointing: Modeling Acquisition of Dynamically Revealed Targets. In Proceedings of the SIGCHI Conference on Human Factors in Computing Systems (CHI '08). ACM, New York, NY, USA, 1699-1708. https://doi.org/10.1145/1357054.1357320

[10] Anup Doshi and Mohan M. Trivedi. 2012. Head and eye gaze dynamics during visual attention shifts in complex environments. fournal of Vision 12, 2 (2012), 9. https://doi.org/10.1167/12.2.9 arXiv:/data/journals/jov/932802/jov-12-29.pdf

[11] Wolfgang Einhäuser, Frank Schumann, Stanislavs Bardins, Klaus Bartl, Guido Böning, Erich Schneider, and Peter König. 2007. Human eye-head co-ordination in natural exploration. Network: Computation in Neural Systems 18, 3 (jan 2007), 267-297. https://doi.org/10.1080/09548980701671094

[12] Virgilio F. Ferrario, Chiarella Sforza, Graziano Serrao, GianPiero Grassi, and Erio Mossi. 2002. Active range of motion of the head and cervical spine: a three-dimensional investigation in healthy young adults. fournal of Orthopaedic Research 20, 1 (jan 2002), 122-129. https://doi.org/10.1016/S0736-0266(01)00079-1

[13] Edward G. Freedman. 2008. Coordination of the eyes and head during visual orienting. Experimental Brain Research 190, 4 (oct 2008), 369-387. https://doi.org/10.1007/s00221-008-1504-8

[14] Edward G. Freedman and David L. Sparks. 2000. Coordination of the eyes and head: movement kinematics. Experimental Brain Research 131, 1 (mar 2000), 22-32. https://doi.org/10.1007/s002219900296

[15] James H. Fuller. 1992. Head movement propensity. Experimental Brain Research 92, 1 (dec 1992), 152-164. https: //doi.org/10.1007/BF00230391

[16] H. H. L. M. Goossens and A. John Van Opstal. 1997. Human eye-head coordination in two dimensions under different sensorimotor conditions. Experimental Brain Research 114, 3 (may 1997), 542-560. https://doi.org/10.1007/PL00005663

[17] Daniel Guitton and Michel Volle. 1987. Gaze control in humans: eye-head coordination during orienting movements to targets within and beyond the oculomotor range. Journal of neurophysiology 58, 3 (1987), 427-459.

[18] J. Gunderson and G. Vanderheiden. 1984. Direct optical head-pointing input to standard computers using a TV screen based keyboard. In Discovery '83: Computers for the Disabled. Stout Vocational Rehabilitation Institute, University of Wisconsin-Stout, Menomonie, WI, USA, 85-89.

[19] John Paulin Hansen, Vijay Rajanna, I. Scott MacKenzie, and Per Bækgaard. 2018. A Fitts' Law Study of Click and Dwell Interaction by Gaze, Head and Mouse with a Head-mounted Display. In Proceedings of the Workshop on Communication by Gaze Interaction (COGAIN '18). ACM, New York, NY, USA, Article 7, 5 pages. https://doi.org/10.1145/3206343.3206344

[20] Craig Hennessey, Borna Noureddin, and Peter Lawrence. 2006. A Single Camera Eye-gaze Tracking System with Free Head Motion. In Proceedings of the 2006 Symposium on Eye Tracking Research \& Applications (ETRA '06). ACM, New York, NY, USA, 87-94. https://doi.org/10.1145/1117309.1117349

[21] Kenneth Holmqvist, Marcus Nyström, Richard Andersson, Richard Dewhurst, Jarodzka Halszka, and Joost van de Weijer. 2011. Eye Tracking : A Comprehensive Guide to Methods and Measures. Oxford University Press. 560 pages.

[22] Brian Hu, Ishmael Johnson-bey, Mansi Sharma, and Ernst Niebur. 2017. Head movements during visual exploration of natural images in virtual reality. In 2017 51st Annual Conference on Information Sciences and Systems (CISS). IEEE, 1-6. https://doi.org/10.1109/CISS.2017.7926138

[23] Brian Hu, Ishmael Johnson-Bey, Mansi Sharma, and Ernst Niebur. 2018. Head movements are correlated with other measures of visual attention at smaller spatial scales. In Information Sciences and Systems (CISS), 2018 52nd Annual Conference on. IEEE, 1-6. https://doi.org/10.1109/CISS.2018.8362264

[24] Jeff Huang, Ryen White, and Georg Buscher. 2012. User See, User Point: Gaze and Cursor Alignment in Web Search. In Proceedings of the SIGCHI Conference on Human Factors in Computing Systems (CHI '12). ACM, New York, NY, USA, 1341-1350. https://doi.org/10.1145/2207676.2208591

[25] Thomas E. Hutchinson, K. Preston White, Worthy N. Martin, Kelly C. Reichert, and Lisa A. Frey. 1989. Human-Computer Interaction Using Eye-Gaze Input. IEEE Transactions on Systems, Man, and Cybernetics 19, 6 (Nov. 1989), 1527-1534. https://doi.org/10.1109/21.44068

[26] Laurent Itti, Nitin Dhavale, and Fréderic Pighin. 2006. Photorealistic attention-based gaze animation. In 2006 IEEE International Conference on Multimedia and Expo. IEEE, 521-524. https://doi.org/10.1109/ICME.2006.262440

[27] Robert J. K. Jacob. 1990. What You Look at is What You Get: Eye Movement-based Interaction Techniques. In Proceedings of the SIGCHI Conference on Human Factors in Computing Systems (CHI '90). ACM, New York, NY, USA, 11-18. https://doi.org/10.1145/97243.97246

[28] Robert J. K. Jacob and Sophie Stellmach. 2016. What you look at is what you get: gaze-based user interfaces. interactions 23,5 (2016), 62-65. 
[29] Shahram Jalaliniya, Diako Mardanbegi, and Thomas Pederson. 2015. MAGIC Pointing for Eyewear Computers. In Proceedings of the 2015 ACM International Symposium on Wearable Computers (ISWC '15). ACM, New York, NY, USA, 155-158. https://doi.org/10.1145/2802083.2802094

[30] Tobit Kollenberg, Alexander Neumann, Dorothe Schneider, Tessa-Karina Tews, Thomas Hermann, Helge Ritter, Angelika Dierker, and Hendrik Koesling. 2010. Visual search in the (un)real world: how head-mounted displays affect eye movements, head movements and target detection. In Proceedings of the 2010 Symposium on Eye-Tracking Research \& Applications (ETRA '10). ACM, New York, NY, USA, 121-124. https://doi.org/10.1145/1743666.1743696

[31] Andrew Kurauchi, Wenxin Feng, Carlos Morimoto, and Margrit Betke. 2015. HMAGIC: Head Movement and Gaze Input Cascaded Pointing. In Proceedings of the 8th ACM International Conference on PErvasive Technologies Related to Assistive Environments (PETRA '15). ACM, New York, NY, USA, Article 47, 4 pages. https://doi.org/10.1145/2769493.2769550

[32] Mikko Kytö, Barrett Ens, Thammathip Piumsomboon, Gun A. Lee, and Mark Billinghurst. 2018. Pinpointing: Precise Head- and Eye-Based Target Selection for Augmented Reality. In Proceedings of the 2018 CHI Conference on Human Factors in Computing Systems (CHI '18). ACM, New York, NY, USA, Article 81, 14 pages. https://doi.org/10.1145/ 3173574.3173655

[33] Michael Land and Benjamin Tatler. 2012. Looking and Acting: Vision and Eye Movements in Natural Behaviour. Oxford University Press, United Kingdom. https://doi.org/10.1093/acprof:oso/9780198570943.001.0001

[34] Michael F. Land. 2004. The coordination of rotations of the eyes, head and trunk in saccadic turns produced in natural situations. Experimental Brain Research 159, 2 (01 Nov 2004), 151-160. https://doi.org/10.1007/s00221-004-1951-9

[35] Christian Lander, Sven Gehring, Antonio Krüger, Sebastian Boring, and Andreas Bulling. 2015. GazeProjector: Accurate Gaze Estimation and Seamless Gaze Interaction Across Multiple Displays. In Proceedings of the 28th Annual ACM Symposium on User Interface Software \& Technology (UIST '15). ACM, New York, NY, USA, 395-404. https: //doi.org/10.1145/2807442.2807479

[36] Otto Lappi. 2016. Eye movements in the wild: Oculomotor control, gaze behavior \& frames of reference. Neuroscience \& Biobehavioral Reviews 69 (2016), 49-68. https://doi.org/10.1016/j.neubiorev.2016.06.006

[37] Diako Mardanbegi, Christopher Clarke, and Hans Gellersen. 2019. Monocular Gaze Depth Estimation Using the Vestibulo-ocular Reflex. In Proceedings of the 11th ACM Symposium on Eye Tracking Research \& Applications (ETRA '19). ACM, New York, NY, USA, Article 20, 9 pages. https://doi.org/10.1145/3314111.3319822

[38] Diako Mardanbegi, Dan Witzner Hansen, and Thomas Pederson. 2012. Eye-based Head Gestures. In Proceedings of the Symposium on Eye Tracking Research and Applications (ETRA '12). ACM, New York, NY, USA, 139-146. https: //doi.org/10.1145/2168556.2168578

[39] Diako Mardanbegi, Tobias Langlotz, and Hans Gellersen. 2019. Resolving Target Ambiguity in 3D Gaze Interaction Through VOR Depth Estimation. In Proceedings of the 2019 CHI Conference on Human Factors in Computing Systems (CHI '19). ACM, New York, NY, USA, Article 612, 12 pages. https://doi.org/10.1145/3290605.3300842

[40] Diako Mardanbegi, Ken Pfeuffer, Alexander Perzl, Benedikt Mayer, Shahram Jalaliniya, and Hans Gellersen. 2019 EyeSeeThrough: Unifying Tool Selection and Application in Virtual Environments. In 2019 IEEE Conference on Virtual Reality and 3D User Interfaces (VR). IEEE, 474-483. https://doi.org/10.1109/VR.2019.8797988

[41] Nicolai Marquardt, Robert Diaz-Marino, Sebastian Boring, and Saul Greenberg. 2011. The Proximity Toolkit: Prototyping Proxemic Interactions in Ubiquitous Computing Ecologies. In Proceedings of the 24th Annual ACM Symposium on User Interface Software \& Technology (UIST '11). ACM, New York, NY, USA, 315-326. https://doi.org/10.1145/2047196.2047238

[42] Mark R Mine. 1995. Virtual environment interaction techniques. UNC Chapel Hill CS Dept (1995).

[43] Carlos H. Morimoto and Marcio R. M. Mimica. 2005. Eye Gaze Tracking Techniques for Interactive Applications. Computer Vision and Image Understanding 98, 1 (April 2005), 4-24. https://doi.org/10.1016/j.cviu.2004.07.010

[44] Orval H. Mowrer. 1932. XXXII. Concerning the Normal Function of the Vestibular Apparatus. Annals of Otology, Rhinology \& Laryngology 41, 2 (1932), 412-421. https://doi.org/10.1177/000348943204100209

[45] Omar Mubin, Tatiana Lashina, and Evert van Loenen. 2009. How Not to Become a Buffoon in Front of a Shop Window: A Solution Allowing Natural Head Movement for Interaction with a Public Display. In Human-Computer Interaction INTERACT 2009. Springer Berlin Heidelberg, Berlin, Heidelberg, 250-263.

[46] Yasuto Nakanishi, Takashi Fujii, Kotaro Kiatjima, Yoichi Sato, and Hideki Koike. 2002. Vision-Based Face Tracking System for Large Displays. In UbiComp 2002: Ubiquitous Computing. Springer Berlin Heidelberg, Berlin, Heidelberg, 152-159.

[47] Brian S. Oommen, Ryan M. Smith, and John S. Stahl. 2004. The influence of future gaze orientation upon eyehead coupling during saccades. Experimental Brain Research 155, 1 (mar 2004), 9-18. https://doi.org/10.1007/ s00221-003-1694-z

[48] Tomislav Pejsa, Daniel Rakita, Bilge Mutlu, and Michael Gleicher. 2016. Authoring Directed Gaze for Full-body Motion Capture. ACM Trans. Graph. 35, 6, Article 161 (Nov. 2016), 11 pages. https://doi.org/10.1145/2980179.2982444

[49] Kevin Pfeil, Eugene M. Taranta, II, Arun Kulshreshth, Pamela Wisniewski, and Joseph J. LaViola, Jr. 2018. A Comparison of Eye-head Coordination Between Virtual and Physical Realities. In Proceedings of the 15th ACM Symposium on Applied 
Perception (SAP '18). ACM, New York, NY, USA, Article 18, 7 pages. https://doi.org/10.1145/3225153.3225157

[50] Ken Pfeuffer, Jason Alexander, Ming Ki Chong, and Hans Gellersen. 2014. Gaze-touch: Combining Gaze with Multitouch for Interaction on the Same Surface. In Proceedings of the 27th Annual ACM Symposium on User Interface Software and Technology (UIST '14). ACM, New York, NY, USA, 509-518. https://doi.org/10.1145/2642918.2647397

[51] Ken Pfeuffer, Jason Alexander, Ming Ki Chong, Yanxia Zhang, and Hans Gellersen. 2015. Gaze-Shifting: Direct-Indirect Input with Pen and Touch Modulated by Gaze. In Proceedings of the 28th Annual ACM Symposium on User Interface Software \& Technology (UIST '15). ACM, New York, NY, USA, 373-383. https://doi.org/10.1145/2807442.2807460

[52] Thammathip Piumsomboon, Gun Lee, Robert W. Lindeman, and Mark Billinghurst. 2017. Exploring Natural Eye-gazebased Interaction for Immersive Virtual Reality. In 2017 IEEE Symposium on 3D User Interfaces (3DUI). IEEE, 36-39. https://doi.org/10.1109/3DUI.2017.7893315

[53] Yuan Yuan Qian and Robert J. Teather. 2017. The Eyes Don't Have It: An Empirical Comparison of Head-based and Eye-based Selection in Virtual Reality. In Proceedings of the 5th Symposium on Spatial User Interaction (SUI '17). ACM, New York, NY, USA, 91-98. https://doi.org/10.1145/3131277.3132182

[54] Robert G. Radwin, Gregg C. Vanderheiden, and Mei-Li Lin. 1990. A Method for Evaluating Head-Controlled Computer Input Devices Using Fitts' Law. Human Factors 32, 4 (aug 1990), 423-438. https://doi.org/10.1177/001872089003200405

[55] Yashas Rai, Jesús Gutiérrez, and Patrick Le Callet. 2017. A Dataset of Head and Eye Movements for 360 Degree Images. In Proceedings of the 8th ACM on Multimedia Systems Conference (MMSys'17). ACM, New York, NY, USA, 205-210. https://doi.org/10.1145/3083187.3083218

[56] Vijay Rajanna and John Paulin Hansen. 2018. Gaze Typing in Virtual Reality: Impact of Keyboard Design, Selection Method, and Motion. In Proceedings of the 2018 ACM Symposium on Eye Tracking Research \& Applications (ETRA '18). ACM, New York, NY, USA, Article 15, 10 pages. https://doi.org/10.1145/3204493.3204541

[57] K. Ruhland, C. E. Peters, S. Andrist, J. B. Badler, N. I. Badler, M. Gleicher, B. Mutlu, and R. McDonnell. 2015. A Review of Eye Gaze in Virtual Agents, Social Robotics and HCI: Behaviour Generation, User Interaction and Perception Computer Graphics Forum 34, 6 (Sept. 2015), 299-326. https://doi.org/10.1111/cgf.12603

[58] Sohrab Saeb, Cornelius Weber, and Jochen Triesch. 2011. Learning the optimal control of coordinated eye and head movements. PLoS Computational Biology 7, 11 (nov 2011), e1002253. https://doi.org/10.1371/journal.pcbi.1002253

[59] Jeffrey S. Shell, Roel Vertegaal, Daniel Cheng, Alexander W. Skaburskis, Changuk Sohn, A. James Stewart, Omar Aoudeh, and Connor Dickie. 2004. ECSGlasses and EyePliances: Using Attention to Open Sociable Windows of Interaction. In Proceedings of the 2004 Symposium on Eye Tracking Research \& Applications (ETRA '04). ACM, New York, NY, USA, 93-100. https://doi.org/10.1145/968363.968384

[60] Gwanseob Shin and Sudeep Hegde. 2010. User-Preferred Position of Computer Displays: Effects of Display Size. Human Factors 52, 5 (2010), 574-585. https://doi.org/10.1177/0018720810380405

[61] Ludwig Sidenmark and Hans Gellersen. 2019. Eye\&Head: Synergetic Eye and Head Movement for Pointing and Selection. In Proceedings of the 32nd Annual ACM Symposium on User Interface Software and Technology (UIST '19). ACM, New York, NY, USA.

[62] Ludwig Sidenmark and Anders Lundström. 2019. Gaze Behaviour on Interacted Objects During Hand Interaction in Virtual Reality for Eye Tracking Calibration. In Proceedings of the 11th ACM Symposium on Eye Tracking Research \& Applications (ETRA '19). ACM, New York, NY, USA, Article 6, 9 pages. https://doi.org/10.1145/3314111.3319815

[63] Vincent Sitzmann, Ana Serrano, Amy Pavel, Maneesh Agrawala, Diego Gutierrez, Belen Masia, and Gordon Wetzstein. 2018. Saliency in VR: how do people explore virtual environments? IEEE Transactions on Visualization and Computer Graphics 24, 4 (apr 2018), 1633-1642. https://doi.org/10.1109/TVCG.2018.2793599

[64] Barton A. Smith, Janet Ho, Wendy Ark, and Shumin Zhai. 2000. Hand Eye Coordination Patterns in Target Selection. In Proceedings of the 2000 Symposium on Eye Tracking Research \& Applications (ETRA '00). ACM, New York, NY, USA, 117-122. https://doi.org/10.1145/355017.355041

[65] Oleg Špakov, Poika Isokoski, and Päivi Majaranta. 2014. Look and Lean: Accurate Head-assisted Eye Pointing. In Proceedings of the Symposium on Eye Tracking Research and Applications (ETRA '14). ACM, New York, NY, USA, 35-42. https://doi.org/10.1145/2578153.2578157

[66] Oleg Špakov and Päivi Majaranta. 2012. Enhanced Gaze Interaction Using Simple Head Gestures. In Proceedings of the 2012 ACM Conference on Ubiquitous Computing (UbiComp '12). ACM, New York, NY, USA, 705-710. https: //doi.org/10.1145/2370216.2370369

[67] John S. Stahl. 1999. Amplitude of human head movements associated with horizontal saccades. Experimental Brain Research 126, 1 (apr 1999), 41-54. https://doi.org/10.1007/s002210050715

[68] John S. Stahl. 2001. Eye-head coordination and the variation of eye-movement accuracy with orbital eccentricity. Experimental Brain Research 136, 2 (jan 2001), 200-210. https://doi.org/10.1007/s002210000593

[69] Vildan Tanriverdi and Robert J. K. Jacob. 2000. Interacting with Eye Movements in Virtual Environments. In Proceedings of the SIGCHI Conference on Human Factors in Computing Systems (CHI '00). ACM, New York, NY, USA, 265-272. https://doi.org/10.1145/332040.332443 
[70] Zachary C. Thumser, Brian S. Oommen, Igor S. Kofman, and John S. Stahl. 2008. Idiosyncratic variations in eye-head coupling observed in the laboratory also manifest during spontaneous behavior in a natural setting. Experimental Brain Research 191, 4 (01 Dec 2008), 419-434. https://doi.org/10.1007/s00221-008-1534-2

[71] Zachary C. Thumser and John S. Stahl. 2009. Eye-head coupling tendencies in stationary and moving subjects. Experimental Brain Research 195, 3 (may 2009), 393-401. https://doi.org/10.1007/s00221-009-1803-8

[72] Jayson Turner, Andreas Bulling, and Hans Gellersen. 2012. Extending the Visual Field of a Head-mounted Eye Tracker for Pervasive Eye-based Interaction. In Proceedings of the Symposium on Eye Tracking Research and Applications (ETRA '12). ACM, New York, NY, USA, 269-272. https://doi.org/10.1145/2168556.2168613

[73] D. Tweed, B. Glenn, and T. Vilis. 1995. Eye-head Coordination during Large Gaze Shifts. fournal of Neurophysiology 73, 2 (Feb. 1995), 766-779. https://doi.org/10.1152/jn.1995.73.2.766

[74] Eduardo Velloso, Markus Wirth, Christian Weichel, Augusto Esteves, and Hans Gellersen. 2016. AmbiGaze: Direct Control of Ambient Devices by Gaze. In Proceedings of the 2016 ACM Conference on Designing Interactive Systems (DIS '16). ACM, New York, NY, USA, 812-817. https://doi.org/10.1145/2901790.2901867

[75] Roel Vertegaal et al. 2003. Attentive user interfaces. Commun. ACM 46, 3 (2003), 30-33.

[76] Daniel Vogel and Ravin Balakrishnan. 2004. Interactive Public Ambient Displays: Transitioning from Implicit to Explicit, Public to Personal, Interaction with Multiple Users. In Proceedings of the 17th Annual ACM Symposium on User Interface Software and Technology (UIST '04). ACM, New York, NY, USA, 137-146. https://doi.org/10.1145/1029632.1029656

[77] Colin Ware and Harutune H. Mikaelian. 1986. An Evaluation of an Eye Tracker As a Device for Computer Input2. SIGCHI Bulletin 17, SI (May 1986), 183-188. https://doi.org/10.1145/30851.275627

[78] Robert C. Zeleznik, Andrew S. Forsberg, and Jürgen P. Schulze. 2005. Look-That-There: Exploiting Gaze in Virtual Reality Interactions. Technical Report. Brown University.

[79] Shumin Zhai, Carlos Morimoto, and Steven Ihde. 1999. Manual and Gaze Input Cascaded (MAGIC) Pointing. In Proceedings of the SIGCHI Conference on Human Factors in Computing Systems (CHI '99). ACM, New York, NY, USA, 246-253. https://doi.org/10.1145/302979.303053

[80] Zhiwei Zhu and Qiang Ji. 2007. Novel Eye Gaze Tracking Techniques Under Natural Head Movement. IEEE Transactions on Biomedical Engineering 54, 12 (Dec. 2007), 2246-2260. https://doi.org/10.1109/TBME.2007.895750 


\section{APPENDIX}

\section{A EYE CONTRIBUTION}

Eye Contribution Amplitude

\begin{tabular}{|c|c|c|c|c|c|c|}
\hline \multirow[t]{7}{*}{ All Amplitudes } & 3-way Interaction & \multicolumn{5}{|c|}{$\mathrm{F}(8.86,168.39)=1.20, p=.296$} \\
\hline & 2-way Interaction & \multicolumn{2}{|c|}{ Sitting } & \multicolumn{3}{|c|}{ Standing } \\
\hline & Amplitude, Direction & \multicolumn{2}{|c|}{$\mathrm{F}(7.86,149.43)=4.92, p<.001$} & \multicolumn{3}{|c|}{$\mathrm{F}(5.17,98.18)=5.64, p<.001$} \\
\hline & & Upwards & Up-Diagonal & Horizontal & Down-Diagonal & Downwards \\
\hline & $\begin{array}{l}\text { 2-way Interaction } \\
\text { Amplitude, Posture }\end{array}$ & $\begin{array}{c}\mathrm{F}(2.91,55.28)=0.53 \\
p=.661\end{array}$ & $\begin{array}{c}\mathrm{F}(3.83,72.68)=0.32 \\
p=.857\end{array}$ & $\begin{array}{c}\mathrm{F}(3.41,64.81)=1.71 \\
p=.168\end{array}$ & $\begin{array}{c}\mathrm{F}(3.02,57.43)=1.43 \\
p=.243\end{array}$ & $\begin{array}{c}\mathrm{F}(2.45,46.57)=1.01 \\
p=.387\end{array}$ \\
\hline & $\begin{array}{l}\text { Amplitude Main Effect, } \\
\text { Sitting Posture }\end{array}$ & $\begin{array}{c}\mathrm{F}(2.92,55.45)=215.90 \\
p<.001\end{array}$ & $\begin{array}{c}\mathrm{F}(2.77,52.60)=283.64 \\
p<.001\end{array}$ & $\begin{array}{c}\mathrm{F}(2.78,52.87)=527.47 \\
p<.001\end{array}$ & $\begin{array}{c}\mathrm{F}(3.00,56.97)=426.78 \\
p<.001\end{array}$ & $\begin{array}{c}\mathrm{F}(2.81,53.46)=289.84 \\
p<.001\end{array}$ \\
\hline & $\begin{array}{l}\text { Amplitude Main Effect, } \\
\text { Standing Posture }\end{array}$ & $\begin{array}{c}\mathrm{F}(2.15,40.77)=207.53 \\
p<.001\end{array}$ & $\begin{array}{c}\mathrm{F}(2.43,46.16)=267.35 \\
p<.001\end{array}$ & $\begin{array}{c}\mathrm{F}(2.20,41.70)=594.60 \\
p<.001\end{array}$ & $\begin{array}{c}\mathrm{F}(1.83,34.82)=492.58 \\
p<.001\end{array}$ & $\begin{array}{c}\mathrm{F}(2.43,46.10)=259.62 \\
p<.001\end{array}$ \\
\hline \multirow[t]{7}{*}{ Within-view } & 3-way Interaction & \multicolumn{5}{|c|}{$\mathrm{F}(6.85,130.05)=0.99, p=.456$} \\
\hline & 2-way Interaction & \multicolumn{2}{|c|}{ Sitting } & & \multicolumn{2}{|c|}{ Standing } \\
\hline & Amplitude, Direction & \multicolumn{2}{|c|}{$\mathrm{F}(5.88,111.77)=3.64, p=.003$} & & \multicolumn{2}{|c|}{$\mathrm{F}(3.82,72.54)=4.91, p=.002$} \\
\hline & & Upwards & Up-Diagonal & Horizontal & Down-Diagonal & Downwards \\
\hline & $\begin{array}{l}\text { 2-way Interaction } \\
\text { Amplitude, Posture }\end{array}$ & $\begin{array}{c}\mathrm{F}(2.07,39.35)=0.76 \\
p=.478\end{array}$ & $\begin{array}{c}\mathrm{F}(2.40,45.64)=0.14 \\
p=.905\end{array}$ & $\begin{array}{c}\mathrm{F}(2.39,45.38)=1.18 \\
p=.323\end{array}$ & $\begin{array}{c}\mathrm{F}(1.91,36.37)=1.33 \\
p=.277\end{array}$ & $\begin{array}{c}\mathrm{F}(1.45,27.58)=0.98 \\
p=.362\end{array}$ \\
\hline & $\begin{array}{l}\text { Amplitude Main Effect, } \\
\text { Sitting Posture }\end{array}$ & $\begin{array}{c}\mathrm{F}(2.42,46.02)=36.76 \\
p<.001\end{array}$ & $\begin{array}{c}\mathrm{F}(1.98,37.67)=24.27 \\
p<.001\end{array}$ & $\begin{array}{c}\mathrm{F}(1.77,33.64)=40.42 \\
p<.001\end{array}$ & $\begin{array}{c}\mathrm{F}(1.81,34.47)=25.00 \\
p<.001\end{array}$ & $\begin{array}{c}\mathrm{F}(1.30,24.64)=24.14 \\
p<.001\end{array}$ \\
\hline & $\begin{array}{l}\text { Amplitude Main Effect, } \\
\text { Standing Posture }\end{array}$ & $\begin{array}{c}\mathrm{F}(1.60,30.35)=41.84 \\
p<.001\end{array}$ & $\begin{array}{c}\mathrm{F}(1.59,30.29)=24.21 \\
p<.001\end{array}$ & $\begin{array}{c}\mathrm{F}(1.42,26.95)=33.96 \\
p<.001\end{array}$ & $\begin{array}{c}\mathrm{F}(1.33,25.33)=25.85 \\
p<.001\end{array}$ & $\begin{array}{c}\mathrm{F}(1.58,29.98)=11.77 \\
p<.001\end{array}$ \\
\hline \multirow[t]{6}{*}{ Beyond-view } & 3-way Interaction & \multicolumn{5}{|c|}{$\mathrm{F}(4.32,82.02)=1.45, p=.221$} \\
\hline & $\begin{array}{l}\text { 2-way Interaction } \\
\text { Amplitude, Direction }\end{array}$ & \multicolumn{2}{|c|}{$\begin{array}{c}\text { Sitting } \\
\mathrm{F}(3.78,60.43)=2.49, p=.055\end{array}$} & & \multicolumn{2}{|c|}{$\begin{array}{c}\text { Standing } \\
\mathrm{F}(4.32,82.02)=1.45, p=.221\end{array}$} \\
\hline & & Upwards & Up-Diagonal & Horizontal & Down-Diagonal & Downwards \\
\hline & $\begin{array}{l}\text { 2-way Interaction } \\
\text { Amplitude, Posture }\end{array}$ & $\begin{array}{c}\mathrm{F}(1.21,22.93)=0.11 \\
p=.791\end{array}$ & $\begin{array}{c}\mathrm{F}(1.52,28.88)=0.59 \\
p=.517\end{array}$ & $\begin{array}{c}\mathrm{F}(1.42,26.91)=0.14 \\
p=.796\end{array}$ & $\begin{array}{c}\mathrm{F}(2,38)=2.78 \\
p=.075\end{array}$ & $\begin{array}{c}\mathrm{F}(2,38)=1.66 \\
p=.203\end{array}$ \\
\hline & $\begin{array}{l}\text { Amplitude Main Effect, } \\
\text { Sitting Posture }\end{array}$ & $\begin{array}{c}\mathrm{F}(1.22,23.10)=44.22 \\
p<.001\end{array}$ & $\begin{array}{c}\mathrm{F}(1.25,28.66)=28.66 \\
p<.001\end{array}$ & $\begin{array}{c}\mathrm{F}(2,38)=65.45 \\
p<.001\end{array}$ & $\begin{array}{c}\mathrm{F}(1.34,25.42)=47.74 \\
p<.001\end{array}$ & $\begin{array}{c}\mathrm{F}(2,38)=38.21 \\
p<.001\end{array}$ \\
\hline & $\begin{array}{l}\text { Amplitude Main Effect, } \\
\text { Standing Posture }\end{array}$ & $\begin{array}{c}\mathrm{F}(1.34,25.51)=57.43 \\
p<.001\end{array}$ & $\begin{array}{c}\mathrm{F}(1.40,26.59)=34.23 \\
p<.001\end{array}$ & $\begin{array}{c}\mathrm{F}(2,38)=133.01 \\
p<.001\end{array}$ & $\begin{array}{c}\mathrm{F}(2,38)=158.15 \\
p<.001\end{array}$ & $\begin{array}{c}\mathrm{F}(2,38)=41.04 \\
p<.001\end{array}$ \\
\hline
\end{tabular}

Table 1. Repeated measures ANOVA statistical analysis on the effect of amplitude on head contribution. 
Eye Contribution Posture and Direction

\begin{tabular}{|c|c|c|c|c|c|c|}
\hline \multirow[t]{3}{*}{$5^{\circ}$} & $\begin{array}{l}\text { 2-way Interaction } \\
\text { Posture, Direction }\end{array}$ & \multicolumn{5}{|c|}{$\mathrm{F}(4,76)=0.89, p=.472$} \\
\hline & \multirow{2}{*}{$\begin{array}{l}\text { Direction Main Effect } \\
\text { Posture Main Effect }\end{array}$} & \multicolumn{2}{|c|}{$\begin{array}{c}\text { Sitting } \\
\mathrm{F}(4,68)=1.67, p=.160\end{array}$} & \multirow[b]{2}{*}{$\begin{array}{c}\text { Horizontal } \\
\mathrm{F}(1,19)=4.11 \\
p=.057\end{array}$} & \multicolumn{2}{|c|}{$\begin{array}{c}\text { Standing } \\
\mathrm{F}(4,76)=1.34, p=.265\end{array}$} \\
\hline & & $\begin{array}{c}\text { Upwards } \\
\mathrm{F}(1,19)=2.35 \\
p=.142 \\
\end{array}$ & $\begin{array}{c}\text { Up-Diagonal } \\
\mathrm{F}(1,19)=0.47 \\
p=.499 \\
\end{array}$ & & $\begin{array}{c}\text { Down-Diagonal } \\
\mathrm{F}(1,19)=3.82 \\
p=.067\end{array}$ & $\begin{array}{c}\text { Downwards } \\
\mathrm{F}(1,19)=3.89 \\
p=.084 \\
\end{array}$ \\
\hline \multirow[t]{3}{*}{$15^{\circ}$} & $\begin{array}{l}\text { 2-way Interaction } \\
\text { Posture, Direction }\end{array}$ & \multicolumn{5}{|c|}{$\mathrm{F}(2.23,42.29)=0.67, p=.532$} \\
\hline & Direction Main Effect & \multicolumn{2}{|c|}{$\begin{array}{c}\text { Sitting } \\
\mathrm{F}(1.96,37.28)=1.26, p=.293\end{array}$} & & \multicolumn{2}{|c|}{$\begin{array}{c}\text { Standing } \\
\mathrm{F}(4,76)=2.46, p=.053\end{array}$} \\
\hline & Posture Main Effect & $\begin{array}{c}\text { Upwards } \\
\mathrm{F}(1,19)=0.01 \\
p=.916\end{array}$ & $\begin{array}{c}\text { Up-Diagonal } \\
\mathrm{F}(1,19)=2.04 \\
p=.169\end{array}$ & $\begin{array}{c}\text { Horizontal } \\
\mathrm{F}(1,19)=3.63 \\
p=.075\end{array}$ & $\begin{array}{c}\text { Down-Diagonal } \\
\mathrm{F}(1,19)=0.19 \\
p=.893\end{array}$ & $\begin{array}{c}\text { Downwards } \\
\mathrm{F}(1,19)=4.02 \\
p=.060\end{array}$ \\
\hline \multirow[t]{3}{*}{$25^{\circ}$} & $\begin{array}{l}\text { 2-way Interaction } \\
\text { Posture, Direction }\end{array}$ & \multicolumn{5}{|c|}{$\mathrm{F}(4,76)=0.86, p=.491$} \\
\hline & Direction Main Effect & \multicolumn{2}{|c|}{$\begin{array}{c}\text { Sitting } \\
\mathrm{F}(2.08,39.55)=3.95, p=.026\end{array}$} & & \multicolumn{2}{|c|}{$\begin{array}{c}\text { Standing } \\
\mathrm{F}(1.99,34.44)=4.70, p=.018\end{array}$} \\
\hline & Posture Main Effect & $\begin{array}{c}\text { Upwards } \\
\mathrm{F}(1,19)=0.281 \\
p=.602\end{array}$ & $\begin{array}{c}\text { Up-Diagonal } \\
\mathrm{F}(1,19)=1.37 \\
p=.257\end{array}$ & $\begin{array}{c}\text { Horizontal } \\
\mathrm{F}(1,19)=1.90 \\
p=.184\end{array}$ & $\begin{array}{c}\text { Down-Diagonal } \\
\mathrm{F}(1,19)=4.26 \\
p=.055 \\
\end{array}$ & $\begin{array}{c}\text { Downwards } \\
\mathrm{F}(1,19)=0.02 \\
p=.889\end{array}$ \\
\hline \multirow[t]{3}{*}{$35^{\circ}$} & $\begin{array}{l}\text { 2-way Interaction } \\
\text { Posture, Direction }\end{array}$ & \multicolumn{5}{|c|}{$\mathrm{F}(2.91,55.36)=0.98, p=.407$} \\
\hline & Direction Main Effect & \multicolumn{2}{|c|}{$\begin{array}{c}\text { Sitting } \\
\mathrm{F}(4,76)=7.10, p<.001\end{array}$} & & \multicolumn{2}{|c|}{$\begin{array}{c}\text { Standing } \\
\mathrm{F}(1.97,37.42)=5.70, p=.007\end{array}$} \\
\hline & Posture Main Effect & $\begin{array}{c}\text { Upwards } \\
\mathrm{F}(1,19)=0.233 \\
p=.635\end{array}$ & $\begin{array}{c}\text { Up-Diagonal } \\
\mathrm{F}(1,19)=0.10 \\
p=.752 \\
\end{array}$ & $\begin{array}{c}\text { Horizontal } \\
\mathrm{F}(1,19)=0.45 \\
p=.512\end{array}$ & $\begin{array}{c}\text { Down-Diagonal } \\
\mathrm{F}(1,19)=0.87 \\
p=.362\end{array}$ & $\begin{array}{c}\text { Downwards } \\
\mathrm{F}(1,19)=3.99 \\
p=.060 \\
\end{array}$ \\
\hline \multirow[t]{3}{*}{$45^{\circ}$} & $\begin{array}{l}\text { 2-way Interaction } \\
\text { Posture, Direction }\end{array}$ & \multicolumn{5}{|c|}{$\mathrm{F}(4,76)=0.96, p=.432$} \\
\hline & Direction Main Effect & \multicolumn{2}{|c|}{$\begin{array}{c}\text { Sitting } \\
\mathrm{F}(2.82,53.67)=6.11, p=.001\end{array}$} & & \multicolumn{2}{|c|}{$\begin{array}{c}\text { Standing } \\
\mathrm{F}(2.08,39.49)=7.18, p=.002\end{array}$} \\
\hline & Posture Main Effect & $\begin{array}{c}\text { Upwards } \\
\mathrm{F}(1,19)=1.54 \\
p=.230\end{array}$ & $\begin{array}{c}\text { Up-Diagonal } \\
\mathrm{F}(1,19)=0.95 \\
p=.343\end{array}$ & $\begin{array}{c}\text { Horizontal } \\
\mathrm{F}(1,19)=0.17 \\
p=.687\end{array}$ & $\begin{array}{c}\text { Down-Diagonal } \\
\mathrm{F}(1,19)=0.48 \\
p=.495\end{array}$ & $\begin{array}{c}\text { Downwards } \\
\mathrm{F}(1,19)=0.06 \\
p=.810\end{array}$ \\
\hline \multirow[t]{3}{*}{$60^{\circ}$} & $\begin{array}{l}\text { 2-way Interaction } \\
\text { Posture, Direction }\end{array}$ & \multicolumn{5}{|c|}{$\mathrm{F}(2.40,45.61)=1.02, p=.381$} \\
\hline & Direction Main Effect & \multicolumn{2}{|c|}{$\begin{array}{c}\text { Sitting } \\
\mathrm{F}(2.58,48.92)=4.01, p=.016\end{array}$} & & \multicolumn{2}{|c|}{$\begin{array}{c}\text { Standing } \\
\mathrm{F}(2.46,46.73)=3.05, p=.047\end{array}$} \\
\hline & Posture Main Effect & $\begin{array}{c}\text { Upwards } \\
\mathrm{F}(1,19)=0.37 \\
p=.549\end{array}$ & $\begin{array}{c}\text { Up-Diagonal } \\
\mathrm{F}(1,19)=1.12 \\
p=.303\end{array}$ & $\begin{array}{c}\text { Horizontal } \\
\mathrm{F}(1,19)=3.54 \\
p=.076\end{array}$ & $\begin{array}{c}\text { Down-Diagonal } \\
\mathrm{F}(1,19)=0.85 \\
p=.369\end{array}$ & $\begin{array}{c}\text { Downwards } \\
\mathrm{F}(1,19)=1.76 \\
p=.201\end{array}$ \\
\hline \multirow[t]{3}{*}{$80^{\circ}$} & $\begin{array}{l}\text { 2-way Interaction } \\
\text { Posture, Direction }\end{array}$ & \multicolumn{5}{|c|}{$\mathrm{F}(2.41,45.83)=1.56, p=.218$} \\
\hline & Direction Main Effect & \multicolumn{2}{|c|}{$\begin{array}{c}\text { Sitting } \\
\mathrm{F}(2.95,56.02)=8.01, p<.001\end{array}$} & & \multicolumn{2}{|c|}{$\begin{array}{c}\text { Standing } \\
\mathrm{F}(2.72,51.75)=7.14, p<.001\end{array}$} \\
\hline & Posture Main Effect & $\begin{array}{c}\text { Upwards } \\
\mathrm{F}(1,19)=3.60 \\
p=.073\end{array}$ & $\begin{array}{c}\text { Up-Diagonal } \\
\mathrm{F}(1,19)=2.85 \\
p=.108\end{array}$ & $\begin{array}{c}\text { Horizontal } \\
\mathrm{F}(1,19)=2.08 \\
p=.166\end{array}$ & $\begin{array}{c}\text { Down-Diagonal } \\
\mathrm{F}(1,19)=0.75 \\
p=.398\end{array}$ & $\begin{array}{c}\text { Downwards } \\
\mathrm{F}(1,19)=3.01 \\
p=.094\end{array}$ \\
\hline \multirow[t]{3}{*}{$100^{\circ}$} & $\begin{array}{l}\text { 2-way Interaction } \\
\text { Posture, Direction }\end{array}$ & \multicolumn{5}{|c|}{$\mathrm{F}(2.28,43.36)=2.91, p=.052$} \\
\hline & Direction Main Effect & \multicolumn{2}{|c|}{$\begin{array}{c}\text { Sitting } \\
\mathrm{F}(2.44,43.88)=6.61, p=.003\end{array}$} & & \multicolumn{2}{|c|}{$\begin{array}{c}\text { Standing } \\
\mathrm{F}(4,76)=14.24, p<.001 \\
\end{array}$} \\
\hline & Posture Main Effect & $\begin{array}{c}\text { Upwards } \\
\mathrm{F}(1,19)=0.74 \\
p=.399\end{array}$ & $\begin{array}{c}\text { Up-Diagonal } \\
\mathrm{F}(1,19)=4.41 \\
p=.062\end{array}$ & $\begin{array}{c}\text { Horizontal } \\
\mathrm{F}(1,19)=3.52 \\
p=.082\end{array}$ & $\begin{array}{c}\text { Down-Diagonal } \\
\mathrm{F}(1,19)=2.06 \\
p=.167\end{array}$ & $\begin{array}{c}\text { Downwards } \\
\mathrm{F}(1,19)=0.56 \\
p=.465 \\
\end{array}$ \\
\hline
\end{tabular}

Table 2. Repeated measures ANOVA statistical analysis on the effect of posture and direction on eye contribution. 


\section{B HEAD CONTRIBUTION}

Head Contribution Amplitude

\begin{tabular}{|c|c|c|c|c|c|c|}
\hline \multirow[t]{7}{*}{ All Amplitudes } & \multirow{4}{*}{$\begin{array}{l}\text { 3-way Interaction } \\
\text { 2-way Interaction } \\
\text { Amplitude, Direction }\end{array}$} & \multicolumn{5}{|c|}{$\mathrm{F}(9.329,177.259)=6.592, p<.001$} \\
\hline & & \multicolumn{2}{|c|}{ Sitting } & \multicolumn{3}{|c|}{ Standing } \\
\hline & & \multicolumn{2}{|c|}{$\mathrm{F}(7.55,143.53)=4.21, p<.001$} & \multicolumn{3}{|c|}{$\mathrm{F}(6.18,117.50)=7.77, p<.001$} \\
\hline & & Upwards & Up-Diagonal & Horizontal & Down-Diagonal & Downwards \\
\hline & $\begin{array}{l}\text { 2-way Interaction } \\
\text { Amplitude, Posture }\end{array}$ & $\begin{array}{c}\mathrm{F}(3.55,67.42)=.434 \\
p=.762\end{array}$ & $\begin{array}{c}\mathrm{F}(2.63,49.88)=7.80 \\
p<.001\end{array}$ & $\begin{array}{c}\mathrm{F}(3.62,68.84)=22.79 \\
p<.001\end{array}$ & $\begin{array}{c}\mathrm{F}(2.84,53.94)=25.44 \\
p<.001\end{array}$ & $\begin{array}{c}\mathrm{F}(2.33,44.35)=.94 \\
p=.413\end{array}$ \\
\hline & $\begin{array}{l}\text { Amplitude Main Effect, } \\
\text { Sitting Posture }\end{array}$ & $\begin{array}{c}\mathrm{F}(3.03,57.49)=200.75 \\
p<.001\end{array}$ & $\begin{array}{c}\mathrm{F}(2.44,46.39)=301.23 \\
p<.001\end{array}$ & $\begin{array}{c}\mathrm{F}(2.52,47.88)=508.84 \\
p<.001\end{array}$ & $\begin{array}{c}\mathrm{F}(2.81,53.36)=441.60 \\
p<.001\end{array}$ & $\begin{array}{c}\mathrm{F}(2.52,47.92)=288.64 \\
p<.001\end{array}$ \\
\hline & $\begin{array}{l}\text { Amplitude Main Effect, } \\
\text { Standing Posture }\end{array}$ & $\begin{array}{c}\mathrm{F}(2.53,48.01)=227.77 \\
p<.001\end{array}$ & $\begin{array}{c}\mathrm{F}(2.44,46.26)=165.12 \\
p<.001\end{array}$ & $\begin{array}{c}\mathrm{F}(3.12,59.28)=306.83 \\
p<.001\end{array}$ & $\begin{array}{c}\mathrm{F}(2.18,41.32)=267.12 \\
p<.001\end{array}$ & $\begin{array}{c}\mathrm{F}(2.61,49.54)=268.02 \\
p<.001\end{array}$ \\
\hline \multirow[t]{7}{*}{ Within-view } & 3-way Interaction & \multicolumn{5}{|c|}{$\mathrm{F}(7.01,133.23)=1.07, \mathrm{p}=.389$} \\
\hline & 2-way Interaction & \multicolumn{2}{|c|}{ Sitting } & & \multicolumn{2}{|c|}{ Standing } \\
\hline & Amplitude, Direction & \multicolumn{2}{|c|}{$\mathrm{F}(5.91,112.34)=3.08, p=.008$} & & \multicolumn{2}{|c|}{$\mathrm{F}(4.38,83.26)=4.53, p=.002$} \\
\hline & & Upwards & Up-Diagonal & Horizontal & Down-Diagonal & Downwards \\
\hline & $\begin{array}{l}\text { 2-way Interaction } \\
\text { Amplitude, Posture }\end{array}$ & $\begin{array}{c}\mathrm{F}(2.50,47.46)=0.30 \\
p=.791\end{array}$ & $\begin{array}{c}\mathrm{F}(2.41,45.81)=0.31 \\
p=.772\end{array}$ & $\begin{array}{c}\mathrm{F}(2.56,48.61)=1.51 \\
p=.227\end{array}$ & $\begin{array}{c}\mathrm{F}(1.81,24.42)=0.86 \\
p=.422\end{array}$ & $\begin{array}{c}\mathrm{F}(1.48,28.07)=1.00 \\
p=.358\end{array}$ \\
\hline & $\begin{array}{l}\text { Amplitude Main Effect, } \\
\text { Sitting Posture }\end{array}$ & $\begin{array}{c}\mathrm{F}(2.43,46.25)=34.73 \\
p<.001\end{array}$ & $\begin{array}{c}\mathrm{F}(1.88,35.77)=29.45 \\
p<.001\end{array}$ & $\begin{array}{c}\mathrm{F}(1.74,33.14)=45.73 \\
p<.001\end{array}$ & $\begin{array}{c}\mathrm{F}(1.76,27.04)=27.04 \\
p<.001\end{array}$ & $\begin{array}{c}\mathrm{F}(1.35,25.72)=28.04 \\
p<.001\end{array}$ \\
\hline & $\begin{array}{l}\text { Amplitude Main Effect, } \\
\text { Standing Posture }\end{array}$ & $\begin{array}{c}\mathrm{F}(1.75,33.16)=46.47 \\
p<.001\end{array}$ & $\begin{array}{c}\mathrm{F}(1.80,34.23)=31.98 \\
p<.001\end{array}$ & $\begin{array}{c}\mathrm{F}(1.69,32.18)=42.02 \\
p<.001\end{array}$ & $\begin{array}{c}\mathrm{F}(1.33,25.32)=28.51 \\
p<.001\end{array}$ & $\begin{array}{c}\mathrm{F}(1.69,32.14)=13.11 \\
p<.001\end{array}$ \\
\hline \multirow[t]{7}{*}{ Beyond-view } & 3-way Interaction & \multicolumn{5}{|c|}{$\mathrm{F}(4.69,89.09)=2.34, p=.052$} \\
\hline & 2-way Interaction & \multicolumn{2}{|c|}{ Sitting } & & \multicolumn{2}{|c|}{ Standing } \\
\hline & Amplitude, Direction & \multicolumn{2}{|c|}{$\mathrm{F}(4.23,80.45)=2.67, \mathrm{p}=.035$} & & \multicolumn{2}{|c|}{$\mathrm{F}(4.11,78.12)=10.75, \mathrm{p}<.001$} \\
\hline & & Upwards & Up-Diagonal & Horizontal & Down-Diagonal & Downwards \\
\hline & $\begin{array}{l}\text { 2-way Interaction } \\
\text { Amplitude, Posture }\end{array}$ & $\begin{array}{c}\mathrm{F}(1.48,28.04)=0.99 \\
p=.361\end{array}$ & $\begin{array}{c}\mathrm{F}(1.40,26.58)=14.98 \\
p<.001\end{array}$ & $\begin{array}{c}\mathrm{F}(2,38)=19.69 \\
p<.001\end{array}$ & $\begin{array}{c}\mathrm{F}(1.49,28.24)=8.70 \\
p=.003\end{array}$ & $\begin{array}{c}\mathrm{F}(2,38)=1.27 \\
p=.293\end{array}$ \\
\hline & $\begin{array}{l}\text { Amplitude Main Effect, } \\
\text { Sitting Posture }\end{array}$ & $\begin{array}{c}\mathrm{F}(2,38)=31.15 \\
p<.001\end{array}$ & $\begin{array}{c}\mathrm{F}(1.31,24.90)=29.15 \\
p<.001\end{array}$ & $\begin{array}{c}\mathrm{F}(2,38)=59.17 \\
p<.001\end{array}$ & $\begin{array}{c}\mathrm{F}(1.23,23.41)=22.82 \\
p<.001\end{array}$ & $\begin{array}{c}\mathrm{F}(1.25,23.82)=37.03 \\
p<.001\end{array}$ \\
\hline & $\begin{array}{l}\text { Amplitude Main Effect, } \\
\text { Standing Posture }\end{array}$ & $\begin{array}{c}\mathrm{F}(1.50,28.44)=36.65 \\
p<.001\end{array}$ & $\begin{array}{c}\mathrm{F}(1.43,27.14)=4.12 \\
p=.028\end{array}$ & $\begin{array}{c}\mathrm{F}(2,38)=14.56 \\
p<.001\end{array}$ & $\begin{array}{c}\mathrm{F}(2,38)=7.89 \\
p<.001\end{array}$ & $\begin{array}{c}\mathrm{F}(2,38)=30.41 \\
p<.001\end{array}$ \\
\hline
\end{tabular}

Table 3. Repeated measures ANOVA statistical analysis on the effect of amplitude on head contribution. 
Head Contribution Posture and Direction

\begin{tabular}{|c|c|c|c|c|c|c|}
\hline \multirow[t]{3}{*}{$5^{\circ}$} & \multirow{3}{*}{$\begin{array}{l}\text { 2-way Interaction } \\
\text { Posture, Direction } \\
\text { Direction Main Effect } \\
\text { Posture Main Effect }\end{array}$} & \multicolumn{5}{|c|}{$\mathrm{F}(4,76)=0.94, p=.445$} \\
\hline & & \multicolumn{2}{|c|}{$\begin{array}{c}\text { Sitting } \\
\mathrm{F}(2.57,48.83)=2.91, p=.051\end{array}$} & \multicolumn{3}{|c|}{$\begin{array}{c}\text { Standing } \\
\mathrm{F}(4,76)=0.24, p=.916\end{array}$} \\
\hline & & $\begin{array}{c}\text { Upwards } \\
\mathrm{F}(1,19)=0.01 \\
p=.952 \\
\end{array}$ & $\begin{array}{c}\text { Up-Diagonal } \\
\mathrm{F}(1,19)=0.03 \\
p=.859\end{array}$ & $\begin{array}{c}\text { Horizontal } \\
\mathrm{F}(1,19)=0.52 \\
p=.480\end{array}$ & $\begin{array}{c}\text { Down-Diagonal } \\
\mathrm{F}(1,19)=1.66 \\
p=.213 \\
\end{array}$ & $\begin{array}{c}\text { Downwards } \\
\mathrm{F}(1,19)=3.51 \\
p=.079 \\
\end{array}$ \\
\hline \multirow[t]{3}{*}{$15^{\circ}$} & $\begin{array}{l}\text { 2-way Interaction } \\
\text { Posture, Direction }\end{array}$ & \multicolumn{5}{|c|}{$\mathrm{F}(1.97,37.40)=1.11, p=.339$} \\
\hline & Direction Main Effect & \multicolumn{2}{|c|}{$\begin{array}{c}\text { Sitting } \\
\mathrm{F}(1.98,37.60)=1.77, p=.185\end{array}$} & & \multicolumn{2}{|c|}{$\begin{array}{c}\text { Standing } \\
\mathrm{F}(2.44,46.29)=2.03, p=.133\end{array}$} \\
\hline & Posture Main Effect & $\begin{array}{c}\text { Upwards } \\
\mathrm{F}(1,19)=0.54 \\
p=.473\end{array}$ & $\begin{array}{c}\text { Up-Diagonal } \\
\mathrm{F}(1,19)=0.55 \\
p=.468\end{array}$ & $\begin{array}{c}\text { Horizontal } \\
\mathrm{F}(1,19)=4.21 \\
p=.055 \\
\end{array}$ & $\begin{array}{c}\text { Down-Diagonal } \\
\mathrm{F}(1,19)=0.38 \\
p=.544\end{array}$ & $\begin{array}{c}\text { Downwards } \\
\mathrm{F}(1,19)=3.27 \\
p=.089\end{array}$ \\
\hline \multirow[t]{3}{*}{$25^{\circ}$} & $\begin{array}{l}\text { 2-way Interaction } \\
\text { Posture, Direction }\end{array}$ & \multicolumn{5}{|c|}{$\mathrm{F}(2.82,53.49)=0.71, p=.540$} \\
\hline & Direction Main Effect & \multicolumn{2}{|c|}{$\begin{array}{c}\text { Sitting } \\
\mathrm{F}(2.04,38.83)=3.86, p=.029\end{array}$} & & \multicolumn{2}{|c|}{$\begin{array}{c}\text { Standing } \\
\mathrm{F}(1.82,34.50)=4.43, p=.022\end{array}$} \\
\hline & Posture Main Effect & $\begin{array}{c}\text { Upwards } \\
\mathrm{F}(1,19)=0.07 \\
p=.795\end{array}$ & $\begin{array}{c}\text { Up-Diagonal } \\
\mathrm{F}(1,19)=1.24 \\
p=.280\end{array}$ & $\begin{array}{c}\text { Horizontal } \\
\mathrm{F}(1,19)=1.95 \\
p=.179\end{array}$ & $\begin{array}{c}\text { Down-Diagonal } \\
\mathrm{F}(1,19)=3.74 \\
p=.071\end{array}$ & $\begin{array}{c}\text { Downwards } \\
\mathrm{F}(1,19)=0.01 \\
p=.948 \\
\end{array}$ \\
\hline \multirow[t]{3}{*}{$35^{\circ}$} & $\begin{array}{l}\text { 2-way Interaction } \\
\text { Posture, Direction }\end{array}$ & \multicolumn{5}{|c|}{$\mathrm{F}(4,76)=1.32, p=.271$} \\
\hline & Direction Main Effect & \multicolumn{2}{|c|}{$\begin{array}{c}\text { Sitting } \\
\mathrm{F}(4,76)=7.22, p<.001\end{array}$} & & \multicolumn{2}{|c|}{$\begin{array}{c}\text { Standing } \\
\mathrm{F}(1.98,37.63)=6.27, p<.001\end{array}$} \\
\hline & Posture Main Effect & $\begin{array}{c}\text { Upwards } \\
\mathrm{F}(1,19)=0.24 \\
p=.629 \\
\end{array}$ & $\begin{array}{c}\text { Up-Diagonal } \\
\mathrm{F}(1,19)=0.05 \\
p=.828 \\
\end{array}$ & $\begin{array}{c}\text { Horizontal } \\
\mathrm{F}(1,19)=0.88 \\
p=.361 \\
\end{array}$ & $\begin{array}{c}\text { Down-Diagonal } \\
\mathrm{F}(1,19)=1.56 \\
p=.227\end{array}$ & $\begin{array}{c}\text { Downwards } \\
\mathrm{F}(1,19)=3.62 \\
p=.072 \\
\end{array}$ \\
\hline \multirow[t]{3}{*}{$45^{\circ}$} & $\begin{array}{l}\text { 2-way Interaction } \\
\text { Posture, Direction }\end{array}$ & \multicolumn{5}{|c|}{$\mathrm{F}(4,76)=0.69, p=.604$} \\
\hline & Direction Main Effect & \multicolumn{2}{|c|}{$\begin{array}{c}\text { Sitting } \\
\mathrm{F}(2.77,52.68)=5.57, p=.003\end{array}$} & & \multicolumn{2}{|c|}{$\begin{array}{c}\text { Standing } \\
\mathrm{F}(2.28,43.30)=7.33, p=.001\end{array}$} \\
\hline & Posture Main Effect & $\begin{array}{c}\text { Upwards } \\
\mathrm{F}(1,19)=0.63 \\
p=.439\end{array}$ & $\begin{array}{c}\text { Up-Diagonal } \\
\mathrm{F}(1,19)=0.28 \\
p=.603\end{array}$ & $\begin{array}{c}\text { Horizontal } \\
\mathrm{F}(1,19)=1.60 \\
p=.221\end{array}$ & $\begin{array}{c}\text { Down-Diagonal } \\
\mathrm{F}(1,19)=0.16 \\
p=.692\end{array}$ & $\begin{array}{c}\text { Downwards } \\
\mathrm{F}(1,19)=0.28 \\
p=.602\end{array}$ \\
\hline \multirow[t]{3}{*}{$60^{\circ}$} & $\begin{array}{l}\text { 2-way Interaction } \\
\text { Posture, Direction }\end{array}$ & \multicolumn{5}{|c|}{$\mathrm{F}(2.40,45.61)=1.02, p=.381$} \\
\hline & Direction Main Effect & \multicolumn{2}{|c|}{$\begin{array}{c}\text { Sitting } \\
\mathrm{F}(2.52,47.80)=3.66, p=.025\end{array}$} & & \multicolumn{2}{|c|}{$\begin{array}{c}\text { Standing } \\
\mathrm{F}(2.36,44.88)=3.05, p=.023\end{array}$} \\
\hline & Posture Main Effect & $\begin{array}{c}\text { Upwards } \\
\mathrm{F}(1,19)=0.22 \\
p=.647\end{array}$ & $\begin{array}{c}\text { Up-Diagonal } \\
\mathrm{F}(1,19)=8.50 \\
p=.009\end{array}$ & $\begin{array}{c}\text { Horizontal } \\
\mathrm{F}(1,19)=26.97 \\
p<.001\end{array}$ & $\begin{array}{c}\text { Down-Diagonal } \\
\mathrm{F}(1,19)=18.81 \\
p<.001\end{array}$ & $\begin{array}{c}\text { Downwards } \\
\mathrm{F}(1,19)=1.48 \\
p=.239\end{array}$ \\
\hline \multirow[t]{3}{*}{$80^{\circ}$} & $\begin{array}{l}\text { 2-way Interaction } \\
\text { Posture, Direction }\end{array}$ & \multicolumn{5}{|c|}{$\mathrm{F}(4,76)=38.49, p<.001$} \\
\hline & Direction Main Effect & \multicolumn{2}{|c|}{$\begin{array}{c}\text { Sitting } \\
\mathrm{F}(2.74,51.98)=10.22, p<.001\end{array}$} & & \multicolumn{2}{|c|}{$\begin{array}{c}\text { Standing } \\
\mathrm{F}(2.71,51.56)=26.95, p<.001\end{array}$} \\
\hline & Posture Main Effect & $\begin{array}{c}\text { Upwards } \\
\mathrm{F}(1,19)=2.31 \\
p=.145 \\
\end{array}$ & $\begin{array}{c}\text { Up-Diagonal } \\
\mathrm{F}(1,19)=45.76 \\
p<.001\end{array}$ & $\begin{array}{c}\text { Horizontal } \\
\mathrm{F}(1,19)=47.23 \\
p<.001\end{array}$ & $\begin{array}{c}\text { Down-Diagonal } \\
\mathrm{F}(1,19)=165.96 \\
p<.001\end{array}$ & $\begin{array}{c}\text { Downwards } \\
\mathrm{F}(1,19)=3.98 \\
p=.061\end{array}$ \\
\hline \multirow[t]{3}{*}{$100^{\circ}$} & $\begin{array}{l}\text { 2-way Interaction } \\
\text { Posture, Direction }\end{array}$ & \multicolumn{5}{|c|}{$\mathrm{F}(4,76)=44.92, p<.001$} \\
\hline & Direction Main Effect & \multicolumn{2}{|c|}{$\begin{array}{c}\text { Sitting } \\
\mathrm{F}(2.73,51.82)=3.82, p=.018\end{array}$} & & \multicolumn{2}{|c|}{$\begin{array}{c}\text { Standing } \\
\mathrm{F}(2.535,48.165)=47.792, p<.001\end{array}$} \\
\hline & Posture Main Effect & $\begin{array}{c}\text { Upwards } \\
\mathrm{F}(1,19)=1.32 \\
p=.264 \\
\end{array}$ & $\begin{array}{c}\text { Up-Diagonal } \\
\mathrm{F}(1,19)=164.62 \\
p<.001 \\
\end{array}$ & $\begin{array}{c}\text { Horizontal } \\
\mathrm{F}(1,19)=168.92 \\
p<.001\end{array}$ & $\begin{array}{c}\text { Down-Diagonal } \\
\mathrm{F}(1,19)=187.83 \\
p<.001\end{array}$ & $\begin{array}{c}\text { Downwards } \\
\mathrm{F}(1,19)=0.09 \\
p=.763\end{array}$ \\
\hline
\end{tabular}

Table 4. Repeated measures ANOVA statistical analysis on the effect of posture and direction on head contribution. 


\section{TORSO CONTRIBUTION}

Torso Contribution Amplitude

\begin{tabular}{|c|c|c|c|c|c|c|}
\hline \multirow[t]{10}{*}{ All Amplitudes } & \multirow{4}{*}{$\begin{array}{l}\text { 3-way Interaction } \\
\text { 2-way Interaction } \\
\text { Amplitude, Direction }\end{array}$} & \multicolumn{5}{|c|}{$\mathrm{F}(5.62,106.70)=36.59, p<.001$} \\
\hline & & \multicolumn{2}{|c|}{ Sitting } & \multicolumn{3}{|c|}{ Standing } \\
\hline & & \multicolumn{2}{|c|}{$\mathrm{F}(4.09,77.61)=1.64, p=.172$} & \multirow[b]{2}{*}{ Horizontal } & \multicolumn{2}{|c|}{$\mathrm{F}(4.96,93.32)=42.19, p<.001$} \\
\hline & & Upwards & Up-Diagonal & & Down-Diagonal & Downwards \\
\hline & 2-way Interaction & $\mathrm{F}(2.83,53.73)=1.86$ & $\mathrm{~F}(2.04,38.67)=56.78$ & $\mathrm{~F}(1.82,36.64)=78.07$ & $\mathrm{~F}(2.21,41.99)=123.64$ & $\mathrm{~F}(2.56,48.70)=0.64$ \\
\hline & Amplitude, Posture & $p=.151$ & $p<.001$ & $p<.001$ & $p<.001$ & $p=.572$ \\
\hline & Amplitude Main Effect, & $\mathrm{F}(2.32,44.06)=13.09$ & $\mathrm{~F}(1.77,33.53)=12.86$ & $\mathrm{~F}(1.74,33.09)=12.18$ & $\mathrm{~F}(1.32,25.11)=12.38$ & $\mathrm{~F}(2.27,43.14)=9.18$ \\
\hline & Sitting Posture & $p<.001$ & $p<.001$ & $p<.001$ & $p<.001$ & $p<.001$ \\
\hline & Amplitude Main Effect, & $\mathrm{F}(2.36,44.76)=6.79$ & $\mathrm{~F}(1.79,34.04)=59.01$ & $\mathrm{~F}(1.66,31.50)=90.02$ & $\mathrm{~F}(1.69,32.10)=179.34$ & $\mathrm{~F}(2.96,56.31)=12.05$ \\
\hline & Standing Posture & $p=.002$ & $p<.001$ & $p<.001$ & $p<.001$ & $p<.001$ \\
\hline \multirow[t]{10}{*}{ Within-view } & 3-way Interaction & \multicolumn{5}{|c|}{$\mathrm{F}(4.52,85.95)=1.34, p=.258$} \\
\hline & 2-way Interaction & \multicolumn{2}{|c|}{ Sitting } & & \multicolumn{2}{|c|}{ Standing } \\
\hline & Amplitude, Direction & \multicolumn{2}{|c|}{$\mathrm{F}(2.73,51.83)=1.38, p=.260$} & & \multicolumn{2}{|c|}{$\mathrm{F}(3.93,74.71)=1.77, p=.144$} \\
\hline & & Upwards & Up-Diagonal & Horizontal & Down-Diagonal & Downwards \\
\hline & 2-way Interaction & $\mathrm{F}(1.98,37.64)=2.12$ & $\mathrm{~F}(1.62,30.85)=1.11$ & $\mathrm{~F}(1.84,35.03)=2.65$ & $\mathrm{~F}(1.44,46.34)=3.13$ & $\mathrm{~F}(1.73,32.87)=0.69$ \\
\hline & Amplitude, Posture & $p=.135$ & $p=.333$ & $p=.089$ & $p=.071$ & $p=.491$ \\
\hline & Amplitude Main Effect, & $\mathrm{F}(1.25,23.79)=16.00$ & $\mathrm{~F}(1.14,21.71)=30.83$ & $\mathrm{~F}(1.72,32.61)=26.45$ & $\mathrm{~F}(1.51,28.69)=33.27$ & $\mathrm{~F}(1.16,22.09)=9.27$ \\
\hline & Sitting Posture & $p<.001$ & $p<.001$ & $p<.001$ & $p<.001$ & $p=.004$ \\
\hline & Amplitude Main Effect, & $\mathrm{F}(1.60,30.35)=41.84$ & $\mathrm{~F}(1.59,30.29)=24.21$ & $\mathrm{~F}(1.42,26.95)=33.96$ & $\mathrm{~F}(1.33,25.33)=25.85$ & $\mathrm{~F}(1.58,29.98)=11.77$ \\
\hline & Standing Posture & $p<.001$ & $p<.001$ & $p<.001$ & $p<.001$ & $p<.001$ \\
\hline \multirow[t]{10}{*}{ Beyond-view } & 3-way Interaction & \multicolumn{5}{|c|}{$\mathrm{F}(3.80,72.24)=17.99, p<.001$} \\
\hline & 2-way Interaction & \multicolumn{2}{|c|}{ Sitting } & & \multicolumn{2}{|c|}{ Standing } \\
\hline & Amplitude, Direction & \multicolumn{2}{|c|}{$\mathrm{F}(3.12,59.36)=1.44, p=.239$} & & \multicolumn{2}{|c|}{$\mathrm{F}(3.84,72.89)=22.98, p<.001$} \\
\hline & & Upwards & Up-Diagonal & Horizontal & Down-Diagonal & Downwards \\
\hline & 2-way Interaction & $\mathrm{F}(1.12,21.23)=2.03$ & $\mathrm{~F}(2,38)=56.17$ & $\mathrm{~F}(2,38)=56.84$ & $\mathrm{~F}(1.39,26.49)=61.35$ & $\mathrm{~F}(1.35,25.58)=0.64$ \\
\hline & Amplitude, Posture & $p=.168$ & $p<.001$ & $p<.001$ & $p<.001$ & $p=.476$ \\
\hline & Amplitude Main Effect, & $\mathrm{F}(1.17,22.25)=19.44$ & $\mathrm{~F}(1.52,28.86)=18.60$ & $\mathrm{~F}(1.68,31.88)=21.26$ & $\mathrm{~F}(1.28,24.36)=16.22$ & $\mathrm{~F}(1.28,24.32)=24.32$ \\
\hline & Sitting Posture & $p<.001$ & $p<.001$ & $p<.001$ & $p<.001$ & $p=.002$ \\
\hline & Amplitude Main Effect, & $\mathrm{F}(1.07,20.39)=11.59$ & $\mathrm{~F}(2,38)=78.53$ & $\mathrm{~F}(1.44,27.30)=91.44$ & $\mathrm{~F}(2,38)=206.04$ & $\mathrm{~F}(2,38)=15.51$ \\
\hline & Standing Posture & $p=.002$ & $p<.001$ & $p<.001$ & $p<.001$ & $p<.001$ \\
\hline
\end{tabular}

Table 5. Repeated measures ANOVA statistical analysis on the effect of amplitude on torso contribution. 
Torso Contribution Posture and Direction

\begin{tabular}{|c|c|c|c|c|c|c|}
\hline \multirow[t]{3}{*}{$5^{\circ}$} & \multirow{2}{*}{$\begin{array}{l}\text { 2-way Interaction } \\
\text { Posture, Direction } \\
\text { Direction Main Effect }\end{array}$} & \multicolumn{5}{|c|}{$\mathrm{F}(4,76)=1.24, p=.303$} \\
\hline & & \multicolumn{2}{|c|}{$\begin{array}{c}\text { Sitting } \\
\mathrm{F}(2.16,40.94)=1.28, p=.291\end{array}$} & \multicolumn{3}{|c|}{$\begin{array}{c}\text { Standing } \\
\mathrm{F}(2.63,49.88)=2.18, p=.109\end{array}$} \\
\hline & Posture Main Effect & $\begin{array}{c}\text { Upwards } \\
\mathrm{F}(1,19)=0.13 \\
p=.718\end{array}$ & $\begin{array}{c}\text { Up-Diagonal } \\
\mathrm{F}(1,19)=3.41 \\
p=.080\end{array}$ & $\begin{array}{c}\text { Horizontal } \\
\mathrm{F}(1,19)=3.68 \\
p=.070\end{array}$ & $\begin{array}{c}\text { Down-Diagonal } \\
\mathrm{F}(1,19)=3.63 \\
p=.081\end{array}$ & $\begin{array}{c}\text { Downwards } \\
\mathrm{F}(1,19)=1.05 \\
p=.317\end{array}$ \\
\hline \multirow[t]{3}{*}{$15^{\circ}$} & $\begin{array}{l}\text { 2-way Interaction } \\
\text { Posture, Direction }\end{array}$ & \multicolumn{5}{|c|}{$\mathrm{F}(4,76)=2.19, p=.078$} \\
\hline & Direction Main Effect & \multicolumn{2}{|c|}{$\begin{array}{c}\text { Sitting } \\
\mathrm{F}(4,76)=1.25, p=.296\end{array}$} & & \multicolumn{2}{|c|}{$\begin{array}{c}\text { Standing } \\
\mathrm{F}(2.79,53.00)=1.50, p=.227\end{array}$} \\
\hline & Posture Main Effect & $\begin{array}{c}\text { Upwards } \\
\mathrm{F}(1,19)=2.35 \\
p=.142 \\
\end{array}$ & $\begin{array}{c}\text { Up-Diagonal } \\
\mathrm{F}(1,19)=4.34 \\
p=.051 \\
\end{array}$ & $\begin{array}{c}\text { Horizontal } \\
\mathrm{F}(1,19)=0.09 \\
p=.762 \\
\end{array}$ & $\begin{array}{c}\text { Down-Diagonal } \\
\mathrm{F}(1,19)=3.98 \\
p=.063\end{array}$ & $\begin{array}{c}\text { Downwards } \\
\mathrm{F}(1,19)=0.09 \\
p=.762 \\
\end{array}$ \\
\hline \multirow[t]{3}{*}{$25^{\circ}$} & $\begin{array}{l}\text { 2-way Interaction } \\
\text { Posture, Direction }\end{array}$ & \multicolumn{5}{|c|}{$\mathrm{F}(2.49,47.32)=0.77, p=.493$} \\
\hline & Direction Main Effect & \multicolumn{2}{|c|}{$\begin{array}{c}\text { Sitting } \\
\mathrm{F}(2.82,53.55)=2.15, p=.108\end{array}$} & & \multicolumn{2}{|c|}{$\begin{array}{c}\text { Standing } \\
\mathrm{F}(2.50,47.40)=1.34, p=.272\end{array}$} \\
\hline & Posture Main Effect & $\begin{array}{c}\text { Upwards } \\
\mathrm{F}(1,19)=2.54 \\
p=.127 \\
\end{array}$ & $\begin{array}{c}\text { Up-Diagonal } \\
\mathrm{F}(1,19)=1.06 \\
p=.316 \\
\end{array}$ & $\begin{array}{c}\text { Horizontal } \\
\mathrm{F}(1,19)=0.03 \\
p=.863 \\
\end{array}$ & $\begin{array}{c}\text { Down-Diagonal } \\
\mathrm{F}(1,19)=0.01 \\
p=.935 \\
\end{array}$ & $\begin{array}{c}\text { Downwards } \\
\mathrm{F}(1,19)=0.18 \\
p=.677 \\
\end{array}$ \\
\hline \multirow[t]{3}{*}{$35^{\circ}$} & $\begin{array}{l}\text { 2-way Interaction } \\
\text { Posture, Direction }\end{array}$ & \multicolumn{5}{|c|}{$\mathrm{F}(1.25,23.81)=2.46, p=.125$} \\
\hline & Direction Main Effect & \multicolumn{2}{|c|}{$\begin{array}{c}\text { Sitting } \\
\mathrm{F}(4,76)=1.81, p=.135\end{array}$} & & \multicolumn{2}{|c|}{$\begin{array}{c}\text { Standing } \\
\mathrm{F}(1.18,22.46)=2.02, p=.168\end{array}$} \\
\hline & Posture Main Effect & $\begin{array}{c}\text { Upwards } \\
\mathrm{F}(1,19)=0.01 \\
p=.921 \\
\end{array}$ & $\begin{array}{c}\text { Up-Diagonal } \\
\mathrm{F}(1,19)=3.37 \\
p=.082 \\
\end{array}$ & $\begin{array}{c}\text { Horizontal } \\
\mathrm{F}(1,19)=9.70 \\
p=.056 \\
\end{array}$ & $\begin{array}{c}\text { Down-Diagonal } \\
\mathrm{F}(1,19)=4.81 \\
p=.107 \\
\end{array}$ & $\begin{array}{c}\text { Downwards } \\
\mathrm{F}(1,19)=0.73 \\
p=.402 \\
\end{array}$ \\
\hline \multirow[t]{3}{*}{$45^{\circ}$} & $\begin{array}{l}\text { 2-way Interaction } \\
\text { Posture, Direction }\end{array}$ & \multicolumn{5}{|c|}{$\mathrm{F}(1.51,28.76)=1.10, p=.330$} \\
\hline & Direction Main Effect & \multicolumn{2}{|c|}{$\begin{array}{c}\text { Sitting } \\
\mathrm{F}(2.29,43.56)=1.18, p=.321\end{array}$} & & \multicolumn{2}{|c|}{$\begin{array}{c}\text { Standing } \\
\mathrm{F}(1.50,28.54)=1.35, p=.270\end{array}$} \\
\hline & Posture Main Effect & $\begin{array}{c}\text { Upwards } \\
\mathrm{F}(1,19)=3.22 \\
p=.089\end{array}$ & $\begin{array}{c}\text { Up-Diagonal } \\
\mathrm{F}(1,19)=5.93 \\
p=.025\end{array}$ & $\begin{array}{c}\text { Horizontal } \\
\mathrm{F}(1,19)=4.95 \\
p=.039\end{array}$ & $\begin{array}{c}\text { Down-Diagonal } \\
\mathrm{F}(1,19)=5.20 \\
p=.034\end{array}$ & $\begin{array}{c}\text { Downwards } \\
\mathrm{F}(1,19)=1.72 \\
p=.206\end{array}$ \\
\hline \multirow[t]{3}{*}{$60^{\circ}$} & $\begin{array}{l}\text { 2-way Interaction } \\
\text { Posture, Direction }\end{array}$ & \multicolumn{5}{|c|}{$\mathrm{F}(2.05,38.97)=37.97, p<.001$} \\
\hline & Direction Main Effect & \multicolumn{2}{|c|}{$\begin{array}{c}\text { Sitting } \\
\mathrm{F}(2.09,39.74)=2.02, p=.144\end{array}$} & & \multicolumn{2}{|c|}{$\begin{array}{c}\text { Standing } \\
\mathrm{F}(1.90,36.04)=31.41, p<.001\end{array}$} \\
\hline & Posture Main Effect & $\begin{array}{c}\text { Upwards } \\
\mathrm{F}(1,19)=3.67 \\
p=.071\end{array}$ & $\begin{array}{c}\text { Up-Diagonal } \\
\mathrm{F}(1,19)=39.06 \\
p<.001\end{array}$ & $\begin{array}{c}\text { Horizontal } \\
\mathrm{F}(1,19)=53.03 \\
p<.001\end{array}$ & $\begin{array}{c}\text { Down-Diagonal } \\
\mathrm{F}(1,19)=80.64 \\
p<.001\end{array}$ & $\begin{array}{c}\text { Downwards } \\
\mathrm{F}(1,19)=0.72 \\
p=.406\end{array}$ \\
\hline \multirow[t]{3}{*}{$80^{\circ}$} & $\begin{array}{l}\text { 2-way Interaction } \\
\text { Posture, Direction }\end{array}$ & \multicolumn{5}{|c|}{$\mathrm{F}(2.20,41.88)=58.12, p<.001$} \\
\hline & Direction Main Effect & \multicolumn{2}{|c|}{$\begin{array}{c}\text { Sitting } \\
\mathrm{F}(1.69,32.04)=1.77, p=.190\end{array}$} & & \multicolumn{2}{|c|}{$\begin{array}{c}\text { Standing } \\
\mathrm{F}(2.04,38.75)=57.11, p<.001\end{array}$} \\
\hline & Posture Main Effect & $\begin{array}{c}\text { Upwards } \\
\mathrm{F}(1,19)=1.64 \\
p=.215\end{array}$ & $\begin{array}{c}\text { Up-Diagonal } \\
\mathrm{F}(1,19)=58.68 \\
p<.001\end{array}$ & $\begin{array}{c}\text { Horizontal } \\
\mathrm{F}(1,19)=71.65 \\
p<.001\end{array}$ & $\begin{array}{c}\text { Down-Diagonal } \\
\mathrm{F}(1,19)=191.68 \\
p<.001\end{array}$ & $\begin{array}{c}\text { Downwards } \\
\mathrm{F}(1,19)=0.08 \\
p=.785\end{array}$ \\
\hline \multirow[t]{3}{*}{$100^{\circ}$} & $\begin{array}{l}\text { 2-way Interaction } \\
\text { Posture, Direction }\end{array}$ & \multicolumn{5}{|c|}{$\mathrm{F}(2.79,53.09)=81.60, p<.001$} \\
\hline & Direction Main Effect & $\begin{array}{r}\text { Sit } \\
\mathrm{F}(2.21,42.00)\end{array}$ & $\begin{array}{l}\text { ting } \\
=1.68, p=.197\end{array}$ & & $\begin{array}{r}\text { Stand } \\
\mathrm{F}(2.44,46.41)=8\end{array}$ & ing \\
\hline & Posture Main Effect & $\begin{array}{c}\text { Upwards } \\
\mathrm{F}(1,19)=2.88 \\
p=.106\end{array}$ & $\begin{array}{c}\text { Up-Diagonal } \\
\mathrm{F}(1,19)=150.15 \\
p<.001\end{array}$ & $\begin{array}{c}\text { Horizontal } \\
\mathrm{F}(1,19)=194.13 \\
p<.001\end{array}$ & $\begin{array}{c}\text { Down-Diagonal } \\
\mathrm{F}(1,19)=201.75 \\
p<.001\end{array}$ & $\begin{array}{c}\text { Downwards } \\
\mathrm{F}(1,19)=0.38 \\
p=.544\end{array}$ \\
\hline
\end{tabular}

Table 6. Repeated measures ANOVA statistical analysis on the effect of posture and direction on torso contribution. 


\section{TOTAL HEAD MOVEMENT}

Total Head Movement Amplitude

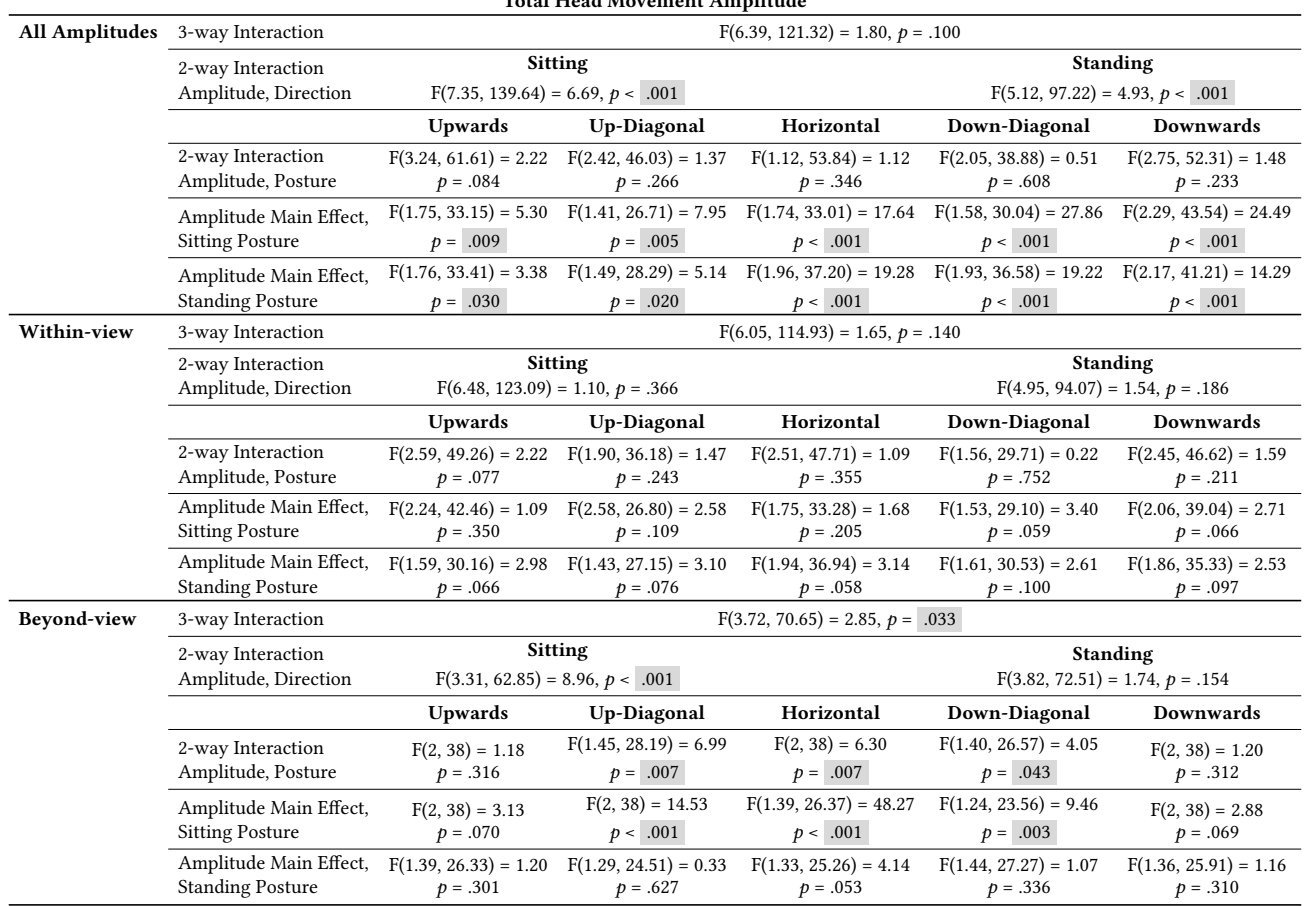

Table 7. Repeated measures ANOVA statistical analysis on the effect of amplitude on total head movement. 
Total Head Movement Posture and Direction

\begin{tabular}{|c|c|c|c|c|c|c|}
\hline \multirow[t]{3}{*}{$5^{\circ}$} & \multirow{3}{*}{$\begin{array}{l}\text {-way Interaction } \\
\text { Posture, Direction } \\
\text { Direction Main Effect } \\
\text { Posture Main Effect }\end{array}$} & \multicolumn{5}{|c|}{$\mathrm{F}(2.47,46.96)=0.57, p=.606$} \\
\hline & & \multicolumn{2}{|c|}{$\begin{array}{c}\text { Sitting } \\
\mathrm{F}(2.51,47.59)=2.19, p=.112\end{array}$} & & \multicolumn{2}{|c|}{$\begin{array}{c}\text { Standing } \\
\mathrm{F}(1.92,36.39)=2.71, p=.082\end{array}$} \\
\hline & & $\begin{array}{c}\text { Upwards } \\
\mathrm{F}(1,19)=3.69 \\
p=.072\end{array}$ & $\begin{array}{c}\text { Up-Diagonal } \\
\mathrm{F}(1,19)=4.30 \\
p=.054\end{array}$ & $\begin{array}{c}\text { Horizontal } \\
\mathrm{F}(1,19)=2.89 \\
p=.106\end{array}$ & $\begin{array}{c}\text { Down-Diagonal } \\
\mathrm{F}(1,19)=1.30 \\
p=.269\end{array}$ & $\begin{array}{c}\text { Downwards } \\
\mathrm{F}(1,19)=1.28 \\
p=.272\end{array}$ \\
\hline \multirow[t]{3}{*}{$15^{\circ}$} & $\begin{array}{l}\text { 2-way Interaction } \\
\text { Posture, Direction }\end{array}$ & \multicolumn{5}{|c|}{$\mathrm{F}(4,76)=2.08, p=.093$} \\
\hline & Direction Main Effect & \multicolumn{2}{|c|}{$\begin{array}{c}\text { Sitting } \\
\mathrm{F}(2.48,47.19)=8.52, p<.001\end{array}$} & & \multicolumn{2}{|c|}{$\begin{array}{c}\text { Standing } \\
\mathrm{F}(2.22,42.17)=1.22, p=.308\end{array}$} \\
\hline & Posture Main Effect & $\begin{array}{c}\text { Upwards } \\
\mathrm{F}(1,19)=0.34 \\
p=.568 \\
\end{array}$ & $\begin{array}{c}\text { Up-Diagonal } \\
\mathrm{F}(1,19)=2.50 \\
p=.131\end{array}$ & $\begin{array}{c}\text { Horizontal } \\
\mathrm{F}(1,19)=0.11 \\
p=.741 \\
\end{array}$ & $\begin{array}{c}\text { Down-Diagonal } \\
\mathrm{F}(1,19)=3.39 \\
p=.082\end{array}$ & $\begin{array}{c}\text { Downwards } \\
\mathrm{F}(1,19)=3.46 \\
p=.077\end{array}$ \\
\hline \multirow[t]{3}{*}{$25^{\circ}$} & $\begin{array}{l}\text { 2-way Interaction } \\
\text { Posture, Direction }\end{array}$ & \multicolumn{5}{|c|}{$\mathrm{F}(4,76)=1.00, p=.416$} \\
\hline & Direction Main Effect & \multicolumn{2}{|c|}{$\begin{array}{c}\text { Sitting } \\
\mathrm{F}(2.22,42.21)=8.52, p=.001\end{array}$} & & \multicolumn{2}{|c|}{$\begin{array}{c}\text { Standing } \\
\mathrm{F}(2.58,48.96)=5.44, p=.004\end{array}$} \\
\hline & Posture Main Effect & $\begin{array}{c}\text { Upwards } \\
\mathrm{F}(1,19)=1.95 \\
p=.179\end{array}$ & $\begin{array}{c}\text { Up-Diagonal } \\
\mathrm{F}(1,19)=3.23 \\
p=.094\end{array}$ & $\begin{array}{c}\text { Horizontal } \\
\mathrm{F}(1,19)=0.61 \\
p=.445\end{array}$ & $\begin{array}{c}\text { Down-Diagonal } \\
\mathrm{F}(1,19)=4.07 \\
p=.058\end{array}$ & $\begin{array}{c}\text { Downwards } \\
\mathrm{F}(1,19)=4.01 \\
p=.064\end{array}$ \\
\hline \multirow[t]{3}{*}{$35^{\circ}$} & $\begin{array}{l}\text { 2-way Interaction } \\
\text { Posture, Direction }\end{array}$ & \multicolumn{5}{|c|}{$\mathrm{F}(4,76)=0.40, p=.805$} \\
\hline & Direction Main Effect & \multicolumn{2}{|c|}{$\begin{array}{c}\text { Sitting } \\
\mathrm{F}(2.37,45.07)=9.64, p<.001\end{array}$} & & \multicolumn{2}{|c|}{$\begin{array}{c}\text { Standing } \\
\mathrm{F}(2.00,38.05)=8.26, p=.001\end{array}$} \\
\hline & Posture Main Effect & $\begin{array}{c}\text { Upwards } \\
\mathrm{F}(1,19)=0.65 \\
p=.431\end{array}$ & $\begin{array}{c}\text { Up-Diagonal } \\
\mathrm{F}(1,19)=2.91 \\
p=.104\end{array}$ & $\begin{array}{c}\text { Horizontal } \\
\mathrm{F}(1,19)=1.01 \\
p=.329\end{array}$ & $\begin{array}{c}\text { Down-Diagonal } \\
\mathrm{F}(1,19)=4.30 \\
p=.053\end{array}$ & $\begin{array}{c}\text { Downwards } \\
\mathrm{F}(1,19)=0.81 \\
p=.379\end{array}$ \\
\hline \multirow[t]{3}{*}{$45^{\circ}$} & $\begin{array}{l}\text { 2-way Interaction } \\
\text { Posture, Direction }\end{array}$ & \multicolumn{5}{|c|}{$\mathrm{F}(2.24,42.55)=3.04, p=.053$} \\
\hline & Direction Main Effect & \multicolumn{2}{|c|}{$\begin{array}{c}\text { Sitting } \\
\mathrm{F}(1.91,36.27)=21.77, p<.001\end{array}$} & & \multicolumn{2}{|c|}{$\begin{array}{c}\text { Standing } \\
\mathrm{F}(2.12,40.36)=15.37, p<.001\end{array}$} \\
\hline & Posture Main Effect & $\begin{array}{c}\text { Upwards } \\
\mathrm{F}(1,19)=0.18 \\
p=.680\end{array}$ & $\begin{array}{c}\text { Up-Diagonal } \\
\mathrm{F}(1,19)=4.92 \\
p=.040\end{array}$ & $\begin{array}{c}\text { Horizontal } \\
\mathrm{F}(1,19)=5.65 \\
p=.028\end{array}$ & $\begin{array}{c}\text { Down-Diagonal } \\
\mathrm{F}(1,19)=10.45 \\
p=.004\end{array}$ & $\begin{array}{c}\text { Downwards } \\
\mathrm{F}(1,19)=0.16 \\
p=.693\end{array}$ \\
\hline \multirow[t]{3}{*}{$60^{\circ}$} & $\begin{array}{l}\text { 2-way Interaction } \\
\text { Posture, Direction }\end{array}$ & \multicolumn{5}{|c|}{$\mathrm{F}(2.19,41.59)=2.65, p=.078$} \\
\hline & Direction Main Effect & \multicolumn{2}{|c|}{$\begin{array}{c}\text { Sitting } \\
\mathrm{F}(2.08,39.48)=10.74, p<.001\end{array}$} & & \multicolumn{2}{|c|}{$\begin{array}{c}\text { Standing } \\
\mathrm{F}(2.18,41.55)=14.33, p<.001\end{array}$} \\
\hline & Posture Main Effect & $\begin{array}{c}\text { Upwards } \\
\mathrm{F}(1,19)=0.45 \\
p=.510\end{array}$ & $\begin{array}{c}\text { Up-Diagonal } \\
\mathrm{F}(1,19)=17.50 \\
p=.001\end{array}$ & $\begin{array}{c}\text { Horizontal } \\
\mathrm{F}(1,19)=15.57 \\
p=.001\end{array}$ & $\begin{array}{c}\text { Down-Diagonal } \\
\mathrm{F}(1,19)=5.75 \\
p=.028\end{array}$ & $\begin{array}{c}\text { Downwards } \\
\mathrm{F}(1,19)=2.76 \\
p=.113\end{array}$ \\
\hline \multirow[t]{3}{*}{$80^{\circ}$} & $\begin{array}{l}\text { 2-way Interaction } \\
\text { Posture, Direction }\end{array}$ & \multicolumn{5}{|c|}{$\mathrm{F}(1.76,33.49)=7.08, p=.004$} \\
\hline & Direction Main Effect & \multicolumn{2}{|c|}{$\begin{array}{c}\text { Sitting } \\
\mathrm{F}(1.52,28.91)=4.43, p=.030\end{array}$} & & \multicolumn{2}{|c|}{$\begin{array}{c}\text { Standing } \\
\mathrm{F}(2.44,46.39)=33.30, p<.001\end{array}$} \\
\hline & Posture Main Effect & $\begin{array}{c}\text { Upwards } \\
\mathrm{F}(1,19)=1.57 \\
p=.226\end{array}$ & $\begin{array}{c}\text { Up-Diagonal } \\
\mathrm{F}(1,19)=29.43 \\
p<.001\end{array}$ & $\begin{array}{c}\text { Horizontal } \\
\mathrm{F}(1,19)=46.09 \\
p<.001\end{array}$ & $\begin{array}{c}\text { Down-Diagonal } \\
\mathrm{F}(1,19)=21.34 \\
p<.001\end{array}$ & $\begin{array}{c}\text { Downwards } \\
\mathrm{F}(1,19)=1.21 \\
p=.284\end{array}$ \\
\hline \multirow[t]{3}{*}{$100^{\circ}$} & $\begin{array}{l}\text { 2-way Interaction } \\
\text { Posture, Direction }\end{array}$ & \multicolumn{5}{|c|}{$\mathrm{F}(1.75,33.19)=9.20, p=.001$} \\
\hline & Direction Main Effect & \multicolumn{2}{|c|}{$\begin{array}{c}\text { Sitting } \\
\mathrm{F}(1.71,32.50)=4.13, p=.030\end{array}$} & & \multicolumn{2}{|c|}{$\begin{array}{c}\text { Standing } \\
\mathrm{F}(2.02,38.45)=18.78, p<.001\end{array}$} \\
\hline & Posture Main Effect & $\begin{array}{c}\text { Upwards } \\
\mathrm{F}(1,19)=0.37 \\
p=.552\end{array}$ & $\begin{array}{c}\text { Up-Diagonal } \\
\mathrm{F}(1,19)=44.26 \\
p<.001\end{array}$ & $\begin{array}{c}\text { Horizontal } \\
\mathrm{F}(1,19)=50.72 \\
p<.001\end{array}$ & $\begin{array}{c}\text { Down-Diagonal } \\
\mathrm{F}(1,19)=30.18 \\
p<.001\end{array}$ & $\begin{array}{c}\text { Downwards } \\
\mathrm{F}(1,19)=0.08 \\
p=.780\end{array}$ \\
\hline
\end{tabular}

Table 8. Repeated measures ANOVA statistical analysis on the effect of posture and direction on total head movement. 


\section{E TOTAL TORSO MOVEMENT}

\begin{tabular}{|c|c|c|c|c|c|c|}
\hline \multicolumn{7}{|c|}{ Total Torso Movement Amplitude } \\
\hline \multirow[t]{7}{*}{ All Amplitudes } & 3-way Interaction & \multicolumn{5}{|c|}{$\mathrm{F}(6.19,117.52)=18.58, p<.001$} \\
\hline & 2-way Interaction & \multicolumn{2}{|c|}{ Sitting } & \multicolumn{3}{|c|}{ Standing } \\
\hline & Amplitude, Direction & \multicolumn{2}{|c|}{$\mathrm{F}(3.85,73.05)=3.32, p=.016$} & \multicolumn{3}{|c|}{$\mathrm{F}(6.09,115.68)=21.13, p<.001$} \\
\hline & & Upwards & Up-Diagonal & Horizontal & Down-Diagonal & Downwards \\
\hline & $\begin{array}{l}\text { 2-way Interaction } \\
\text { Amplitude, Posture }\end{array}$ & $\begin{array}{c}\mathrm{F}(2.40,45.56)=3.01 \\
p=.052\end{array}$ & $\begin{array}{c}\mathrm{F}(2.66,50.51)=40.25 \\
p<.001\end{array}$ & $\begin{array}{c}\mathrm{F}(2.17,41.19)=36.22 \\
p<.001\end{array}$ & $\begin{array}{c}\mathrm{F}(2.27,43.13)=47.68 \\
p<.001\end{array}$ & $\begin{array}{c}\mathrm{F}(2.52,47.90)=1.27 \\
p=.295\end{array}$ \\
\hline & $\begin{array}{l}\text { Amplitude Main Effect, } \\
\text { Sitting Posture }\end{array}$ & $\begin{array}{c}\mathrm{F}(2.43,46.15)=20.00 \\
p<.001\end{array}$ & $\begin{array}{c}\mathrm{F}(1.77,33.70)=22.72 \\
p<.001\end{array}$ & $\begin{array}{c}\mathrm{F}(1.71,32.43)=23.05 \\
p<.001\end{array}$ & $\begin{array}{c}\mathrm{F}(2.10,39.85)=18.66 \\
p<.001\end{array}$ & $\begin{array}{c}\mathrm{F}(2.43,46.24)=17.19 \\
p<.001\end{array}$ \\
\hline & $\begin{array}{l}\text { Amplitude Main Effect, } \\
\text { Standing Posture }\end{array}$ & $\begin{array}{c}\mathrm{F}(1.91,36.22)=19.93 \\
p<.001\end{array}$ & $\begin{array}{c}\mathrm{F}(2.39,45.44)=50.04 \\
p<.001\end{array}$ & $\begin{array}{c}\mathrm{F}(1.93,36.75)=45.07 \\
p<.001\end{array}$ & $\begin{array}{c}\mathrm{F}(2.63,50.00)=70.72 \\
p<.001\end{array}$ & $\begin{array}{c}\mathrm{F}(2.66,50.60)=20.95 \\
p<.001\end{array}$ \\
\hline \multirow[t]{6}{*}{ Within-view } & 3-way Interaction & \multicolumn{5}{|c|}{$\mathrm{F}(4.53,86.03)=1.41, p=.232$} \\
\hline & $\begin{array}{l}\text { 2-way Interaction } \\
\text { Amplitude, Direction }\end{array}$ & \multicolumn{2}{|c|}{$\begin{array}{c}\text { Sitting } \\
\mathrm{F}(4.23,80.44)=1.13, p=.347 \\
\end{array}$} & \multicolumn{3}{|c|}{$\begin{array}{c}\text { Standing } \\
\mathrm{F}(4.35,82.71)=1.83, p=.125\end{array}$} \\
\hline & & Upwards & Up-Diagonal & Horizontal & Down-Diagonal & Downwards \\
\hline & $\begin{array}{l}\text { 2-way Interaction } \\
\text { Amplitude, Posture }\end{array}$ & $\begin{array}{c}\mathrm{F}(1.31,24.95)=3.22 \\
p=.074\end{array}$ & $\begin{array}{c}\mathrm{F}(2.10,39.97)=2.65 \\
p=.081\end{array}$ & $\begin{array}{c}\mathrm{F}(1.68,31.94)=1.77 \\
p=.190\end{array}$ & $\begin{array}{c}\mathrm{F}(1.72,32.61)=3.27 \\
p=.070\end{array}$ & $\begin{array}{c}\mathrm{F}(1.30,24.75)=2.30 \\
p=.137\end{array}$ \\
\hline & $\begin{array}{l}\text { Amplitude Main Effect, } \\
\text { Sitting Posture }\end{array}$ & $\begin{array}{c}\mathrm{F}(1.55,29.38)=43.41 \\
p<.001\end{array}$ & $\begin{array}{c}\mathrm{F}(1.20,22.78)=62.63 \\
p<.001\end{array}$ & $\begin{array}{c}\mathrm{F}(1.13,37.27)=37.27 \\
p<.001\end{array}$ & $\begin{array}{c}\mathrm{F}(1.20,22.74)=36.60 \\
p<.001\end{array}$ & $\begin{array}{c}\mathrm{F}(1.15,21.92)=24.32 \\
p<.001\end{array}$ \\
\hline & $\begin{array}{l}\text { Amplitude Main Effect, } \\
\text { Standing Posture }\end{array}$ & $\begin{array}{c}\mathrm{F}(1.16,22.06)=39.42 \\
p<.001\end{array}$ & $\begin{array}{c}\mathrm{F}(2.30,43.77)=30.82 \\
p<.001\end{array}$ & $\begin{array}{c}\mathrm{F}(1.93,36.68)=16.24 \\
p<.001\end{array}$ & $\begin{array}{c}\mathrm{F}(1.54,29.33)=21.77 \\
p<.001\end{array}$ & $\begin{array}{c}\mathrm{F}(1.27,24.06)=30.34 \\
p<.001\end{array}$ \\
\hline \multirow[t]{6}{*}{ Beyond-view } & 3-way Interaction & \multicolumn{5}{|c|}{$\mathrm{F}(3.42,65.05)=3.73, p=.012$} \\
\hline & $\begin{array}{l}\text { 2-way Interaction } \\
\text { Amplitude, Direction }\end{array}$ & \multicolumn{2}{|c|}{ Sitting } & & \multicolumn{2}{|c|}{ Standing } \\
\hline & & Upwards & Up-Diagonal & Horizontal & Down-Diagonal & Downwards \\
\hline & $\begin{array}{l}\text { 2-way Interaction } \\
\text { Amplitude, Posture }\end{array}$ & $\begin{array}{c}\mathrm{F}(1.09,20.68)=3.54 \\
p=.071\end{array}$ & $\begin{array}{c}\mathrm{F}(1.28,24.23)=3.49 \\
p=.065\end{array}$ & $\begin{array}{c}\mathrm{F}(1.54,29.29)=5.81 \\
p=.012\end{array}$ & $\begin{array}{c}\mathrm{F}(1.43,27.11)=0.65 \\
p=.482\end{array}$ & $\begin{array}{c}\mathrm{F}(1.23,23.30)=0.56 \\
p=.497\end{array}$ \\
\hline & $\begin{array}{l}\text { Amplitude Main Effect, } \\
\text { Sitting Posture }\end{array}$ & $\begin{array}{c}\mathrm{F}(1.17,22.17)=10.76 \\
p=.002\end{array}$ & $\begin{array}{c}\mathrm{F}(1.60,30.35)=26.42 \\
p<.001\end{array}$ & $\begin{array}{c}\mathrm{F}(1.37,26.00)=27.54 \\
p<.001\end{array}$ & $\begin{array}{c}\mathrm{F}(1.57,29.82)=27.17 \\
p<.001\end{array}$ & $\begin{array}{c}\mathrm{F}(1.26,23.85)=15.82 \\
p<.001\end{array}$ \\
\hline & $\begin{array}{l}\text { Amplitude Main Effect, } \\
\text { Standing Posture }\end{array}$ & $\begin{array}{c}\mathrm{F}(1.08,20.46)=13.79 \\
p=.001\end{array}$ & $\begin{array}{c}\mathrm{F}(1.28,24.36)=17.84 \\
p<.001\end{array}$ & $\begin{array}{c}\mathrm{F}(2,38)=0.14 \\
p=.869\end{array}$ & $\begin{array}{c}\mathrm{F}(1.38,26.15)=5.01 \\
p=.024\end{array}$ & $\begin{array}{c}\mathrm{F}(1.32,25.16)=15.37 \\
p<.001\end{array}$ \\
\hline
\end{tabular}

Table 9. Repeated measures ANOVA statistical analysis on the effect of amplitude on total torso movement. 
Total Torso Movement Posture and Direction

\begin{tabular}{|c|c|c|c|c|c|c|}
\hline \multirow[t]{3}{*}{$5^{\circ}$} & \multirow{3}{*}{$\begin{array}{l}\text { 2-way Interaction } \\
\text { Posture, Direction } \\
\text { Direction Main Effect } \\
\text { Posture Main Effect }\end{array}$} & \multicolumn{5}{|c|}{$\mathrm{F}(4,76)=0.38, p=.819$} \\
\hline & & \multicolumn{2}{|c|}{$\begin{array}{c}\text { Sitting } \\
\mathrm{F}(4,76)=0.87, p=.486\end{array}$} & \multicolumn{3}{|c|}{$\begin{array}{c}\text { Standing } \\
\mathrm{F}(3.02,57.40)=0.13, p=.941\end{array}$} \\
\hline & & $\begin{array}{c}\text { Upwards } \\
\mathrm{F}(1,19)=4.23 \\
p=.056\end{array}$ & $\begin{array}{c}\text { Up-Diagonal } \\
\mathrm{F}(1,19)=26.11 \\
p<.001\end{array}$ & $\begin{array}{c}\text { Horizontal } \\
\mathrm{F}(1,19)=3.61 \\
p=.073\end{array}$ & $\begin{array}{c}\text { Down-Diagonal } \\
\mathrm{F}(1,19)=33.76 \\
p<.001\end{array}$ & $\begin{array}{c}\text { Downwards } \\
\mathrm{F}(1,19)=4.05 \\
p=.059\end{array}$ \\
\hline \multirow[t]{3}{*}{$15^{\circ}$} & $\begin{array}{l}\text { 2-way Interaction } \\
\text { Posture, Direction }\end{array}$ & \multicolumn{5}{|c|}{$\mathrm{F}(2.12,40.26)=5.11, p=.009$} \\
\hline & Direction Main Effect & \multicolumn{2}{|c|}{$\begin{array}{c}\text { Sitting } \\
\mathrm{F}(4,76)=3.39, p=.013\end{array}$} & & \multicolumn{2}{|c|}{$\begin{array}{c}\text { Standing } \\
\mathrm{F}(1.95,37.07)=4.71, p=.016\end{array}$} \\
\hline & Posture Main Effect & $\begin{array}{c}\text { Upwards } \\
\mathrm{F}(1,19)=0.15 \\
p=.705 \\
\end{array}$ & $\begin{array}{c}\text { Up-Diagonal } \\
\mathrm{F}(1,19)=8.09 \\
p=.010\end{array}$ & $\begin{array}{c}\text { Horizontal } \\
\mathrm{F}(1,19)=12.72 \\
p=.002\end{array}$ & $\begin{array}{c}\text { Down-Diagonal } \\
\mathrm{F}(1,19)=7.44 \\
p=.013\end{array}$ & $\begin{array}{c}\text { Downwards } \\
\mathrm{F}(1,19)=3.24 \\
p=.092 \\
\end{array}$ \\
\hline \multirow[t]{3}{*}{$25^{\circ}$} & $\begin{array}{l}\text { 2-way Interaction } \\
\text { Posture, Direction }\end{array}$ & \multicolumn{5}{|c|}{$\mathrm{F}(1.60,30.33)=3.88, p=.040$} \\
\hline & Direction Main Effect & \multicolumn{2}{|c|}{$\begin{array}{c}\text { Sitting } \\
\mathrm{F}(2.36,44.81)=1.27, p=.293\end{array}$} & & \multicolumn{2}{|c|}{$\begin{array}{c}\text { Standing } \\
\mathrm{F}(1.65,31.28)=4.04, p=.034\end{array}$} \\
\hline & Posture Main Effect & $\begin{array}{c}\text { Upwards } \\
\mathrm{F}(1,19)=3.50 \\
p=.077\end{array}$ & $\begin{array}{c}\text { Up-Diagonal } \\
\mathrm{F}(1,19)=10.68 \\
p=.004\end{array}$ & $\begin{array}{c}\text { Horizontal } \\
\mathrm{F}(1,19)=10.30 \\
p=.005\end{array}$ & $\begin{array}{c}\text { Down-Diagonal } \\
\mathrm{F}(1,19)=10.67 \\
p=.004\end{array}$ & $\begin{array}{c}\text { Downwards } \\
\mathrm{F}(1,19)=3.69 \\
p=.072 \\
\end{array}$ \\
\hline \multirow[t]{3}{*}{$35^{\circ}$} & $\begin{array}{l}\text { 2-way Interaction } \\
\text { Posture, Direction }\end{array}$ & \multicolumn{5}{|c|}{$\mathrm{F}(1.55,29.47)=8.17, p=.003$} \\
\hline & Direction Main Effect & \multicolumn{2}{|c|}{$\begin{array}{c}\text { Sitting } \\
\mathrm{F}(4,76)=1.14, p=.342\end{array}$} & & \multicolumn{2}{|c|}{$\begin{array}{c}\text { Standing } \\
\mathrm{F}(1.63,30.88)=8.74, p=.002\end{array}$} \\
\hline & Posture Main Effect & $\begin{array}{c}\text { Upwards } \\
\mathrm{F}(1,19)=5.51 \\
p=.030\end{array}$ & $\begin{array}{c}\text { Up-Diagonal } \\
\mathrm{F}(1,19)=10.87 \\
p=.004\end{array}$ & $\begin{array}{c}\text { Horizontal } \\
\mathrm{F}(1,19)=14.42 \\
p=.001\end{array}$ & $\begin{array}{c}\text { Down-Diagonal } \\
\mathrm{F}(1,19)=13.01 \\
p=.002\end{array}$ & $\begin{array}{c}\text { Downwards } \\
\mathrm{F}(1,19)=14.91 \\
p=.001\end{array}$ \\
\hline \multirow[t]{3}{*}{$45^{\circ}$} & $\begin{array}{l}\text { 2-way Interaction } \\
\text { Posture, Direction }\end{array}$ & \multicolumn{5}{|c|}{$\mathrm{F}(1.52,28.78)=8.85, p=.002$} \\
\hline & Direction Main Effect & \multicolumn{2}{|c|}{$\begin{array}{c}\text { Sitting } \\
\mathrm{F}(3.09,58.75)=1.66, p=.183\end{array}$} & & \multicolumn{2}{|c|}{$\begin{array}{c}\text { Standing } \\
\mathrm{F}(1.45,27.60)=9.85, p=.002\end{array}$} \\
\hline & Posture Main Effect & $\begin{array}{c}\text { Upwards } \\
\mathrm{F}(1,19)=11.77 \\
p=.003\end{array}$ & $\begin{array}{c}\text { Up-Diagonal } \\
\mathrm{F}(1,19)=11.59 \\
p=.003\end{array}$ & $\begin{array}{c}\text { Horizontal } \\
\mathrm{F}(1,19)=13.24 \\
p=.002\end{array}$ & $\begin{array}{c}\text { Down-Diagonal } \\
\mathrm{F}(1,19)=15.23 \\
p=.001\end{array}$ & $\begin{array}{c}\text { Downwards } \\
\mathrm{F}(1,19)=13.24 \\
p=.002\end{array}$ \\
\hline \multirow[t]{3}{*}{$60^{\circ}$} & $\begin{array}{l}\text { 2-way Interaction } \\
\text { Posture, Direction }\end{array}$ & \multicolumn{5}{|c|}{$\mathrm{F}(2.54,47.57)=99.97, p<.001$} \\
\hline & Direction Main Effect & \multicolumn{2}{|c|}{$\begin{array}{c}\text { Sitting } \\
\mathrm{F}(4,76)=3.14, p=.036\end{array}$} & & \multicolumn{2}{|c|}{$\begin{array}{c}\text { Standing } \\
\mathrm{F}(2.30,43.60)=83.92, p<.001\end{array}$} \\
\hline & Posture Main Effect & $\begin{array}{c}\text { Upwards } \\
\mathrm{F}(1,19)=6.14 \\
p=.023\end{array}$ & $\begin{array}{c}\text { Up-Diagonal } \\
\mathrm{F}(1,19)=84.13 \\
p<.001\end{array}$ & $\begin{array}{c}\text { Horizontal } \\
\mathrm{F}(1,19)=147.06 \\
p<.001\end{array}$ & $\begin{array}{c}\text { Down-Diagonal } \\
\mathrm{F}(1,19)=145.96 \\
p<.001\end{array}$ & $\begin{array}{c}\text { Downwards } \\
\mathrm{F}(1,19)=14.57 \\
p=.001\end{array}$ \\
\hline \multirow[t]{3}{*}{$80^{\circ}$} & $\begin{array}{l}\text { 2-way Interaction } \\
\text { Posture, Direction }\end{array}$ & \multicolumn{5}{|c|}{$\mathrm{F}(4,76)=117.62, p<.001$} \\
\hline & Direction Main Effect & \multicolumn{2}{|c|}{$\begin{array}{c}\text { Sitting } \\
\mathrm{F}(2.39,45.34)=3.05, p=.048\end{array}$} & & \multicolumn{2}{|c|}{$\begin{array}{c}\text { Standing } \\
\mathrm{F}(2.07,39.36)=96.42, p<.001 \\
\end{array}$} \\
\hline & Posture Main Effect & $\begin{array}{c}\text { Upwards } \\
\mathrm{F}(1,19)=8.25 \\
p=.011\end{array}$ & $\begin{array}{c}\text { Up-Diagonal } \\
\mathrm{F}(1,19)=133.45 \\
p<.001\end{array}$ & $\begin{array}{c}\text { Horizontal } \\
\mathrm{F}(1,19)=148.69 \\
p<.001\end{array}$ & $\begin{array}{c}\text { Down-Diagonal } \\
\mathrm{F}(1,19)=273.97 \\
p<.001\end{array}$ & $\begin{array}{c}\text { Downwards } \\
\mathrm{F}(1,19)=8.64 \\
p=.009\end{array}$ \\
\hline \multirow[t]{3}{*}{$100^{\circ}$} & $\begin{array}{l}\text { 2-way Interaction } \\
\text { Posture, Direction }\end{array}$ & \multicolumn{5}{|c|}{$\mathrm{F}(2.34,44.41)=42.78, p<.001$} \\
\hline & Direction Main Effect & \multicolumn{2}{|c|}{$\begin{array}{c}\text { Sitting } \\
\mathrm{F}(1.69,32.10)=4.13, p=.031\end{array}$} & & \multicolumn{2}{|c|}{$\begin{array}{c}\text { Standing } \\
\mathrm{F}(2.08,39.52)=35.44, p<.001\end{array}$} \\
\hline & Posture Main Effect & $\begin{array}{c}\text { Upwards } \\
\mathrm{F}(1,19)=6.08 \\
p=.023\end{array}$ & $\begin{array}{c}\text { Up-Diagonal } \\
\mathrm{F}(1,19)=231.92 \\
p<.001\end{array}$ & $\begin{array}{c}\text { Horizontal } \\
\mathrm{F}(1,19)=221.07 \\
p<.001\end{array}$ & $\begin{array}{c}\text { Down-Diagonal } \\
\mathrm{F}(1,19)=183.91 \\
p<.001\end{array}$ & $\begin{array}{c}\text { Downwards } \\
\mathrm{F}(1,19)=7.30 \\
p=.017\end{array}$ \\
\hline
\end{tabular}

Table 10. Repeated measures ANOVA statistical analysis on the effect of posture and direction on total torso movement. 